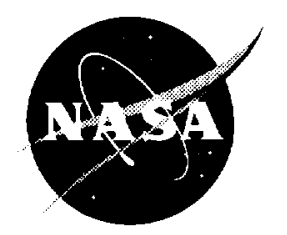

\title{
Vehicle and Mission Design Options for the Human Exploration of Mars/Phobos Using "Bimodal" NTR and LANTR Propulsion
}

Stanley K. Borowski and Leonard A. Dudzinski

Lewis Research Center, Cleveland, Ohio

Melissa L. McGuire

Analex Corporation, Brook Park, Ohio

Prepared for the

34th Joint Propulsion Conference

cosponsored by the AIAA, ASME, SAE, and ASEE

Cleveland, Ohio, July 13-15, 1998

National Aeronautics and

Space Administration

Lewis Research Center 


\section{Acknowledgments}

The authors wish to express their thanks to LeRC management (Pat Symons, Harry Cikanek, and Joe Nieberding) and NASA Headquarters (Lewis Peach) for support and encouragement during the course of this work, and to a number of individuals for key contributions to various topics addressed in this study. They include: Don Culver

(Aerojet) on bimodal CIS engine design issues, Lee Mason (NASA Lewis) on Brayton cycle PCU analysis and system characterization, Dave Plachta (NASA Lewis) on $\mathrm{LH}_{2}$ thermal protection and active refrigeration systems, Mike Stancati (Science Applications International Corporation--SAIC) on disposal $\Delta \mathrm{V}$ estimates and Pat Rawlings (SAIC) for artwork depicted in Figure 2.

Available from

NASA Center for Aerospace Information 7121 Standard Drive Hanover, MD 21076

Price Code: A04
National Technical Information Service 5285 Port Royal Road Springfield, VA 22100 Price Code: A04 


\title{
VEHICLE AND MISSION DESIGN OPTIONS FOR THE HUMAN EXPLORATION \\ OF MARS / PHOBOS USING "BIMODAL" NTR and LANTR PROPULSION
}

\author{
Stanley K. Borowski* and Leonard A. Dudzinski** \\ NASA Lewis Research Center \\ Cleveland, $\mathrm{OH} 44135$ \\ (216)977-7091 and -7107 \\ Melissa L. McGuire* \\ Analex Corporation \\ Brook Park, OH 44145
}

(216) $977-7128$

\section{ABSTRACT}

The nuclear thermal rocket (NTR) is one of the leading propulsion options for future human missions to Mars because of its high specific impulse (Isp 850-1000 s) capability and its attractive engine thrust-to-weight ratio ( 3-10). To stay within the available mass and payload volume limits of a "Magnum" heavy lift vehicle, a high performance propulsion system is required for trans-Mars injection (TMI). An expendable TMI stage, powered by three 15 thousand pounds force (klbf) NTR engines is currently under consideration by NASA for its Design Reference Mission (DRM). However, because of the miniscule burnup of enriched uranium-235 during the Earth departure phase ( -10 grams out of 33 kilograms in each NTR core), disposal of the TMI stage and its engines after a single use is a costly and inefficient use of this high performance stage. By reconfiguring the engines for both propulsive thrust and modest power generation (referred to as "bimodal" operation), a robust, multiple burn, "power-rich" stage with propulsive Mars capture and reuse capability is possible. A family of modular "bimodal" NTR (BNTR) vehicles are described which utilize a common "core" stage powered by three $15 \mathrm{klbf}$ BNTRs that produce 50 $k W e$ of total electrical power for crew life support, an active refrigeration / reliquification system for long term, "zero-boiloff" liquid hydrogen $\left(\mathrm{LH}_{2}\right)$ storage, and high data rate communications. An innovative, spine-like "saddle truss" design connects the core stage and payload element and is open underneath to allow supplemental "in-line" propellant tanks and contingency crew consumables to be easily jettisoned to improve vehicle performance. A "modified" DRM using BNTR transfer vehicles requires fewer transportation system elements, reduces IMLEO and mission risk, and simplifies space operations. By taking the next logical step--use of the BNTR for propulsive capture of all payload elements into Mars orbit--the power available in Mars orbit grows to $150 \mathrm{kWe}$ compared to $30 \mathrm{kWe}$ for the DRM. Propulsive capture also eliminates the complex, higher risk aerobraking and capture maneuver which is replaced by a simpler reentry using a standardized, lower mass "aerodescent" shell. The attractiveness of the "all BNTR" option is further increased by the substitution of the lightweight, inflatable "TransHab" module in place of the heavier, hard-shell hab module. Use of TransHab introduces the potential for propulsive recovery and reuse of the BNTR / ERV. It also allows the crew to travel to and from Mars on the same BNTR transfer vehicle thereby cutting the duration of the ERV mission in half--from $\sim 4.7$ to 2.5 years. Finally, for difficult Mars options, such as Phobos rendezvous and sample return missions, volume (not mass) constraints limit the performance of the "all $\mathrm{LH}_{2}$ " BNTR stage. The use of "LOX-augmented" NTR (LANTR) engines, operating at a modest oxygen-to-hydrogen mixture ratio (MR) of 0.5 , helps to increase "bulk" propellant density and total thrust during the TMI burn. On all subsequent burns, the bimodal LANTR engines operate on $\mathrm{LH}_{2}$ only $(\mathrm{MR}=0$ ) to maximize vehicle performance while staying within the lift capability of two Magnum launches.

"Ph.D. / Nuclear Engineering, Member AIAA

"Aerospace Engineer, Member AIAA 


\section{INTRODUCTION AND BACKGROUND}

The possible discovery of ancient microfossils in the Mars meteorite ALH84001, along with the excitement provided by the Mars Pathfinder and current Mars Surveyor missions 1 has stirred worldwide interest in the question of extraterrestrial life and in NASA's plans for future human exploration missions to Mars. Over the last decade, NASA study teams have assessed a variety of mission and technology options for human exploration missions to the Moon and Mars. In FY1988, NASA's Office of Exploration sponsored four separate Exploration Case Studies 2,3 which outlined strategies for human expeditions to Phobos and Mars, a humantended lunar observatory, and an evolutionary expansion strategy beginning with a lunar outpost and progressing to similar bases of operations on Mars and its moons. Phobos mission objectives included basic exploration, resource surveys to determine the existence of water, and the establishment of a science station. For the Mars / Phobos missions, a "split / sprint" transportation approach was utilized that predeployed cargo using "minimum-energy" trajectories to reduce propellant mass, and higher energy trajectories to reduce in-space transit times for the crew. Short stay time, opposition-class missions employing aerobraking, chemical and NTR propulsion options were also assumed.

The Exploration Case Studies were followed in 1989 by NASA's "90-Day" Study4, which focussed primarily on the establishment of a permanent lunar base and "all-up" exploration missions to Mars. "All-up" refers to an operational mode in which all of the payload and propellant required for the entire Mars mission is carried on a single vehicle. The expendable chemical / aerobrake option used direct capsule reentry at Earth for crew recovery and had an initial mass in low Earth orbit (IMLEO) of $\sim 831 \mathrm{t}$. The chemical TMI stage utilized $\mathrm{LOX} / \mathrm{LH}_{2}$ propulsion, and two large diameter $(\sim 30 \mathrm{~m})$ aerobrakes, constructed in low Earth orbit, were used to capture the piloted lander / ascent vehicle and $\mathrm{LOX} / \mathrm{LH}_{2}$ trans-Earth injection (TEI) stage into Mars orbit. The "all NTR" option 5 used a single $75 \mathrm{klbf}$ engine for all primary propulsion maneuvers, including Earth orbit capture (EOC), and had an IMLEO of $-668 \mathrm{t}$.

In May 1991, the Synthesis Group issued its report6 entitled "America at the Threshold:
America's Space Exploration Initiative." In it different architectural approaches and technical strategies were outlined and fourteen key technologies necessary for safe and cost effective exploration of the Moon and Mars were identified. The top two technologies listed were a heavy lift launch vehicle and NTR propulsion. The Synthesis report stated that for Mars transit "the nuclear thermal rocket is the preferred propulsion system allowing significantly reduced mass to low Earth orbit, shorter transit times and greater operational flexibility." 6 The use of aerobraking for Mars orbit capture (MOC) was rejected by the Synthesis Group in favor of propulsive capture using NTR propulsion because of a variety of mission-, spacecraft design-, and safety-related issues. 6

In FY93, an intercenter NASA Mars Study Team was organized by the Exploration Project Office (ExPO) at the Johnson Space Center (JSC) and tasked with assessing the requirements for a piloted mission to Mars as early as 2010. A split / sprint mission with predeployed cargo was baselined and NTR propulsion was selected for all primary propulsion maneuvers in keeping with the Synthesis Group recommendations. "Fast conjunction-class" trajectories 7,8 were also featured to maximize the exploration time at Mars while reducing the total "in-space" transit time to approximately one year.

The reference Mars architecture was later changed by ExPO to incorporate a common, "dual use" aerobrake / descent shell and "in-situ" resource utilization (ISRU) in an effort to achieve a single launch cargo and piloted mission capability using a 240 t-class heavy lift launch vehicle (HLLV). Common habitat modules were also assumed for the piloted lander, surface hab and ERV. Using $\mathrm{LH}_{2}$ brought from Earth, an ISRU plant would convert Martian carbon dioxide into liquid oxygen / methane $\left(\mathrm{LOX} / \mathrm{CH}_{4}\right)$ propellant to fuel a "dry" ascent stage carried to the Mars surface on the cargo lander mission 9 . A second cargo lander provided an additional habitat module, science equipment and consumables needed to support the crew during the long ( $~ 500$ day) Mars surface exploration phase. A separate ERV, placed in Mars orbit, returned the crew and "dual use" ascent stage crew capsule to Earth where it provided a direct Earth entry capability. $\mathrm{LOX} / \mathrm{CH}_{4}$ propulsion was used on both the descent and TEI 
stages to maximize hardware commonality, and NTR propulsion was used only for the TMI stage. Additional details on the FY93 reference Mars architecture are provided elsewhere. 10,11

A common TMI stage powered by three to four $15 \mathrm{klbf}$ NTR engines was developed for both the cargo and piloted missions ${ }^{10}$ (see Figure 1). The TMl stage was sized by the 2009 piloted mission and its more energetically demanding 180-day trajectory and then used in the minimum energy cargo missions to maximize payload deliveny to Mars. After a "2-perigee burn" Earth departure, the spent TMI stage was jettisoned and targeted for long-duration disposal into heliocentric space. In addition to the reference Mars architecture, LeRC developed "all NTR" mission options (to capitalize on the NTR's higher performance) and modular vehicle designs using "standardized" engine and stage components. ${ }^{10}$ The "modular approach" provided a number of attractive features which included enhanced mission flexibility and safety, simplified vehicle design and assembly, and reduced development / procurement costs through standardization of the fewest number" of components. Vehicle designs compatible with a 120 t-class HLLV were also developed and utilized a dual launch, Earth orbit rendezvous and dock (EOR\&D) scenario for vehicle assembly. Particularly noteworthy, was the introduction and integration of "bimodal" NTR engines and active $\mathrm{LH}_{2}$ refrigeration systems into the basic design of the ERV 10 (see Figure 2). The elimination of boil-off over the $\sim 4.1$ year mission duration of the ERV led to dramatic reductions in IMLEO, total engine bum time and $\mathrm{LH}_{2}$ tank size.

In FY97, NASA's intercenter Mars Human Exploration Study Team was reconvened to reevaluate, refine and update the FY93 DRM. Key mission changes 12 included the use of an $\sim 80 \mathrm{t}$-class HLLV called "Magnum" and adoption of a dual launch EOR\&D vehicle assembly scenario. Payload manifests, including crew accommodations and consumables, were critically examined on each cargo and piloted mission to save mass and eliminate duplications. Mass reductions in large structures, like propellant tanks and habitat modules, were achieved through the use of advanced composites. A lightweight, inflatable hab module design developed by JSC was also examined. The expendable NTR TMI stage and "new" bimodal NTR vehicle concepts developed during this
2007 Carro Mission 1

"Dry" Ascent Stage \& Lander
2007 Cargo Mission 2 Hab Module \& Lander

\section{Carge Mission 3 $\mathrm{LOXKCH}_{4}$ TEIS \& Hab}

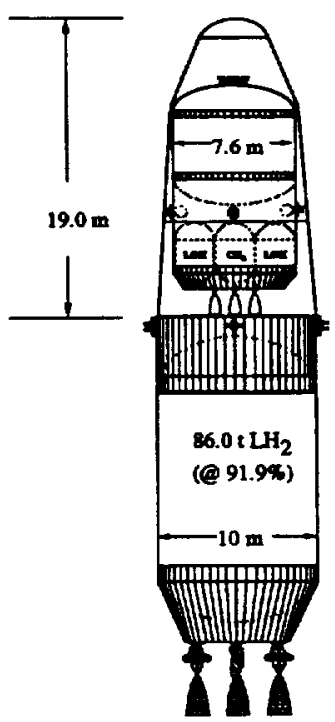

$204.7 t$
2009 Piloted Mission 1 Piloted MEV \& Surface Hab
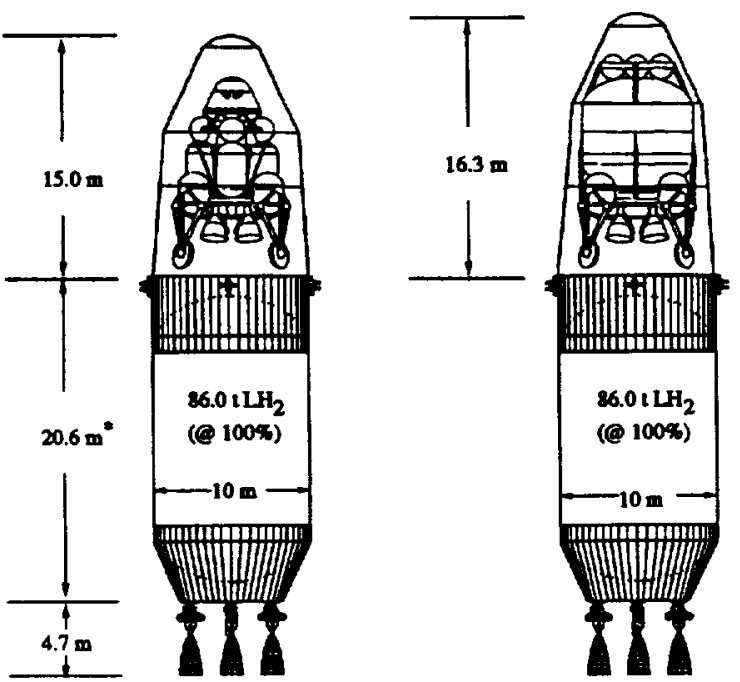

$216.6 \mathrm{t}$

IMLEO $=216.6 \mathrm{t}$
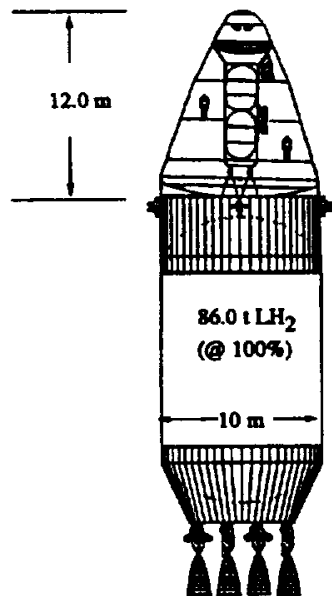

212.1t

Expendable TMI Stage LH2 Tank (@ $18.2 \mathrm{~m}$ length) sized by 2009 Mars Ploted Mission

Fig. 1 Reference Mars Cargo and Piloted Vehicles Using Common "NTR-Powered" TMI Stage 


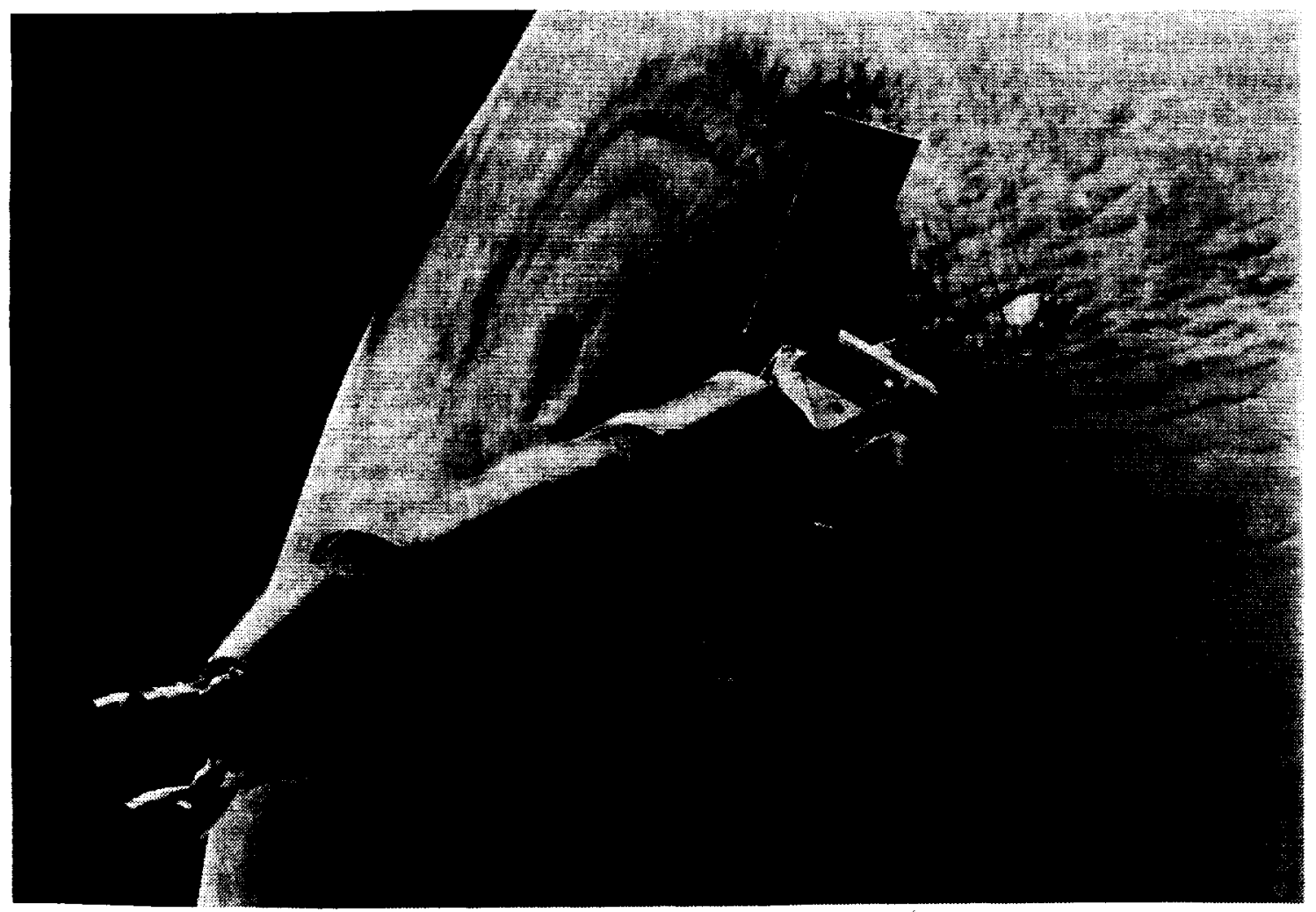

Fig. 2 Artist's lllustration of ERV with $50 \mathrm{kWe}$ "Bimodal" NTR System and Active $\mathrm{LH}_{2}$ Refrigeration. A $5 \mathrm{kWe}$ Solar Array is Shown on the ERV for Scale

study period were sized to fit within the mass and payload volume limits of the Magnum HLLV. To circumvent volume limitations, "LOX-augmented" NTR (LANTR) engines were also examined to increase "bulk" propellant density and maximize vehicle performance while staying within the mass limitations of a two Magnum scenario.

This paper describes the NTR vehicle and mission analysis results performed by the Lewis Research Center over the last $\sim 18$ months in support of NASA's intercenter Mars study effort. The paper first describes the operating principles and charateristics of the small, $15 \mathrm{klbf}$ solid core NTR engines baselined in the study. This is followed by a discussion of the operational characteristics and benefits of the "bimodal" NTR and LANTR engine concepts. Next, key features of the Mars DRM are reviewed and a summary of mission and transportation system ground rules and assumptions are provided. Representative vehicle concepts and their operational characteristics are then presented for an expendable NTR TMI stage, several bimodal NTR vehicle options, and a LANTR vehicle configuration capable of adding Phobos rendezvous and landing options to the current DRM. The paper concludes with a summary of our findings and a brief discussion of the evolvability of bimodal LANTR vehicles to support a fully reusable, Mars mission architecture and future human expansion.

\section{NUCLEAR THERMAL ROCKET PROPULSION}

The "solid core" NTR represents the next major evolutionary step in propulsion technology and is key to providing "low cost access through space" for future human exploration missions to the Moon, Near Earth Asteroids and Mars. The NTR is not a new technology. Its feasibility was convincingly demonstrated in the United States during the Rover / NERVA (Nuclear Engine for Rocket Vehicle Application) nuclear rocket programs. ${ }^{13}$ From 1955 until the program was stopped in 1973, a total of twenty rocket reactors were designed, built and tested. These integrated reactor /engine tests, using $\mathrm{LH}_{2}$ as both reactor coolant and propellant, demonstrated a wide range of engine sizes (from $\sim 50$ to $250 \mathrm{klbf})$, high temperature graphite fuel 
providing substantial hydrogen exhaust temperatures $(-2350-2550 \mathrm{~K})$, sustained engine operation (over 60 minutes for a single burn) and restart capability (over 20 startups and shutdowns on the same engine). The Rover / NERVA program costs were estimated at $-\$ 1.4$ billion (an $\sim \$ 10$ billion investment today).

Approximately four years after the start of the NERVA program, a nuclear rocket program was initiated in the former Soviet Union known today as the Commonwealth of Independent States (CIS). 14 Extensive nuclear and non-nuclear subsystem tests were conducted, including fuel element and reactor tests at the Semipalatinsk facility in Kazakhstan. 15 Although no integrated engine system tests were conducted, a high temperature ternary carbide fuel element was developed capable of producing hydrogen exhaust temperatures in excess of $3000 \mathrm{~K}-$ - about $500 \mathrm{~K}$ higher than the best NERVA fuels.

\section{NTR Operating Principles}

Conceptually, the NTR engine is relatively simple (see Figure 3). High pressure propellant flowing from pumps cools the nozzle, reactor pressure vessel, neutron reflector, control drums, core support structure and internal radiation shield, and in the process picks up heat to drive the turbines. The hydrogen exhaust is then routed through coolant channels in the reactor core's fuel elements where it absorbs the energy released by fissioning uranium atoms, is superheated (to 2700-3100 K), and then expanded out a supersonic nozzle for thrust. Controlling the NTR engine during its operational phases (startup, full thrust, and shutdown) is accomplished by matching the turbopumpsupplied hydrogen flow to the reactor power level. Control drums, located in the surrounding reflector region, regulate the number of fissionreleased neutrons that are reflected back into the core and hence the reactor power level. An internal neutron and gamma radiation shield, containing interior coolant passages, is also placed between the reactor core and sensitive engine components to prevent excessive radiation heating and material damage.

\section{Iernary Carbide Fuel NTR Engine Design}

What's new about NTR propulsion today that warrants renewed investment in this technology? The answer lies in a reduced size, higher performance engine that can be ground tested at full power in a "contained facility" meeting current environmental regulations. Design studies 16,17 , funded by NASA's Nuclear Propulsion Office in 1992-1993 and conducted by a US / CIS industry team of Aerojet, Energopool and Babcock and Wilcox (B\&W), produced a small advanced NTR engine concept with impressive parameters: thrust $15 \mathrm{klbf}$, Isp -940-960 s, engine thrust-to-

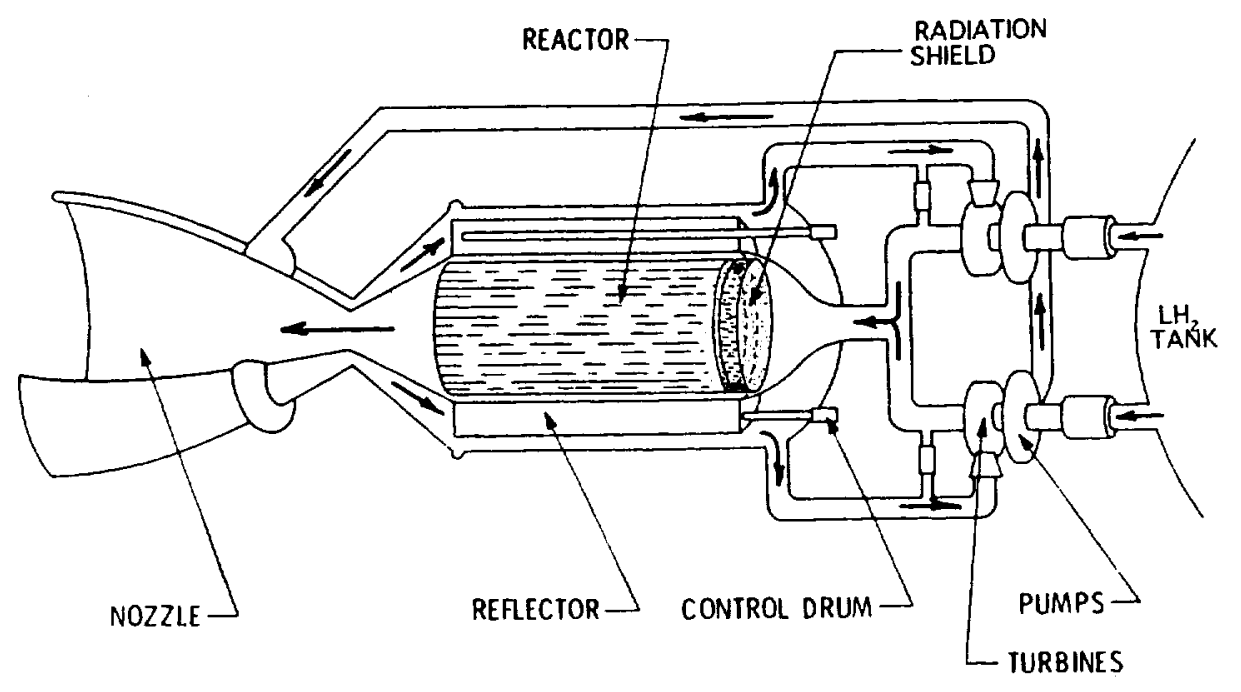

Fig. 3 Schematic of "Solid Core" NTR Using Dual Turbopump Expander Cycle 


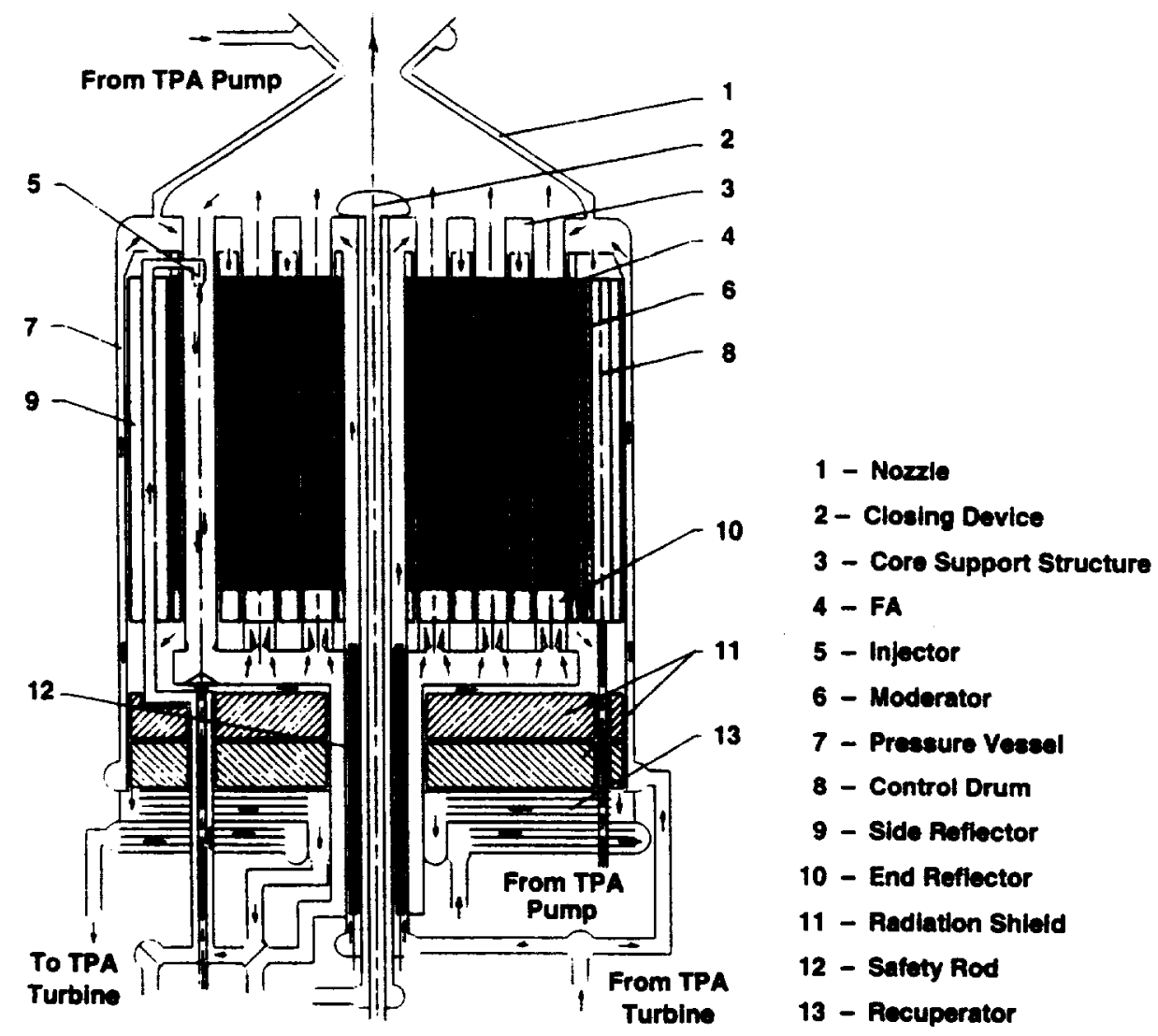

Fig. 4 Component Layout / Flow Schematic of CIS Engine

weight 3.1, and "full power" engine fuel lifetime of -4.5 hours. The ClS engine design (shown in Figure 4) utilizes a heterogeneous reactor core design with hydrogen-cooled zirconium hydride ( $\mathrm{ZHH}$ moderator and temary carbide fuel materials. The $\mathrm{ZrH}$ moderator is located between reactor fuel assemblies and is very efficient in minimizing the inventory of fissile material in the reactor core. The CIS fuel assembly is an axial flow design and contains a series of stacked $45 \mathrm{~mm}$ diameter bundles of thin $(\sim 1 \mathrm{~mm})$ "twisted ribbon" fuel elements approximately $2 \mathrm{~mm}$ in width by $100 \mathrm{~mm}$ in length. The "fueled length" and power output from each assembly is determined by specifying the engine thrust level and hydrogen exhaust temperature (or desired lsp). For a $15 \mathrm{klbf}$ engine, 36 fuel assemblies (with 6 fuel bundles each) are used to generate the required $335 \mathrm{MWt}$ of reactor power at the same Isp.

The ternary or "tricarbide" fuel material in each "twisted ribbon" element is composed of a solid solution of uranium, zirconium and niobium carbides having a maximum operating tempera- ture expected to be about $3200 \mathrm{~K}$. The fuel composition along the fuel assembly length is tailored to provide increased power generation where the propellant temperature is low, and reduced power output near the bottom of the fuel assembly where the propellant is nearing its exhaust temperature design limit. In this current study, the CIS engine total power output has been fixed at $335 \mathrm{MWt}$ and the hydrogen exhaust temperature allowed to vary from 2900 to $3075 \mathrm{~K}$ to provided increased Isp operation (from $\sim 940$ to $955 \mathrm{~s})$ when needed. During reactor tests, hydrogen exhaust temperatures of $3100 \mathrm{~K}$ for over one hour and $2000 \mathrm{~K}$ for 2000 hours were demonstrated in the CIS. 14

\section{CIS Engine Power Cycle / Design Characteristics}

The CIS engine design utilizes a dual turbopump, "recuperated" topping cycle.16,17 Hydrogen flowing from each pump is split (see Figure 5), with $\sim 84 \%$ of the flow going to a combination recuperator/gamma radiation shield and the remaining $16 \%$ used to cool the nozzle. 


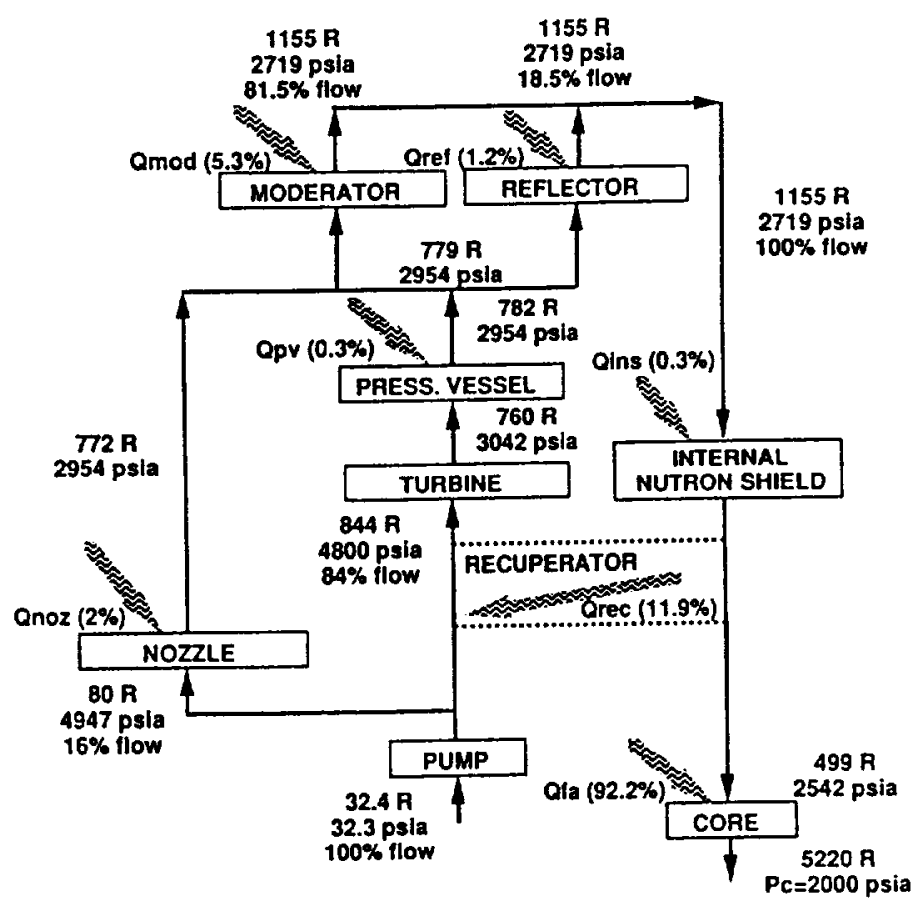

Fig. 5 Flow Schematic of Recuperated Topping Cycle for the CIS Engine

The recuperator/shield, located at the top of the engine, provides all of the necessary turbine drive power. The turbine exhaust cools the reactor pressure vessel and is then merged with the nozzle coolant to cool the moderator and reflector regions of the engine. The coolant then passes through borated $\mathrm{ZrH}$ and lithium hydride (LiH) neutron shields located within the pressure vessel between the reactor core and the recuperator/gamma shield (see Figures 4 and 5), before returning to the recuperator where it heats the pump discharge flow. Exiting the recuperator, the cooled hydrogen is then routed to the core fuel assemblies where it is heated to the required design temperatures. The $15 \mathrm{klbf} \mathrm{ClS}$ engine design has a chamber pressure of 2000 psia, a nozzle area ratio of 300 to1, and a $110 \%$ bell length nozzle resulting in Isp values of $\sim 940$ to $955 \mathrm{~s}$ for hydrogen exhaust temperatures in the range of 2900-3075 K. The approximate engine length and nozzle exit diameter for the $15 \mathrm{klbf} \mathrm{ClS}$ engine is $\sim 4.3 \mathrm{~m}$ and $-1.0 \mathrm{~m}$, respectively. A summary of key design features of the CIS engine is found in Table 1.

\section{The "Bimodal" NTR -A Fully Integrated System}

The bimodal NTR engine and vehicle concept was examined in detail during this study period to more fully exploit the performance potential of the NTR and enhance stage capabilities. Besides its impressive propulsion characteristics, the solid core NTR represents a "rich source of energy" because it contains substantially more uranium-235 fuel in its reactor core than it consumes during its primary propulsion maneuvers. By reconfiguring the NTR engine for "bimodal" operation (Figure 6), abundant electrical power can also be generated to support spacecraft environmental systems, high data rate communications, and enhanced stage operations such as active refrigeration / reliquification system for long term, "zero-boiloff" $\mathrm{LH}_{2}$ storage. A bimodal NTR-powered spacecraft would be very similar to today's nuclear-powered submarine which uses high-pressure steam provided to a turbine engine to drive the submarine's propeller. Steam from the reactor also generates all of the submarine's electricity.

Besides providing a continuous source of reactor thermal energy, bimodal operation is also beneficial because it: 1) reduces thermal stress on the reactor (it's pre-heated); 2) minimizes large thermal cycling (no prolonged, deep "cold soak" of the engine); 3 ) allows rapid reactor restart (in case of emergency); 4) minimizes "decay heat removal" propellant penalty (by rejecting low power, "after-heat" through the power system's space radiator); and 5) provides a source of 
Table 1. Key Design Features of CIS NTR Engine

\begin{tabular}{ll} 
Reactor Power & 335 \\
Engine Thrust (klbf) & $(15-14.76)$ \\
Hydrogen Exhaust Temperature, K & $2,900-3,075$ \\
Propellant Flow Rate, kg/s & $7.24-7.01$ \\
Specific Impulse, $\mathrm{s}$ & $940-955$ \\
& \\
Fuel Composition & $(\mathrm{U}, \mathrm{Nb}, \mathrm{Zr}) \mathrm{C}$ \\
Fuel Form ("Twisted Ribbon"), mm & Approximate $100 \times 1.6 \times 1.0$ \\
Fuel Element Power Density (ave), MW/L & 30 \\
Core Power Density, MW/L & 5.0 \\
Fuel Volume, liters & 11.5 \\
Number of Assemblies (Elements) & 36 \\
Number of Safety Rods & 13 \\
& \\
Vessel Diameter, m & 0.65 \\
Reactor Fueled Length, cm & 55 \\
Reactor Mass (with internal & \\
shielding and recuperator), kg & \\
Engine Thrust-to-Weight Ratio & 2224 \\
Total Engine Length, m & 3.06 \\
Nozzle Exit Diameter, m & 4.3 \\
\hline
\end{tabular}

heated, gaseous hydrogen $\left(\mathrm{GH}_{2}\right)$ for propellant tank pressurization, and possible high Isp attitude control and orbital maneuvering systems.

During the power generation phase, the bimodal engine's reactor core operates in essentially an "idle mode" with a thermal power output of $\sim 110$ kilowatts. The energy generated within the reactor fuel assemblies would be removed using a variety of "closed loop" concept options (such as core support tie tubes, integrated energy extraction ducts within the individual fuel assemblies, or a throat closure plug) and then routed to a turboalternator-compressor Brayton power conversion unit using a heliumxenon ( $\mathrm{He}-\mathrm{Xe})$, hydrogen-nitrogen $\left(\mathrm{H}_{2}-\mathrm{N}_{2}\right)$, or other working fluid combination (see in Figure 6) . A pumped-loop radiator system is used to reject system waste heat and is also available to help remove low level decay heat power following high thrust engine operation.

Several options for closed Brayton cycle (CBC) power generation are being considered for the
CIS engine design. Although the current CIS/ CBC system is designed to radiate small amounts of thermal power at lower temperature $(-1300 \mathrm{~K})$ during the electric power generation phase, the same system can reject several megawatts of decay heat by operating the radiators at higher temperatures since heat transfer to space depends on the radiator surface temperature raised to the fourth power. Molybdenum alloy turbine wheels and niobium alloy static structures can withstand 1400 to $1500 \mathrm{~K} \mathrm{GH}_{2}$ inlet temperatures because the materials are compatible with $\mathrm{GH}_{2}$ and have high strength-to-density ratios at these temperatures. 16,17 Within an hour or two after thrust generation, reactor power decays significantly and the CIS / CBC temperatures drop. For decay heat removal or higher power mode operation, coolant is routed through the fuel assemblies (FA) after the CIS Brayton cycle loop is closed by inserting a nozzle "throat plug" located at the aft end of a central drive shaft (see Figure 7). This action opens an annular duct which carries the coolant / working fluid to the CBC turbine inlet. 16,17 In order to prevent excessive 


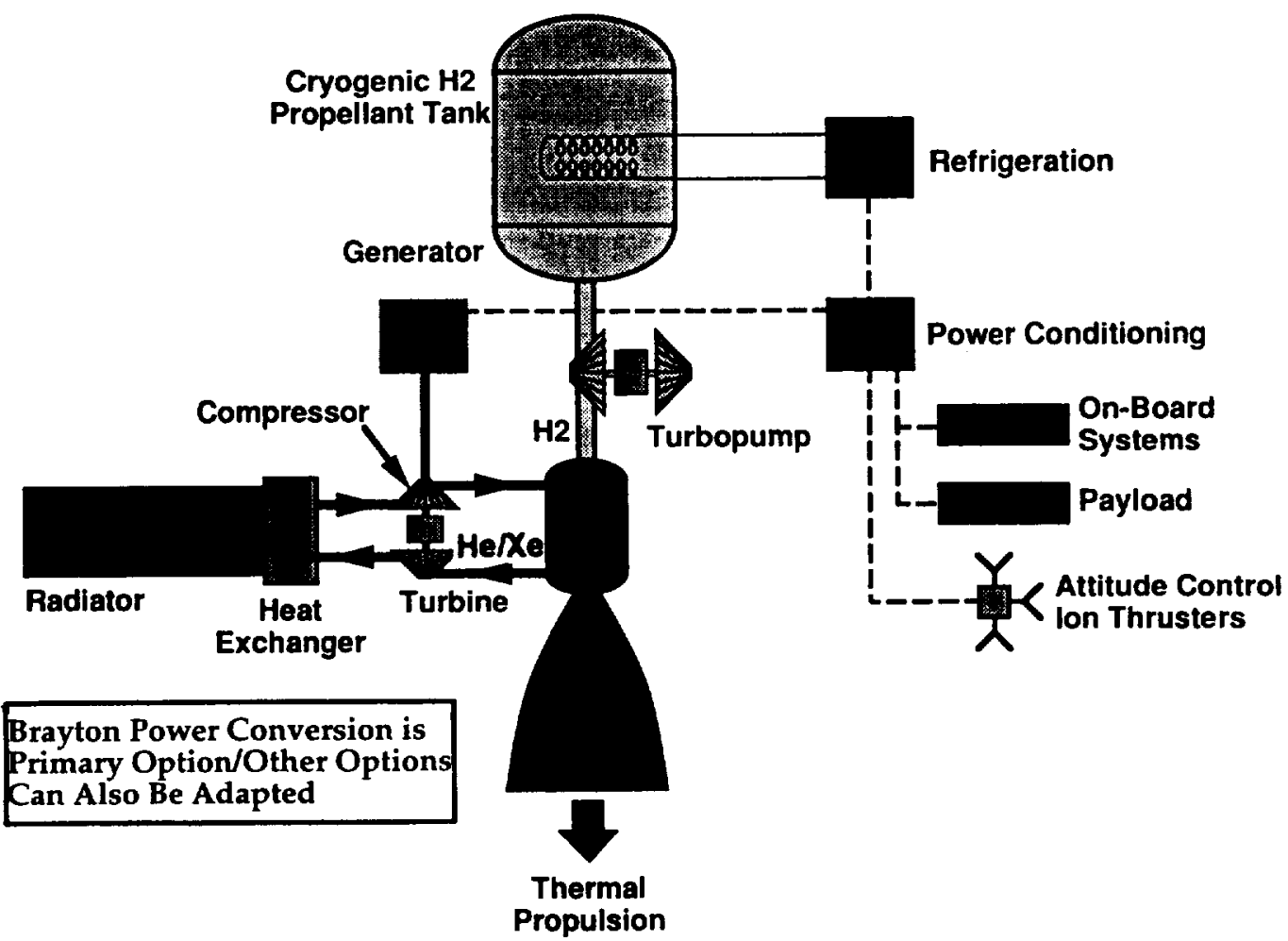

Fig. 6 Key Components of "Bimodal" NTR Stage -- "A Fully Integrated System"

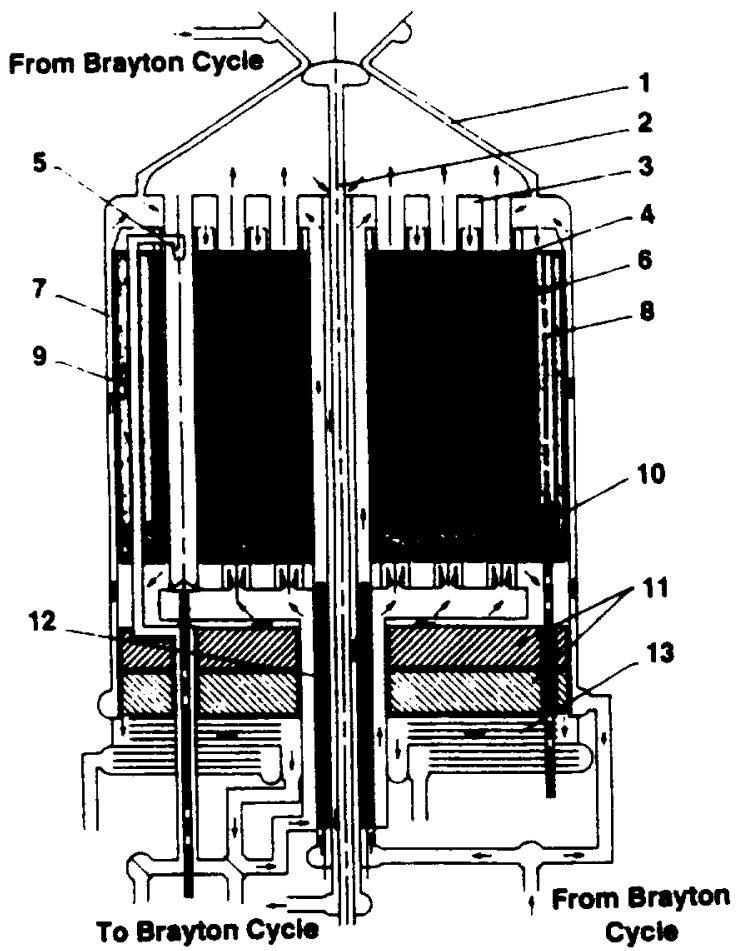

$$
\begin{aligned}
& 1 \text { - Nozzle } \\
& 2 \text { - Closing Device } \\
& 3 \text { - Core Support Structure } \\
& 4 \text { - FA } \\
& 5 \text { - Injector } \\
& 6 \text { - Moderator } \\
& 7 \text { - Pressure Vessel } \\
& 8 \text { - Control Drum } \\
& 9 \text { - Side Reflector } \\
& 10 \text { - End Reflector } \\
& 11 \text { - Radlatlon Shield } \\
& 12 \text { - Safety Rod } \\
& 13 \text { - Recuperator }
\end{aligned}
$$

Fig. 7 Design Features of "Bimodal" CIS Engine Concept 
loss of coolant past the throat plug during many months of low electrical power generation, the $\mathrm{GH}_{2}$ coolant / working fluid is rerouted to passages through the FA walls before entering the Brayton rotating unit. During this period, the throat plug remains closed as a reliability enhancement feature, inhibiting possible coolant leakage from the system through any cracks that may develop in the FA wall.

\section{The "LOX-Augmented" NTR (LANTB) Concept}

An innovative "trimodal" NTR concept, 18,19 known as LANTR, is presently under study by NASA LeRC which combines conventional $\mathrm{LH}_{2}-$ cooled NTR, Brayton cycle power generation and supersonic combustion ramjet (scramjet) technologies. During LANTR operation, oxygen is injected into the large divergent section of the NTR nozzle which functions as an "afterburner" (see Figure 8). Here, it burns spontaneously with the reactor-heated hydrogen emerging from the LANTR's sonic throat adding both mass and chemical energy to the rocket exhaust--essentially "scramjet propulsion in reverse."
The trimodal LANTR engine, illustrated in Figure 9, can operate as a conventional $\mathrm{LH}_{2}$ cooled NTR, a bipropellant $\mathrm{LOX}^{\mathrm{L}} \mathrm{H}_{2}$ engine and a power reactor. Its prinicipal components include a reactor and nozzle to heat and expand propellant, hydrogen and oxygen tankage and feed systems (using autogenous gas bleed for tank pressurization), and a closed Brayton cycle system for electric power generation and deep throttling. The CBC can also be used for engine "cooldown" assist as discussed above. The hydrogen feed system is powered by engine waste heat using the CIS recuperated topping cycle which enables the engine to run at a nozzle inlet pressure of 2000 psia. This and the fact that the recuperator also doubles as the reactor's cooled gamma radiation shield helps reduce engine size and mass. The LANTR engine generates electricity by bleeding reactor-heated $\mathrm{GH}_{2}$ or other working fluid through the Brayton cycle turbine, which drives an electric motor / generator and compressor. An "on-off" valve or throat plug is used to shut the nozzle throat during $\mathrm{CBC}$ operation and prevent leakage of the working fluid to space, and opened to the hot hydrogen exhaust during thrust mode

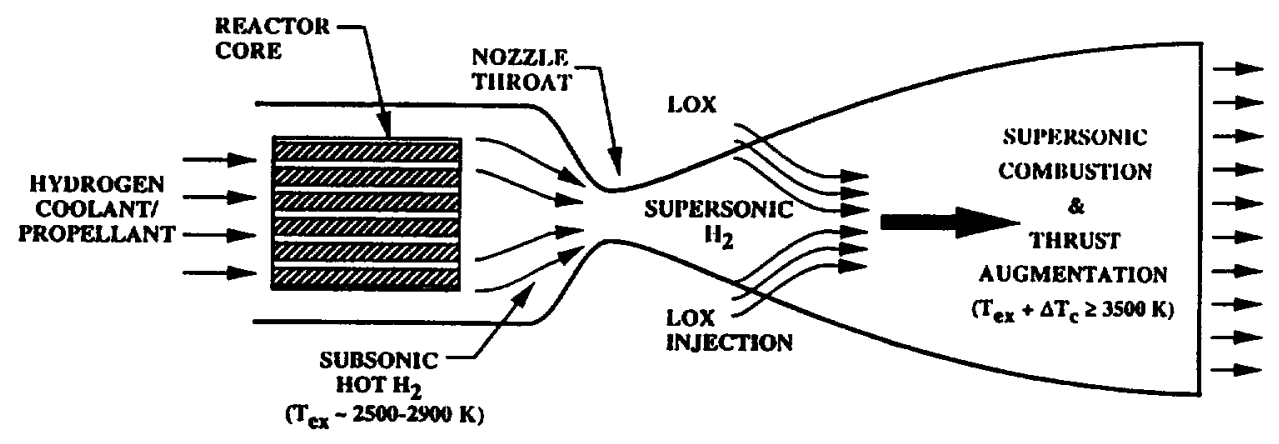

\begin{tabular}{|c|c|c|c|c|c|}
\hline \multirow[b]{2}{*}{$\begin{array}{l}\text { Life (hrs.) } \\
T_{c}\left({ }^{\circ} \mathbf{K}\right)\end{array}$} & \multicolumn{3}{|c|}{ Isp (sec) } & \multirow[b]{2}{*}{$\begin{array}{l}\text { Tankage } \\
\text { Fraction (\%) } \\
\end{array}$} & \multirow[b]{2}{*}{$\begin{array}{l}\text { T/W } \\
\text { Ratio }\end{array}$} \\
\hline & $\begin{array}{r}5 \\
2900\end{array}$ & $\begin{array}{c}10 \\
2800\end{array}$ & $\begin{array}{c}35 \\
2600\end{array}$ & & \\
\hline $\begin{array}{r}\mathrm{O} / \mathrm{H} \mathbf{M R}= \\
0.0 \\
1.0 \\
3.0 \\
5.0 \\
7.0\end{array}$ & $\begin{array}{l}941 \\
772 \\
647 \\
576 \\
514\end{array}$ & $\begin{array}{l}925 \\
762 \\
642 \\
573 \\
512\end{array}$ & $\begin{array}{l}891 \\
741 \\
631 \\
566 \\
508\end{array}$ & $\begin{array}{r}14.0 \\
7.4 \\
4.1 \\
3.0 \\
2.5\end{array}$ & $\begin{array}{r}3.0^{\circ} \\
4.8 \\
8.2 \\
11.0 \\
13.1\end{array}$ \\
\hline
\end{tabular}

- For $15 \mathrm{klbf}$ LANTR with chamber pressure $=2000$ psia and $€=500$ to 1

Fig. 8 Schematic / Characteristics of "LOX-Augmented" NTR 


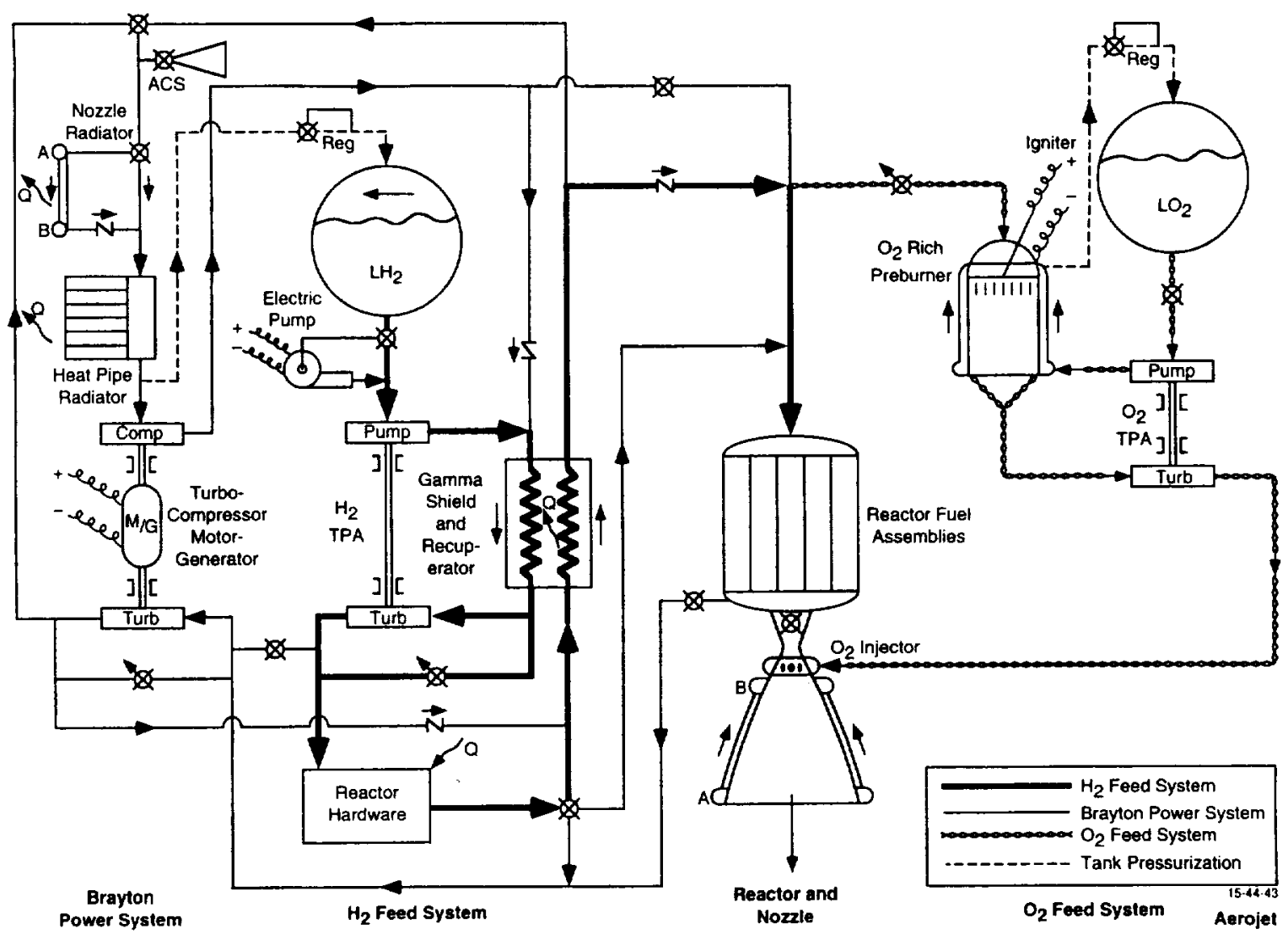

Fig. 9 Flow Schematic of "bimodal" LANTR Engine

operation. Waste heat can be rejected to space using a combination of nozzle and heat pipe radiator (as shown in Figure 9), or a dedicated radiator system as assumed in this study.

During bipropellant operation the oxygen feed system uses a topping cycle powered by an oxidizer-rich preburner. Downstream nozzle injection isolates the reactor core from oxygen damage provided the throat retains choked flow. This condition is satisfied by using a "cascade" scramjet injector concept developed by Aerojet which controls oxygen addition and heat release profiles (via staged injection) to keep the flow supersonic. 18 It also increases penetration, mixing and combustion of the oxygen injectant in the supersonic hydrogen flow while minimizing shock losses and formation of high heat flux regions (hot spots), thereby maximizing engine performance and life. The high reactor outlet pressure of the LANTR ( 2000 psia) also enables high area ratio nozzles ( $\varepsilon=500$ to 1 ), important for combustion efficiency, at reasonable size and mass.
The LANTR concept has the potential to be an extremely versatile propulsion system. By varying the engine's oxygen-to-hydrogen $(\mathrm{O} / \mathrm{H})$ mixture ratio (MR), LANTR can operate over a wide range of thrust and Isp values (Figure 8) while the reactor core produces a relatively constant power output. For example, as the MR varies from 0 to 7 , the engine thrust-to-weight ratio for a $15 \mathrm{kbf}$ NTR increases by $-440 \%$-- from 3 to 13 --while the Isp decreases by only $\sim 45 \%$--from 940 to 515 seconds. This thrust augmentation feature means that "big engine" performance can be obtained using smaller, more affordable, $\mathrm{LH}_{2}$-cooled NTR engines that are easier to develop and test in "contained" ground facilities. The engines can then be operated in space in the augmented high thrust mode to shorten burn times (thereby extending engine life) and reduce gravity losses (thereby eliminating the need for and concern over multiple, "perigee burn" Earth departure maneuvers). Reactor preheating of hydrogen before oxygen injection and combustion also results in higher Isp values than found in $\mathrm{LOX} / \mathrm{LH}_{2}$ 
chemical engines operating at the same mixture ratio $(-100 \mathrm{~s}$ at $\mathrm{MR}=6)$. Lastly, the ability to substitute high-density LOX for low-density $\mathrm{LH}_{2}$ provides the vehicle designer substantial flexibility in configuring spacecraft which can accommodate a wide variety of mission needs, as well as, "volume-constrained" launch vehicle designs.

\section{DESIGN REFERENCE MISSION DESCRIPTION}

The Mars Exploration Study Team is presently assessing a variety of mission architectures and transportation system options for conducting a human mission to Mars in the 2014 timeframe centered around a split cargo/piloted sprint mission approach. The mission profile shown in Figure 10 assumes the use of aerobraking at Mars and "insitu" production of ascent propellants to reduce mission mass and transportation system requirements from Earth. The piloted mission is preceded by two cargo missions which depart Earth in
November 2011 and arrive at Mars $\sim 297$ days later. Each cargo and piloted vehicle requires two $\sim 80 \mathrm{t}$ "Magnum" HLLVs (one for the aerobraked payload and the other for the NTR TMl stage) and utilizes an EOR\&D vehicle assembly sequence. A "common" aerobrake / descent shell is used for either capture into Mars orbit or direct descent to the Mars surface. The expendable NTR TMI stage (not shown in Figure 10) is jettisoned after an appropriate "cooldown" period and subsequently disposed of along its heliocentric trajectory.

The cargo lander mission carries a surface payload consisting of a "dry" Mars ascent stage and crew cab combination, nuclear power systems, $\mathrm{LH}_{2}$ "feedstock" and ISRU plant, an inflatable laboratory module, rovers and science equipment (The complete mass manifest for the cargo lander is found in the Appendix in Table A-2). The payload element delivered to Mars orbit consists of the crew return habitat module. "fueled" TEI stage

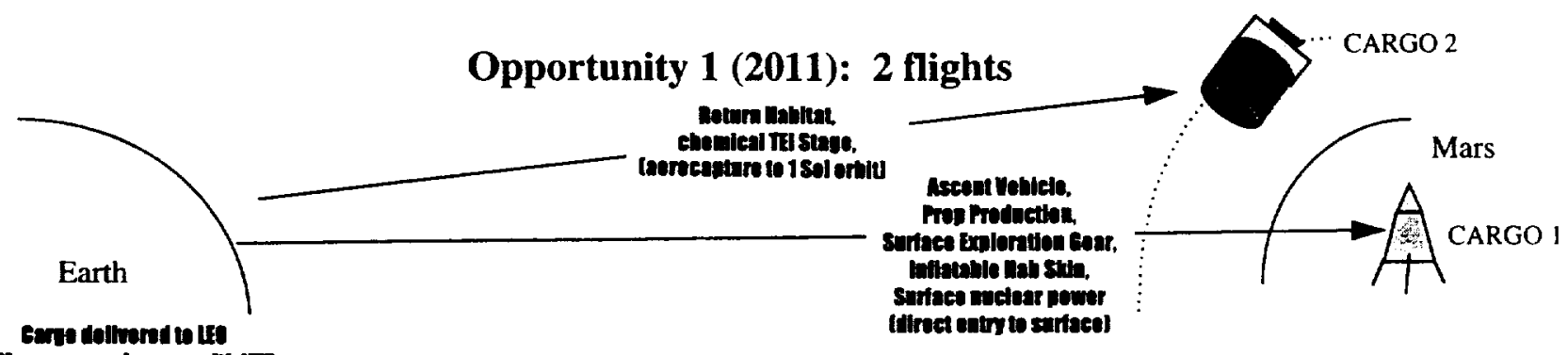
on Mayaun, nudeanes with iTR.
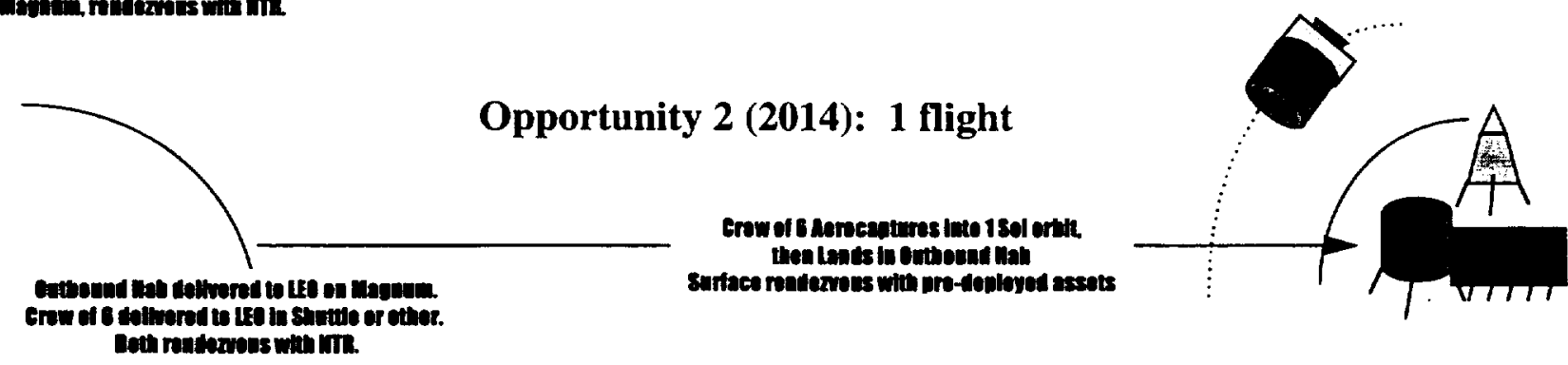

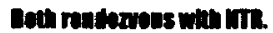
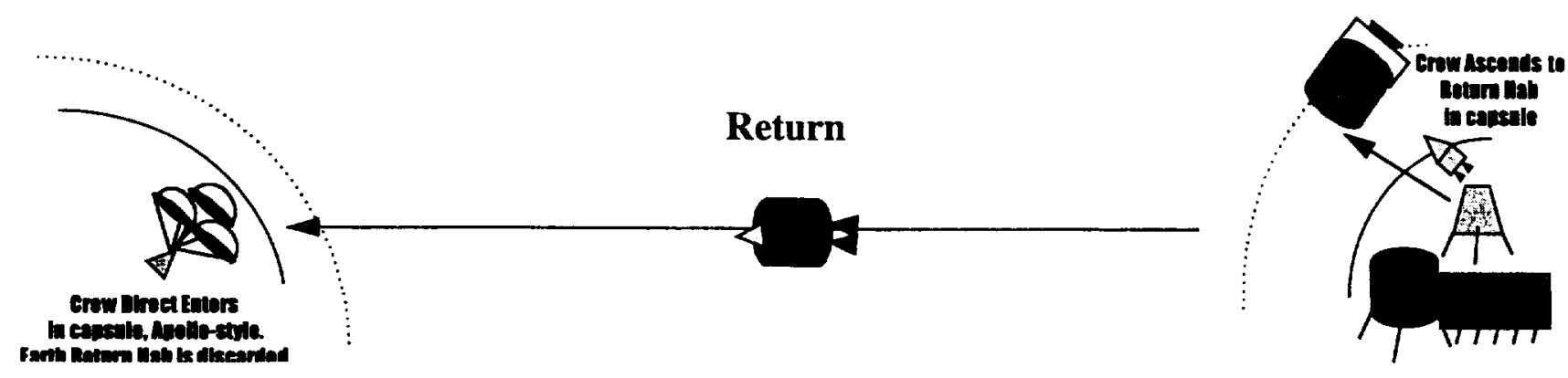

Fig. 10 Candidate Mission Profile for Mars Design Reference Mission 
and integrated aerobrake structure. After the operational functions of the ERV and cargo lander are verified, and the ascent stage is fully fueled with $\mathrm{LOX} / \mathrm{CH}_{4}$ propellant, the piloted vehicle leaves Earth in January 2014 (mass manifests for the ERV and piloted lander are found in the Appendix Tables A-1 and A-3, respectively). It arrives at Mars -180 days later using a "fast conjunction-class" trajectory, 7,8 which maximizes the exploration time at Mars while reducing the total in-space transit time to approximately a year. After a 554-day stay at Mars, the crew returns in the ascent portion of the cargo lander to a waiting ERV to begin preparations for the 6 month journey back to Earth. The ascent stage crew cab doubles as an Earth crew return vehicle (ECRV) and is retained by the ERV for the trip home. Nearing Earth, the crew separates from the ERV and reenters the atmosphere in the ECRV while the ERV flys by Earth and continues on into deep space. The total duration of the piloted and ERV missions are 914 days and 1701 days, respectively.

MARS MISSION / TRANSPORTATION SYSTEM GROUND RULES AND ASSUMPTIONS

The ground rules and assumptions for the reference mission architecture and NTR-based transportation system examined in this study are are summarized in Tables 2 and 3, respectively. In Table 4, the $\Delta V$ budgets are listed for both the aerobrake $(A B)$ and "propulsive capture" (PC) versions of the DRM. Table 5 provides additional $\triangle V$ requirements for the "all NTR" mission options which take into account disposal of spent cargo and piloted NTR stages (either along their interplanetary trajectories or into a stable heliocentric orbit between Earth and Mars at 1.19 astronomical units [A.U.]) at mission end. While Table 2 highlights key features and characteristics of the DRM (e.g., scaling of the" triconic" aerobrake/descent shell mass), Table 3 provides details on NTR and LANTR systems, auxiliary RCS propulsion, cryogenic tankage, propellant thermal protection and boiloff rates, refrigeration system mass and power requirements, and contingency factors used in this study. Although primary propulsion maneuvers are performed using either the NTR or LANTR engines, the spacecraft also executes midcourse and secondary maneuvers using a storable, bipropellant RCS system.

The use of composite materials is assumed for all Mars transportation stage masses (e.g., descent/ ascent stages, NTR $\mathrm{LH}_{2}$ propellant tanks and primary structures, etc.) for weight reduction. The wall thicknesses for the $\mathrm{LH}_{2}$ tanks were calculated based on a 35 psi internal pressure and included hydrostatic loads using a " $5 \mathrm{~g}$ " loading and a safety factor of 1.5. A 3 percent ullage factor was also baselined in this study. For the LOX tanks on LANTR, a 50 psi internal pressure was assumed resulting in wall thicknesses of -0.05 inches.

An 80 layer $(-2.1$ inch), multilayer insulation (MLI) system (at 38 layers per inch) is assumed for thermal protection 20 of the $\mathrm{LH}_{2}$ and $\mathrm{LOX}$ cryogenic tanks. This insulation thickness exceeds the "ground hold" thermal protection requirements for "wet-launched" $\mathrm{LH}_{2}$ tanks which need a minimum of $\sim 1.5$ inches of helium-purged insulation. 21 The installed density of the 80 layer MLI system is $\sim 1.44 \mathrm{~kg} / \mathrm{m}^{2}$, and the resulting $\mathrm{LH}_{2}$ boiloff rate in LEO is $-3.11 \times 10^{-2} \mathrm{~kg} / \mathrm{m}^{2} /$ day (based on an estimated heat flux of $\sim 0.161 \mathrm{~W} / \mathrm{m}^{2}$ at a LEO sink temperature of $\sim 230 \mathrm{~K}$ ). The corresponding boiloff rate for LOX is shown in Table 3. Finally, to account for micrometeoroid protection of propellant tanks ( while in LEO, Mars orbit, and during transit to and from Mars), an $\sim 0.50 \mathrm{~mm}$ thick sheet of aluminum (corresponding mass of $-1.35 \mathrm{~kg} / \mathrm{m}^{2}$ ) is also included in the total tank weight estimates.

The NTR vehicle concepts developed in this study employ different thermal protection systems for $\mathrm{LH}_{2}$ consistent with the vehicle's mission application and expected lifetime. For the expendable NTR TMI stages, which have a "limited life" in LEO of -32 days before departure, an -2 inch "minimum mass" MLI system is used resulting in a L $\mathrm{H}_{2}$ boiloff of $\sim 0.46 \mathrm{t}$. The "all BNTR"-powered ERV mission has the most demanding requirements for thermal protection with a mission ellapsed time between TMI and TEI of 1521 days ( -4.2 years). For this mission application, an active system was developed consisting of a 2 inch MLI blanket and a turbo-Brayton refrigerator. Selection of the turbo-Brayton system was based on a NASA-funded study and survey22 of various refrigeration systems which indicated its suitability for large $\mathrm{LH}_{2}$ tanks requiring refrigeration capacities in the 10 to 100 watt cooling range. Table 3 shows the specific mass and input power assumptions used in estimating the inert weight and electrical power demands for the common, "refrigerated" BNTR core stage developed in this study. 
- Split Mission Scenario: (2 Cargo Missions in 2011, 1 Piloted Mission in 2014)

- Payload Elements Consist of Mars Cargo Lander, Earth Return Vehicle (ERV) and Piloted Lander with 6 Crew.

- Dual Launch Earth Orbit Rendezvous and Dock Vehicle Assembly at $407 \mathrm{~km}$ using two $80-88 \mathrm{t}$ "Magnum" HLLVs.

- Magnum Payload Shroud Dimensions:

$7.6 \mathrm{~m}$ (I.D.) $\mathrm{x} \sim 28.0 \mathrm{~m}$ Length

- Aerobraking and Propulsive Capture into 250 x 33,793 km (1 sol) Elliptical Mars Parking Orbit

- Aerodescent Shell and Parachutes for Descent to Mars (descent $\Delta \mathrm{V}=632 \mathrm{~m} / \mathrm{s}$ )

- Aerobrake/Descent Shell Sizing: $M_{A B}(t)=\sqrt{ } M_{P L}(a+b V e)+M_{s}$; where $\mathrm{M}_{\mathrm{PL}}=$ payload mass in $\mathrm{t}, \mathrm{a}=-0.55, \mathrm{~b}=0.19, \mathrm{Ve}=$ entry velocity in $\mathrm{km} / \mathrm{s}$ and $M_{s}=$ structural mass $=6 \mathrm{t}$

- Mars Descent Stage uses 4-15 klbf LOX/CH${ }_{4}$ Engines (Isp $=379 \mathrm{~s}, \mathrm{MR}=3.5$, Stage Boiloff Rate: $~ 0.4 \% /$ month)

- "In-Situ” Production of $\mathrm{LOX} \mathrm{CH}_{4}$ Ascent Propellant using Earth-Supplied $\mathrm{LH}_{2}$

- Mars Ascent Stage $\Delta \mathrm{V}$ to 1 sol orbit: $5625 \mathrm{~m} / \mathrm{s}$

- Mars Ascent Stage $\Delta V$ to Phobos orbit: $5400 \mathrm{~m} / \mathrm{s}$

- Mars Ascent Stage and Crew Capsule Rendezvous with ERV / Crew Capsule Retained / Doubles as Earth Crew Return Vehicle (ECRV)

- Chemical Trans-Earth Injection (TEI) Stage uses $2-15 \mathrm{klbf} \mathrm{LOX} / \mathrm{CH}_{4}$ Engines (Stage Boiloff Rate: $\sim 0.2 \% /$ month)

- Direct Reentry of ECRV and Crew at Earth Arrival

- Mission Abort Strategy:

- Outbound: Abort to Mars Surface

- At Mars: Abort to ERV which carries contingency consumables. 
Table 3. Mars NTR / LANTR Transportation System Assumptions

\begin{tabular}{|c|c|c|c|}
\hline \multirow{8}{*}{$\begin{array}{l}\text { - NTR / LANTR } \\
\text { Systems: }\end{array}$} & Thrust /Weight & $=$ & $15 \mathrm{kJbf} / 2224 \mathrm{~kg}\left(\mathrm{LH}_{2}\right.$ NTR$)$ \\
\hline & & $=$ & $15 \mathrm{klbf} / 2630 \mathrm{~kg}$ (LANTR @ MR $=0.0)$ \\
\hline & Fuel / Propellants & $=$ & Temary Carbide / Cryogenic $\mathrm{LH}_{2} \&$ LOX \\
\hline & & $\begin{array}{l}= \\
=\end{array}$ & $\begin{array}{l}940 \text { - } 955 \mathrm{~s}\left(@ \mathrm{O} / \mathrm{F} \mathrm{MR}=0.0 / \mathrm{LH}_{2} \text { only }\right) \\
831 \mathrm{~s}(@ \mathrm{O} / \mathrm{F} \mathrm{MR}=0.5)\end{array}$ \\
\hline & External Shield Mass & $=$ & $2.84 \mathrm{~kg} / \mathrm{MWt}$ of reactor power \\
\hline & Flight Reserve & $=$ & $1 \%$ on $\Delta V$ \\
\hline & Residual & $=$ & $2 \%$ of total tank capacity \\
\hline & Cooldown (effective) & $=$ & $3 \%$ of usable $\mathrm{LH}_{2}$ propellant \\
\hline \multirow[t]{3}{*}{ - RCS System: } & Propellant & $=$ & $\mathrm{N}_{2} \mathrm{O}_{4} / \mathrm{MMH}$ \\
\hline & & $=$ & $320 \mathrm{~s}$ \\
\hline & Tankage & $=$ & $5 \%$ of total RCS propellants \\
\hline \multirow{6}{*}{$\begin{array}{l}\text { Cryogenic } \\
\text { Tankage/ } \\
\text { Thermal } \\
\text { Protection: }\end{array}$} & Material & $=$ & Advanced Composite \\
\hline & Diameter & $=$ & $7.4 \mathrm{~m}\left(\mathrm{LH}_{2}\right) / 2.6 \mathrm{~m}(\mathrm{LOX})$ \\
\hline & Geometry & $=$ & cylindrical with $\sqrt{2} / 2$ domes $/$ spherical \\
\hline & Insulation & $=$ & 2.1 inches (80 layers) ML1 @ $1.44 \mathrm{~kg} / \mathrm{m}$ \\
\hline & $\mathrm{LH}_{2} / \mathrm{LOX}$ Boiloff & $=$ & $3.11 \times 10^{-2} / 6.49 \times 10^{-2} \mathrm{~kg} / \mathrm{m}^{2} / \mathrm{day}$ \\
\hline & $\begin{array}{l}\text { Micrometeoroid } \\
\text { Shield }\end{array}$ & $=$ & $1.35 \mathrm{~kg} / \mathrm{m}^{2}(\sim 0.5 \mathrm{~mm}$ sheet of Aluminum) \\
\hline \multirow{2}{*}{$\begin{array}{l}\text { - } \mathrm{LH}_{2} \text { Refrigeration } \\
\text { System: }\end{array}$} & Specific Mass & $=$ & $4.57 \mathrm{~kg} / \mathrm{W}$ refrig. @ 75 Watts \\
\hline & Input Power & $=$ & $\sim 0.11-0.20 \mathrm{kWe} / \mathrm{W}$ refrig. \\
\hline - Contingency & Engine, shields and stage dry mass & $=$ & $15 \%$ \\
\hline
\end{tabular}

- Based on estimated heat flux of $\sim 0.1608 \mathrm{~W} / \mathrm{m}^{2}$ at LEO sink temperature of $\sim 230 \mathrm{~K}$

Table 4. Mars Cargo and Piloted Mission $\Delta V$ Budgets (Ideal)

\begin{tabular}{|c|c|c|c|c|c|c|c|c|}
\hline $\begin{array}{l}\text { Vehicle } \\
\text { Mission } \\
\text { Mode } \\
\end{array}$ & $\begin{array}{l}\text { Launch } \\
\text { Date }\end{array}$ & $\begin{array}{c}\begin{array}{c}\text { Uutbound } \\
\text { Transit Time } \\
\text { (days) }\end{array} \\
\end{array}$ & $\begin{array}{c}\text { Inbound } \\
\begin{array}{c}\text { Transit Time } \\
\text { (days) }\end{array} \\
\end{array}$ & $\begin{array}{c}\text { Total } \\
\text { Mission Time } \\
\text { (days) } \\
\end{array}$ & $\begin{array}{c}\mathrm{TMI} \\
\mathbf{\Delta V} \\
(\mathbf{k m} / \mathbf{s})\end{array}$ & $\begin{array}{c}\mathbf{M O C} \\
\Delta \mathbf{V} \\
(\mathrm{km} / \mathrm{s})\end{array}$ & $\begin{array}{c}\text { TELEOC } \\
\Delta V \\
(\mathbf{k m} / \mathbf{s}) \\
\end{array}$ & $\begin{array}{l}\text { Total } \\
\text { Ideal } \Delta V \\
(\mathbf{k m} / \mathbf{s}) \\
\end{array}$ \\
\hline \multirow[t]{4}{*}{ Cargo } & $\begin{array}{c}11 / 8 / 2011 \\
\text { (AB @ Mars) }\end{array}$ & 297 & NA & 297 & 3.580 & $A B$ & NA & 3.580 \\
\hline & $\begin{array}{c}11 / 9 / 2011 \\
\text { (PC@Mars) }\end{array}$ & 307 & NA & 307 & 3.581 & 0.925 & NA & 4.505 \\
\hline & $\begin{array}{c}\text { 12/4/2013 } \\
\text { (PC @ Mars) }\end{array}$ & 294 & NA & 294 & 3.605 & 1.162 & NA & 4.767 \\
\hline & $\begin{array}{c}12 / 31 / 2013 \\
\text { (AB @ Mars) }\end{array}$ & 328 & NA & 328 & 3.572 & $\mathbf{A B}$ & NA & 3.572 \\
\hline \multirow[t]{4}{*}{ Piloted } & $\begin{array}{c}1 / 4 / 2014 \\
(\mathrm{AB} @ \mathrm{Mars})\end{array}$ & 180 & 180 & $\begin{array}{c}914 \\
\text { (554 @ Mars) }\end{array}$ & 3.672 & $\mathbf{A B}$ & $\mathrm{NA}$ & 3.672 \\
\hline & $\begin{array}{c}2 / 2 / 2014 \\
\text { (PC @ Mars) }\end{array}$ & 180 & 180 & $\begin{array}{c}885 \\
\text { (525@ Mars) }\end{array}$ & 4.214 & 2.251 & NA & 6.465 \\
\hline & $\begin{array}{c}1 / 21 / 2014 \\
\text { (PC @ Mars) }\end{array}$ & 210 & 180 & $\begin{array}{c}897 \\
\text { (507@ Mars) }\end{array}$ & 3.861 & 1.720 & NA & 5.581 \\
\hline & $\begin{array}{c}1 / 18 / 2014 \\
\text { (PC @ Mars) }\end{array}$ & 220 & 180 & $\begin{array}{c}900 \\
(500 @ M a r s)\end{array}$ & 3.823 & 1.629 & NA & 5.452 \\
\hline \multirow{3}{*}{$\begin{array}{l}\text { ERV } \\
\text { Outbound/ } \\
\text { Piloted } \\
\text { Inbound }\end{array}$} & $\begin{array}{c}11 / 8 / 2011 \\
(\mathrm{AB} @ \text { Mars) }\end{array}$ & 297 & 180 & $\begin{array}{c}1702 \\
(1225 @ \text { Mars) }\end{array}$ & 3.580 & $\mathbf{A B}$ & 1.079 & 4.659 \\
\hline & $\begin{array}{c}11 / 9 / 2011 \\
\text { (PC @ Mars) }\end{array}$ & 307 & 180 & $\begin{array}{c}1701 \\
(1214 @ \text { Mars) }\end{array}$ & 3.581 & 0.925 & 1.079 & 5.585 \\
\hline & $\begin{array}{c}11 / 9 / 2011 \\
\text { (PC @ Mars) }\end{array}$ & 307 & 180 & $\begin{array}{c}1731 \\
\text { (1244@ Mars) }\end{array}$ & 3.581 & 0.925 & $1.419 / 1.365$ & 7.290 \\
\hline
\end{tabular}

Note:

$\Delta V$ based on $407 \mathrm{~km}$ circular orbit at Earth and $250 \times 33793$ Mars parking orbit.

G-losses appropriate to "single or double perigee bum" Earth departure must be added to the TMI $\Delta V$ shown.

Apsidal/nodal alignment penalty of $500 \mathrm{~m} / \mathrm{s}$ must be added to the TEl $\Delta V$ value shown. 
Because of the inventory of radioactive fission products that will be generated in the BNTR engines during their service life, care must be taken to dispose of these vehicles in a responsible manner at mission end. Calculations by Stancati23,24 using the Planetary Encounter Probability Analysis (PEPA) code have provided estimates of the $\Delta V$ requirements and probabilities of NTR vehicle collisions with Earth for various disposal scenarios (shown in Table 5). In the Mars mission scenario depicted in Figure 10, the expendable NTR TMI stages are disposed of along their interplanetary path after payload separation. Table 5 shows that the probabilities for Earth reencounter over the course of a million years are $-13 \%$ and $11 \%$ for the cargo and piloted TMI stages, respectively. The increased probability for the cargo missions are due to their near-Hohmann trajectories. For the "all NTR" mission scenarios, the BNTR stages used on cargo and piloted lander missions are removed from Mars orbit shortly after the ERV leaves for Earth. Although a stable parking orbit exists at $-1.19 \mathrm{~A}$. U., the $\Delta V$ penalty for disposal to this location is appreciable at $\sim 2.52$ $\mathrm{km} / \mathrm{s}$ (see Table 5). A second disposal option adopted in this study is to leave the NTR vehicles on their flight paths to $1.19 \mathrm{~A}$. U., but to eliminate the final capture and circularization burns. This option reduces the disposal $\Delta \mathrm{V}$ to $\sim 0.33 \mathrm{~km} / \mathrm{s}$ and though it allows for possible future encounters with Earth, the probabilities are very small $(\ll<1 \%)$.

\section{EXPENDABLE TRANS-MARS INJECTION STAGE}

A "common" TMI stage design has been developed for both the Mars cargo and piloted missions which employs three $\sim 15 \mathrm{klbf}$ CIS / NTR engines, each weighing $2224 \mathrm{~kg}$ and operating

Table 5. Mars Disposal $\Delta V$ Requirements

\begin{tabular}{|c|c|c|c|c|}
\hline Mission & $\begin{array}{l}\text { Disposal } \\
\text { Initiated }\end{array}$ & Req'd Maneuvers & $\begin{array}{c}\Delta V \text { Disposal } \\
(\mathrm{km} / \mathrm{s})\end{array}$ & $\begin{array}{l}\text { Earth Encounter } \\
\text { Probability }\end{array}$ \\
\hline $\begin{array}{l}\text { - } 2011 \text { Cargo } \\
\text { (AB @ Mars) }\end{array}$ & $\begin{array}{l}\text { after TMI/ } \\
\text { before MOC }\end{array}$ & $\begin{array}{l}\text { none - TMl stage } \\
\text { disposed along } \\
\text { interplanetary path }\end{array}$ & 0 & $\begin{array}{c}13 \% \text { in } 10^{6} \\
\text { years }\end{array}$ \\
\hline $\begin{array}{l}-2011 \text { Cargo } \\
\text { (PC @ Mars) }\end{array}$ & $\begin{array}{l}\text { from Mars orbit } \\
\text { after cargo } \\
\text { delivery }\end{array}$ & $\begin{array}{l}\text { depart Mars orbit } \\
\text { circularize } @ 1.19 \mathrm{AU}\end{array}$ & $\begin{array}{l}0.331 \\
2.184 \\
2.515\end{array}$ & 0 \\
\hline $\begin{array}{l}-2011 \text { Cargo } \\
\text { (PC @ Mars) }\end{array}$ & $\begin{array}{l}\text { from Mars orbit } \\
\text { after cargo } \\
\text { delivery }\end{array}$ & $\begin{array}{c}\text { depart Mars orbit to } \\
1.19 \mathrm{AU} / \text { dispose } \\
\text { along interplanetary } \\
\text { path }\end{array}$ & $\begin{array}{c}0.331 \\
0 \\
0.331\end{array}$ & $\begin{array}{c}0.02 \% \text { in } 10^{6} \\
\text { years }\end{array}$ \\
\hline $\begin{array}{l}2014 \text { Piloted } \\
\text { (AB @ Mars) }\end{array}$ & $\begin{array}{l}\text { after TMII } \\
\text { before MOC }\end{array}$ & $\begin{array}{c}\text { none - TMI stage } \\
\text { disposed along } \\
\text { interplanetary path }\end{array}$ & 0 & $\begin{array}{c}11 \% \text { in } 10^{6} \\
\text { years }\end{array}$ \\
\hline $\begin{array}{l}2014 \text { Piloted } \\
\text { (PC @ Mars) }\end{array}$ & $\begin{array}{l}\text { from Mars orbit } \\
\text { after cargo } \\
\text { delivery }\end{array}$ & $\begin{array}{c}\text { depart Mars orbit } \\
\text { circularize } @ 1.19 A U\end{array}$ & $\begin{array}{l}0.331 \\
2.184 \\
2.515\end{array}$ & 0 \\
\hline $\begin{array}{l}2014 \text { Piloted } \\
\text { (PC @ Mars) }\end{array}$ & $\begin{array}{l}\text { from Mars orbit } \\
\text { after cargo } \\
\text { delivery }\end{array}$ & $\begin{array}{c}\text { depart Mars orbit to } \\
1.19 A \cup \text { / dispose } \\
\text { along interplanetary } \\
\text { path }\end{array}$ & $\begin{array}{c}0.331 \\
0 \\
0.331\end{array}$ & $\begin{array}{c}0.02 \% \text { in } 10^{6} \\
\text { years }\end{array}$ \\
\hline $\begin{array}{l}2011 \text { Earth } \\
\text { Return Stage } \\
\text { (PC @ Mars) }\end{array}$ & $\begin{array}{l}\text { after Earth } \\
\text { flyby \& ECRV } \\
\text { separation }\end{array}$ & $\begin{array}{l}\text { Earth gravity assist } \\
\text { circularize } 1.19 \mathrm{AU}\end{array}$ & $\begin{array}{c}0 \\
2.951 \\
2.951\end{array}$ & 0 \\
\hline $\begin{array}{l}2011 \text { Earth } \\
\text { Return Stage } \\
\text { (PC@ Mars) }\end{array}$ & $\begin{array}{l}\text { after Earth } \\
\text { flyby \& ECRV } \\
\text { separation }\end{array}$ & $\begin{array}{l}\text { Earth gravity assist } \\
\text { disposal along } \\
\text { interplanetary path }\end{array}$ & 0 & $\begin{array}{c}11 \% \text { in } 10^{6} \\
\text { years }\end{array}$ \\
\hline
\end{tabular}


with a Isp of $\sim 940 \mathrm{~s}$. For a fixed total reactor power output of $\sim 335 \mathrm{MWt}$, the engines are capable of operating at higher Isp values ( $-955 \mathrm{~s})$ by increasing fuel temperature (from $2900 \mathrm{~K}$ to $\sim 3075 \mathrm{~K}$ ) which results in a small decrease in thrust (down to $\sim 14.76 \mathrm{klbf}$ ). The single tank stage is sized to accommodate both the 2007 ERV cargo mission with a $\mathrm{C} 3=13.41 \mathrm{~km}^{2} / \mathrm{s}^{2}$ and a payload of $\sim 74 \mathrm{t}$, or the energetically demanding, fast transit 2009 piloted mission (with $\mathrm{C} 3=20.06 \mathrm{~km}^{2} / \mathrm{s}^{2}$ ).

The size, mass and key features of the common NTR TMI stage and its aerobraked payloads is illustrated in Figure 11 and a rendered threedimensional (3-D) image of the stage and payload is provided in Figure 12. The TMI stage $\mathrm{LH}_{2}$ tank is cylindrical with $\sqrt{2} / 2$ ellipsoidal domes. It has an inner diameter of $7.4 \mathrm{~m}$, an $\sim 20.6 \mathrm{~m}$ length, and a maximum propellant capacity of $\sim 56 \mathrm{t}$ assuming a $3 \%$ ullage factor. The main stage components include the $\mathrm{LH}_{2}$ tank; thermal and micrometeoroid protection; a forward cylindrical adaptor section housing avionics and auxiliary power, RCS and docking systems; forward and aft skirts; thrust structure; propellant feed system; and NTR engines. Stage auxiliary power is provided by an oxygen/hydrogen fuel cell system which supplies $1.5 \mathrm{kWe}$ for up to 32 days in LEO. Assuming a consumption rate of $\sim 0.415 \mathrm{~kg}$ per $\mathrm{kWe}$-hour, $\sim 0.48 \mathrm{t}$ of reactants (at an $\mathrm{O} / \mathrm{H}$ ratio of 8 to 1 ) are required. The hydrogen reactant is drawn from the main propellant tank while the oxygen reactant is stored in several small spherical tanks in the forward section of the stage. The expendable TMI stage has a length of $\sim 27.5 \mathrm{~m}$ as shown in Figure 11 and a total "dry mass" estimated to be $-22.2 \mathrm{t}$. For the piloted missions, an external disk shield is added to each engine to provide crew radiation protection. This added shielding increases the stage dry mass by $\sim 3.2 \mathrm{t}$. A summary mass breakdown for the TMl stage is provided in Table 6.

To minimize $\mathrm{LH}_{2}$ boiloff during the vehicle assembly phase, the cargo lander and ERV payloads are launched first, followed by the two TMI stages. Assuming 30 days between Magnum launches and $\sim 2$ days for vehicle checkout, the longest period any TMI stage is in LEO is -32 days. After EOR\&D and checkout, the $\sim 51 \mathrm{~m}$ long cargo and piloted vehicles are ready to leave for Mars. A "2-perigee burn" Earth departure scenario is assumed which includes gravity losses and a $1 \%$ margin on total TMI $\Delta \mathrm{V}$. The gravity losses for the
Table 6. Mass Breakdown for "Common" NTR TMI Stage*

\begin{tabular}{|l|c|}
\hline \multicolumn{1}{|c|}{ Stage Element } & Mass (t) \\
\hline Structure & 2.45 \\
Propellant Tank $\left(\mathrm{L}_{\mathrm{t}}=20.6 \mathrm{~m} \times \mathbf{7 . 4} \mathrm{m}\right.$ I.D.) & 6.66 \\
Thermal/Micrometeor Protection System & 1.39 \\
Avionics and Power & 1.2 \\
Reaction Control System (RCS) & 0.42 \\
NTR Assemblies & \\
• 15 klbf CIS NTRs (3) & 6.67 \\
- External Shields (3) & $0-2.82$ \\
- Propellant Feed, TVC, etc. & 0.56 \\
Contingency (15\%) & $2.90-3.33$ \\
\hline "Dry" TMI Stage & $22.24-25.48$ \\
\hline LH, Propellant (max $\mathrm{LH}_{2}$ cap. = 56.0 t) & $52.0-52.61$ \\
RCS Propellant & $0.77-0.88$ \\
Fuel Cell Reactants $\left(\mathrm{O}_{2}\right)$ & 0.43 \\
\hline "Wet" TMI Stage & $75.44-79.40$ \\
\hline
\end{tabular}

* 2007 ERV mission sizes the TMI stage $\mathrm{LH}_{2}$ tank.

cargo lander and ERV missions (C3 $\sim 8.95 \mathrm{~km}^{2} / \mathrm{s}^{2}$ ), and the piloted lander mission (C3 $\sim 11.04 \mathrm{~km}^{2} / \mathrm{s}^{2}$ ) are $\sim 95,110$ and $101 \mathrm{~m} / \mathrm{s}$, respectively. Similarly, the corresponding total TMl engine burn times for the three missions are $\sim 35,39$ and 36 minutes-well within previously demonstrated capabilities.

Table 7 summarizes the mission mass manifests for the first two cargo flights and the subsequent piloted mission. The cargo lander carries the crew ascent stage (shown in Figure 13) and utilizes a jettisonable aerobrake / descent shell. It has a total mass of $\sim 66 \mathrm{t}$ of which $\sim 40.2 \mathrm{t}$ is surface landed payload. The mass of the aerobrake is estimated to be $\sim 9.9 t$ assuming a Mars entry velocity of $-5.65 \mathrm{~km} / \mathrm{s}$ and a entry mass (not including the aerobrake) of $\sim 56.1 \mathrm{t}$. Of the total $9.9 \mathrm{t}, \sim 3.9 \mathrm{t}$ is associated with the TPS system and the remaining $6.0 \mathrm{t}$ with the triconic aerobrake structure (see Table 2). Following orbit capture, subsequent deorbit and atmospheric reentry, the aerobrake shell is jettisoned, and parachutes are deployed to slow the spacecraft descent velocity to $\sim 632 \mathrm{~m} / \mathrm{s}$. This final terminal velocity is removed by the descent stage which carries -11 t of propellant and uses four $\mathrm{RL}$ 10-class engines modified to burn $\mathrm{LOX} / \mathrm{CH}_{4}$. The "wet" TMl stage carries $\sim 48 \mathrm{t}$ of $\mathrm{LH}_{2}$ propellant and has a total mass of $\sim 71.1 \mathrm{t}$ resulting in an IMLEO of $\sim 137.1 \mathrm{t}$ for the cargo lander mission.

The ERV mission utilizes an integrated aerobrake / hab module / TEl stage design with $\mathrm{LOX} / \mathrm{CH}_{4}$ engines, and has a total mass of $\sim 74.1 \mathrm{t}$. 

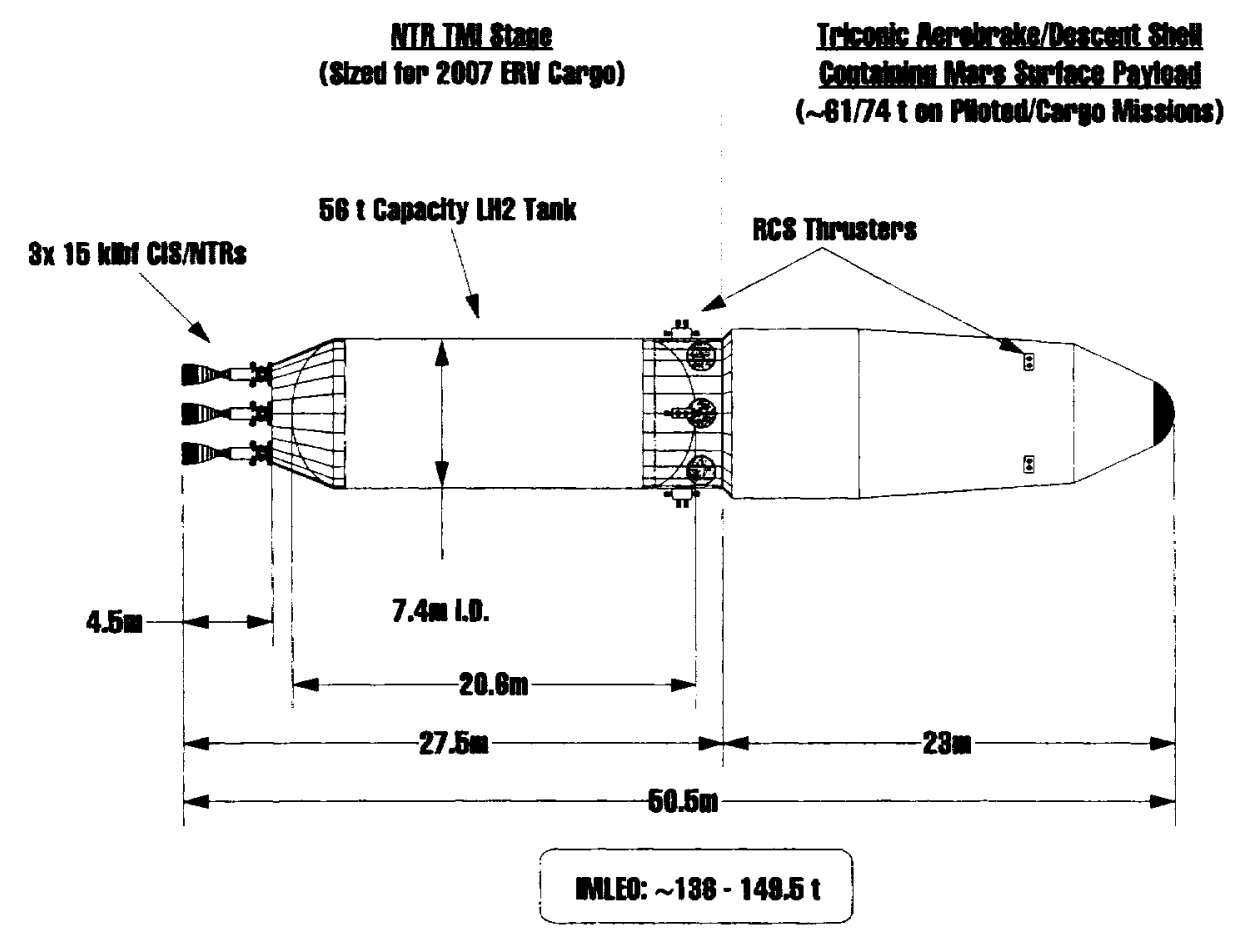

Fig. 11 Size, Mass and Key Features of "Common" TMI Stage and Aerobraked Payloads

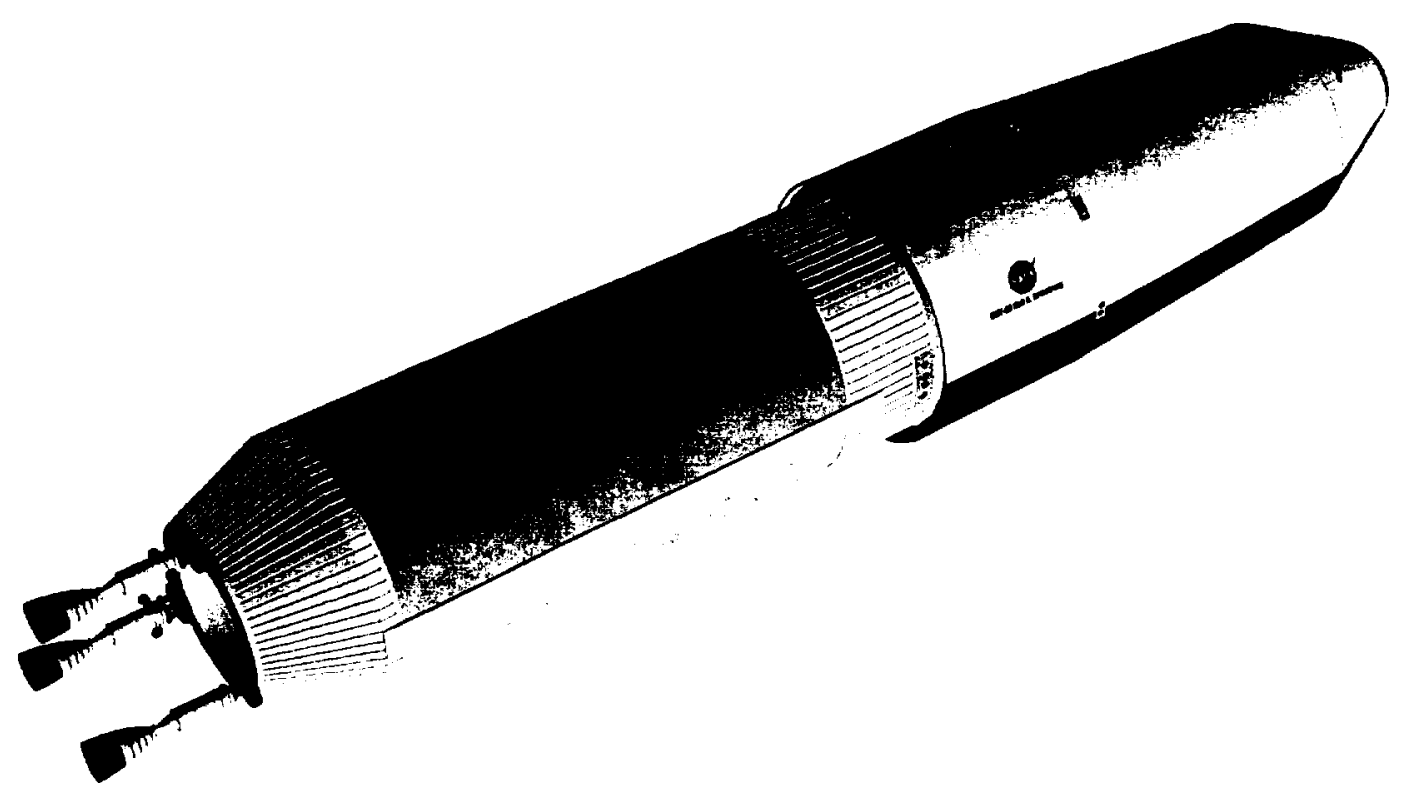

Fig. 12 3-D Image of Expendable TMI Stage and Aerobraked Payload 
Table 7. DRM "Three Mission" IMLEO Summary

(“2 Perigee Burn" Earth Departure Scenario)

(IMLEO $\leq 160$ t/ 2 - 80 t "Magnum" / Shuttle C HLLVs)

\begin{tabular}{|c|c|c|c|c|}
\hline $\begin{array}{c}\text { Stage/ } \\
\text { Propulsion/Isp }\end{array}$ & Element Masses ( $t$ ) & $\begin{array}{c}2011 \text { Cargo } \\
\text { Lander Mission }\end{array}$ & $\begin{array}{l}2011 \text { ERV } \\
\text { Mission }\end{array}$ & $\begin{array}{c}2014 \text { Piloted } \\
\text { Lander } \\
\text { Mission }\end{array}$ \\
\hline \multirow{4}{*}{$\begin{array}{l}\text { TEI Stage } \\
\text { LOX/CH4 } \\
\text { Isp }=379 \mathrm{~s} \\
(\mathrm{O} / \mathrm{F}=3.5: 1)\end{array}$} & Retum Habitat & & 29.10 & \\
\hline & TEI Stage & & 5.89 & \\
\hline & Propellant & & 28.90 & \\
\hline & & & & \\
\hline \multirow{4}{*}{$\begin{array}{c}\text { Ascent Stage } \\
\text { LOX/CH4 } \\
\text { Isp }=379 \mathrm{~s} \\
(\mathrm{O} / \mathrm{F}=3.5: 1)\end{array}$} & Crew (6) \& Suits & & & 1.44 \\
\hline & MAV Crew Cab/ ECRV & 4.80 & & \\
\hline & Ascent Stage & 4.10 & & \\
\hline & Propellant* & 38.40 & & \\
\hline \multirow{4}{*}{$\begin{array}{c}\text { Descent Stage } \\
\text { LOX/CH4 } \\
I s p=379 s \\
(\mathrm{O} / \mathrm{F}=3.5: 1)\end{array}$} & Habitat \& Surface Payload & 31.34 & & 29.51 \\
\hline & Descent Stage & 4.20 & & 4.20 \\
\hline & Propellant** & 10.98 & & 11.38 \\
\hline & & & & \\
\hline \multirow[t]{3}{*}{ MOC System } & $\begin{array}{l}\text { Aerobrake/Descent Shell } \\
\left(\sqrt{M}_{\mathrm{pl}} *(\mathrm{a}+\mathrm{b} * \mathrm{Ve})+\mathrm{Ms}\right)^{+}\end{array}$ & 9.92 & 10.18 & 13.58 \\
\hline & Parachutes & 0.70 & & 0.70 \\
\hline & Total Payload Mass & 66.04 & 74.07 & 60.81 \\
\hline \multirow{5}{*}{$\begin{array}{l}\text { Expendable } \\
\text { TMI Stage } \\
\text { LH }_{2} \text { NTRs } \\
@ \text { 940-955 s }\end{array}$} & $\mathrm{F}(\mathrm{klbf})$ per eng/lsp(s) & $14.76 / 955$ & $14.76 / 955$ & $14.76 / 955$ \\
\hline & CIS Engines (\#) & $7.67(3)$ & $7.67(3)$ & $7.67(3)$ \\
\hline & Radiation Shields (\#) & & & $3.24(3)$ \\
\hline & $\begin{array}{r}\text { TMI Stage } \\
\text { Tank \& Structure }\end{array}$ & 12.72 & 12.72 & 12.72 \\
\hline & Avionics \& Aux. Power & 1.37 & 1.37 & 1.37 \\
\hline \multirow{2}{*}{$\begin{array}{c}\text { RCS } \\
\text { @ 320s }\end{array}$} & Propulsion \& Tankage & 0.47 & 0.47 & 0.48 \\
\hline & & & & \\
\hline \multirow{5}{*}{$\begin{array}{l}\text { Propellants } \\
\text { /Reactamts }\end{array}$} & $\mathrm{LH}_{2}$ Propellant *** & 47.67 & 52.01 & 48.20 \\
\hline & NTO/MMH Propellant & 0.77 & 0.77 & 0.88 \\
\hline & Fuel Cell Reactants $\left(\mathrm{O}_{2}\right)$ & 0.43 & 0.43 & 0.43 \\
\hline & Total "Wet" TMI Stage & 71.10 & 75.44 & 74.99 \\
\hline & Total IMLEO & 137.14 & 149.51 & 135.80 \\
\hline
\end{tabular}

* Ascent propellant produced @ Mars $(\Delta V=5625 \mathrm{~m} / \mathrm{s}$ and Isp $=379 \mathrm{~s})$

** Assumes use of parachutes with descent $\Delta V=632 \mathrm{~m} / \mathrm{s}$

*** Contains boiloff, cooldown, and "tank trapped" residuals

+ ARC Triconic aerobrake mass estimation formula 


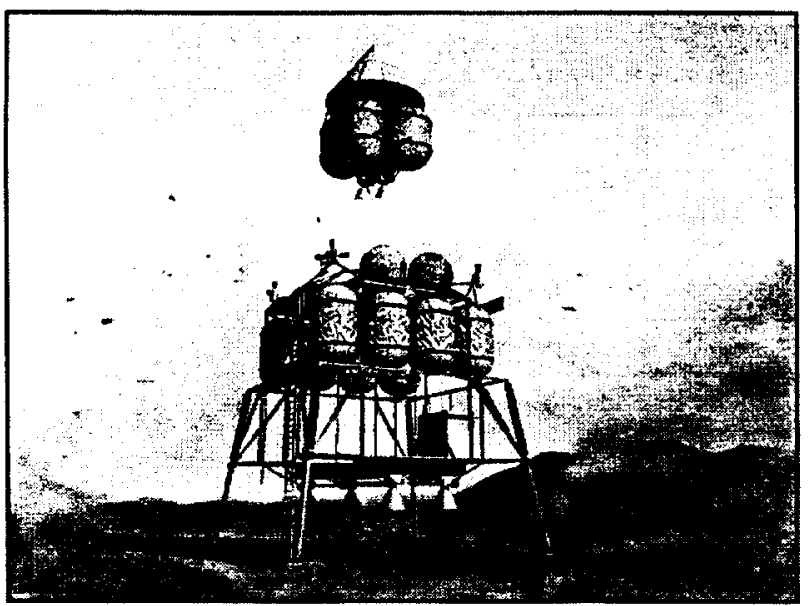

Fig. 13 Cargo Lander Showing Crew Ascent Stage Departure

This heavier payload increases the $\mathrm{LH}_{2}$ propellant loading to $\sim 52 \mathrm{t}$ and the total TMl stage mass to $\sim 75.4 \mathrm{t}$ resulting in an IMLEO of $\sim 149.5 \mathrm{t}$. The piloted mission has an IMLEO of $\sim 135.8 \mathrm{t}$ consisting of a 75 t TMI stage and an "integrated" habitat / aerobrake lander configuration (shown in Figure 14) weighing $-61 \mathrm{t}$. Approximately $31 \mathrm{t}$ of the piloted lander mass is surface payload which includes a crew of six. Because of its fast transit time ( 180 days) and higher entry velocity at Mars $(-8.7 \mathrm{~km} / \mathrm{s})$, the piloted lander also requires an aerobrake which is $-3.5 \mathrm{t}$ heavier than that used on the preceding cargo missions. To reduce aerobrake development costs and eliminate the need for "customized" designs on each mission, a "common" aerobrake configuration could be developed and used on all cargo and piloted

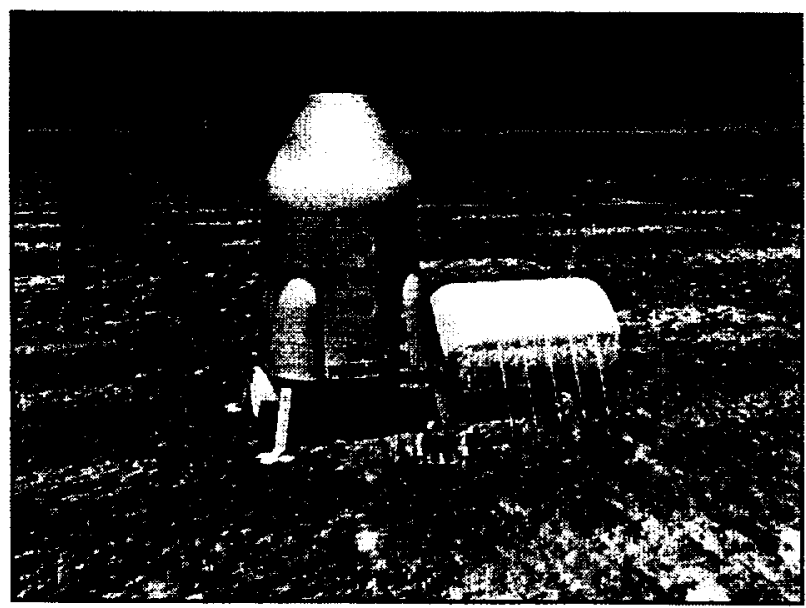

Fig. 14 Piloted Lander Concept with Inflatable Surface Habitat missions. The common design would be sized to accommodate the heaviest payloads and entry velocities anticipated over the -15 year synodic cycle. The use of the heavier piloted aerobrake on the 2011 ERV mission would require enlarging the size and propellant capacity of the TMI stage $\mathrm{LH}_{2}$ tank, further increasing the total mission IMLEO and Magnum lift requirements.

Although a "2-perigee burn" departure scenario has been baselined for the DRM, "single burn" departures can also be easily accommodated on the cargo and piloted lander missions since the TMI stage $\mathrm{LH}_{2}$ tanks contain only $\sim 85 \%$ of their maximum propellant capacity. Decreasing engine fuel temperature and Isp to $2900 \mathrm{~K}$ and $940 \mathrm{~s}$, and using a single burn departure increases gravity losses, engine burn time, propellant loading and IMLEO to $-362 \mathrm{~m} / \mathrm{s}, 38.2 \mathrm{~min}, 52.9 \mathrm{t}$ and $142.3 \mathrm{t}$, respectively, for the cargo lander mission, and $\sim 380 \mathrm{~m} / \mathrm{s}, 38.7 \mathrm{~min}, 53.6 \mathrm{t}$ and $141.2 \mathrm{t}$ for the piloted mission.

Following the short TMI maneuver and an appropriate engine cooldown period, the aerobraked payload and "spent" NTR TMI stage separate with the Mars spacecraft continuing on its nominal mission. The storable bipropellant RCS system onboard the TMI stage is then used to perform the final midcourse correction and targeting maneuvers $(\Delta V-100 \mathrm{~m} / \mathrm{s})$ which place the TMI stage onto its final disposal trajectory. Because of the miniscule burnup of enriched uranium-235 during the Earth departure burn ( 10 grams out of 33 kilograms in each NTR core), disposal of the TMI stage and its engines after a single use is a costly and inefficient use of this high performance stage. By reconfiguring the engines for both propulsion and power generation ("bimodal" operation), a multiple burn, "power-rich" stage with enhanced mission capabilities and reuse potential becomes possible as we discuss below.

\section{"BIMODAL" NTR VEHICLE / MISSION CONCEPT}

The bimodal NTR (BNTR) vehicle concept 10 , proposed in FY93, was examined in greater detail during this study to quantify its performance benefits and mission versatility, and to provide a point of comparison with the expendable TMI stage. A "modified" DRM scenario (Figure 15) was evaluated that employed BNTR transfer vehicles 


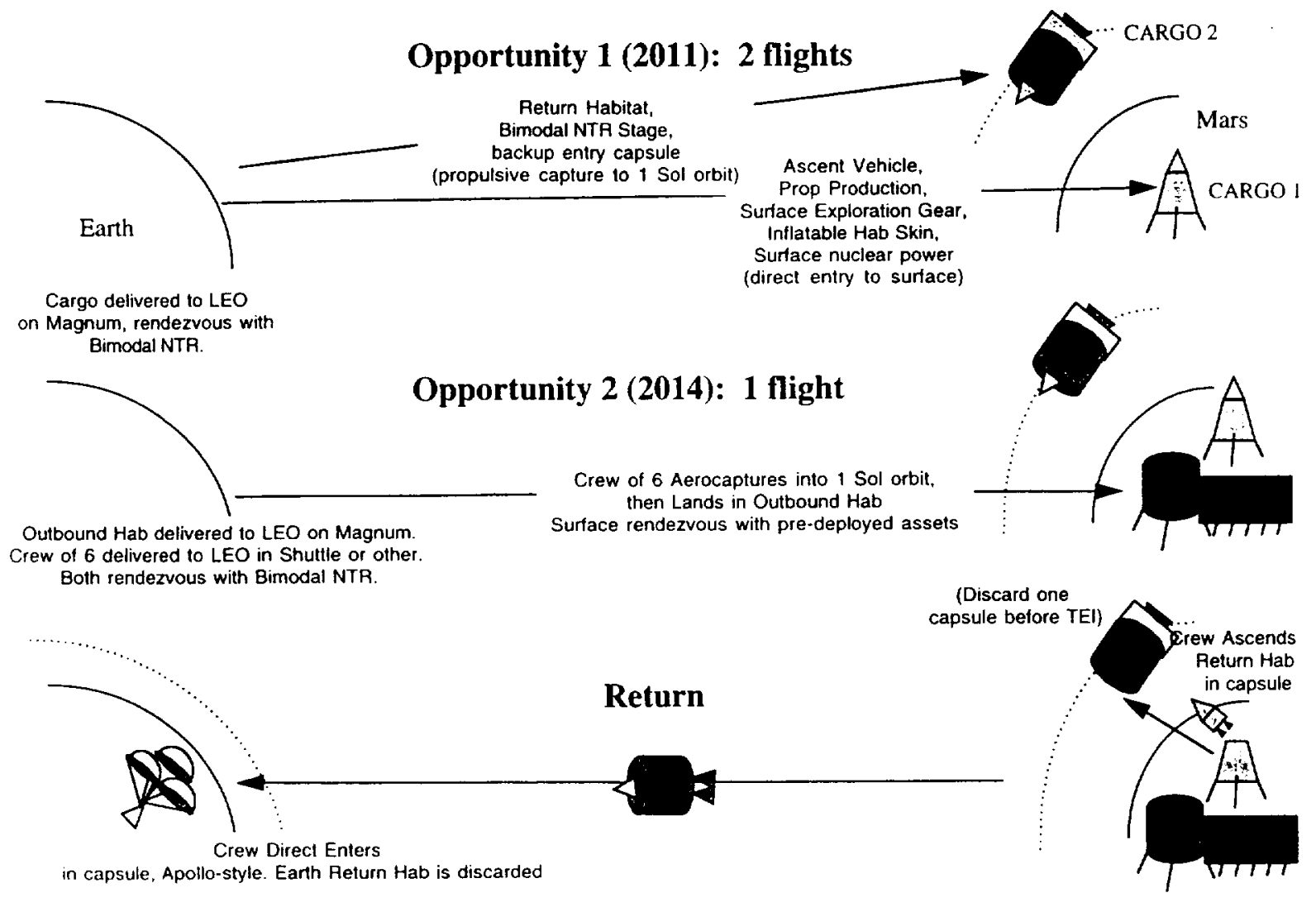

Fig. 15 "Modified" Mars Mission Profile Using Bimodal NTR Vehicle Concept

in place of the expendable TMI stage option discussed above. A common "core" stage, used on cargo and piloted vehicles alike, is outfitted with three $15 \mathrm{kJbf}$ BNTR engines capable of providing up to $50 \mathrm{kWe}$ using any two engines. Configured for launch on a single Magnum booster, the bimodal core stage is not jettisoned after the TMI maneuver but remains with the cargo and piloted payload elements providing them with both midcourse correction (MCC) propulsion and all necessary power during transit. As it nears Mars, the bimodal stage separates from the aerobraked payload and performs its final disposal maneuvers.

A key difference between the DRM and the bimodal option described here is the absence of the aerobraked LOX / $\mathrm{CH}_{4}$ TEI stage which is replaced by an "all BNTR"-powered ERV illustrated in Figures 16 and 17. The bimodal core stage is connected to the hard-shelled ERV habitat module by a rigid, spine-like "saddle truss" to which a jettisonable "in-line" TMI propellant tank is attached. Propellant for the Mars orbit capture MOC and TEI burns is contained within the core stage $\mathrm{LH}_{2}$ tank. The 554 days of contingency consumables carried by the ERV (in case an emergency crew abort to Mars orbit becomes necessary) is also attached to the rear of the hab module and can be easily jettisoned prior to TEI. In the DRM, sizeable doors must be opened on the ERV's integrated aerobrake in order to remove these excess consumables. Approximately 30 days after the core stage is launched, a second Magnum booster delivers the saddle truss, in-line propellant tank, hab module and consumables, to LEO where rendezvous and docking with the bimodal core stage takes place. Because of its higher performance engines ( $-940 \mathrm{~s}$ versus $379 \mathrm{~s}$ for LOX/CH $\mathrm{CH}_{4} \mathrm{RL} 10$ engines), and the elimination of the large $30 \mathrm{kWe}$ PVA ( $3.6 \mathrm{t})$ and heavy aerobrake $(-10.2 \mathrm{t})$, the BNTR / ERV is capable of a "single burn" Earth departure while also carrying a spare Earth return crew vehicle (ECRV) to Mars. This enhanced vehicle capability reduces mission risk by providing a backup option for Earth return should a problem arise that prevents the crew from landing on Mars and recovering their primary ECRV from the ascent stage. Adding a spare ECRV to the aerobraked ERV option increases its IMLEO by an additional $10 \mathrm{t}$ (from 147.5 to 


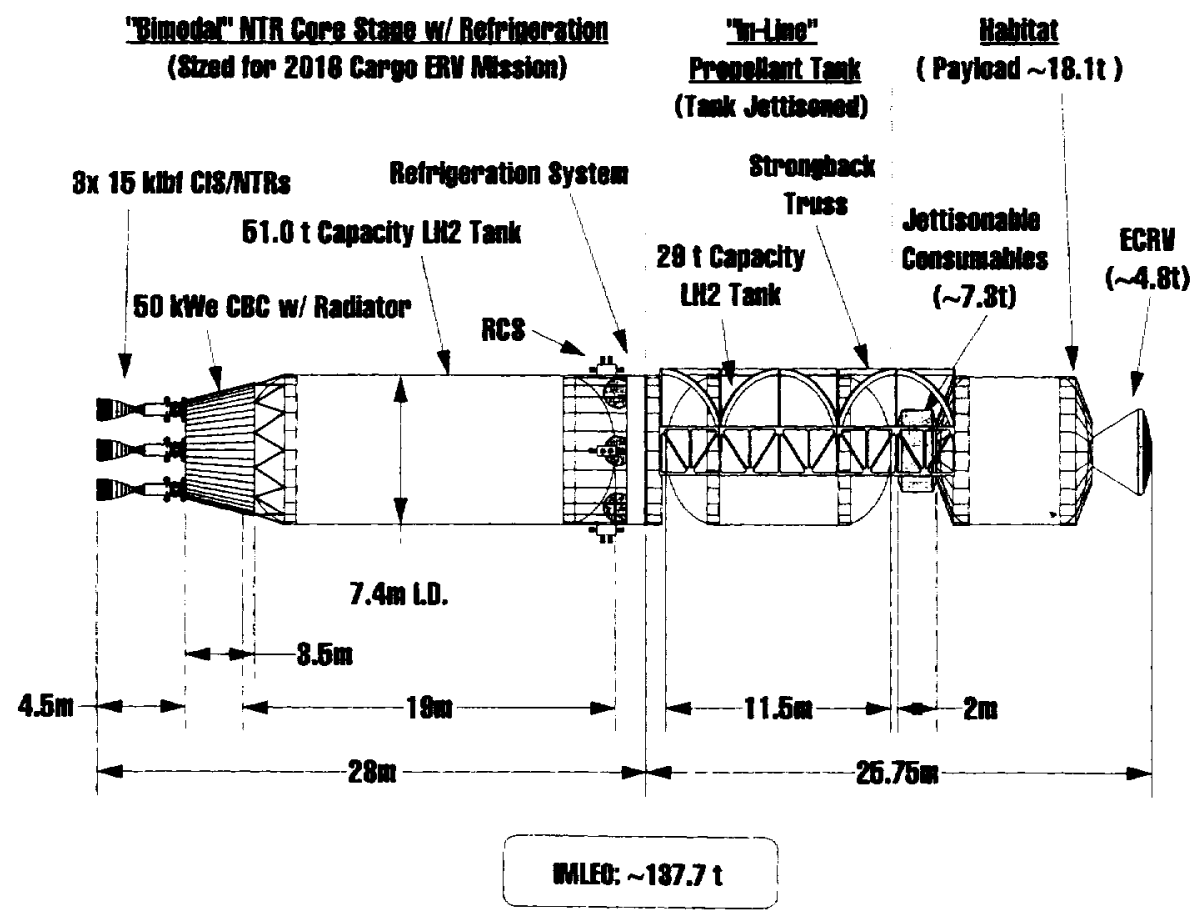

Fig. 16 Size, Mass and Key Features of BNTR-Powered ERV with Crew Habitat and Spare ECRV

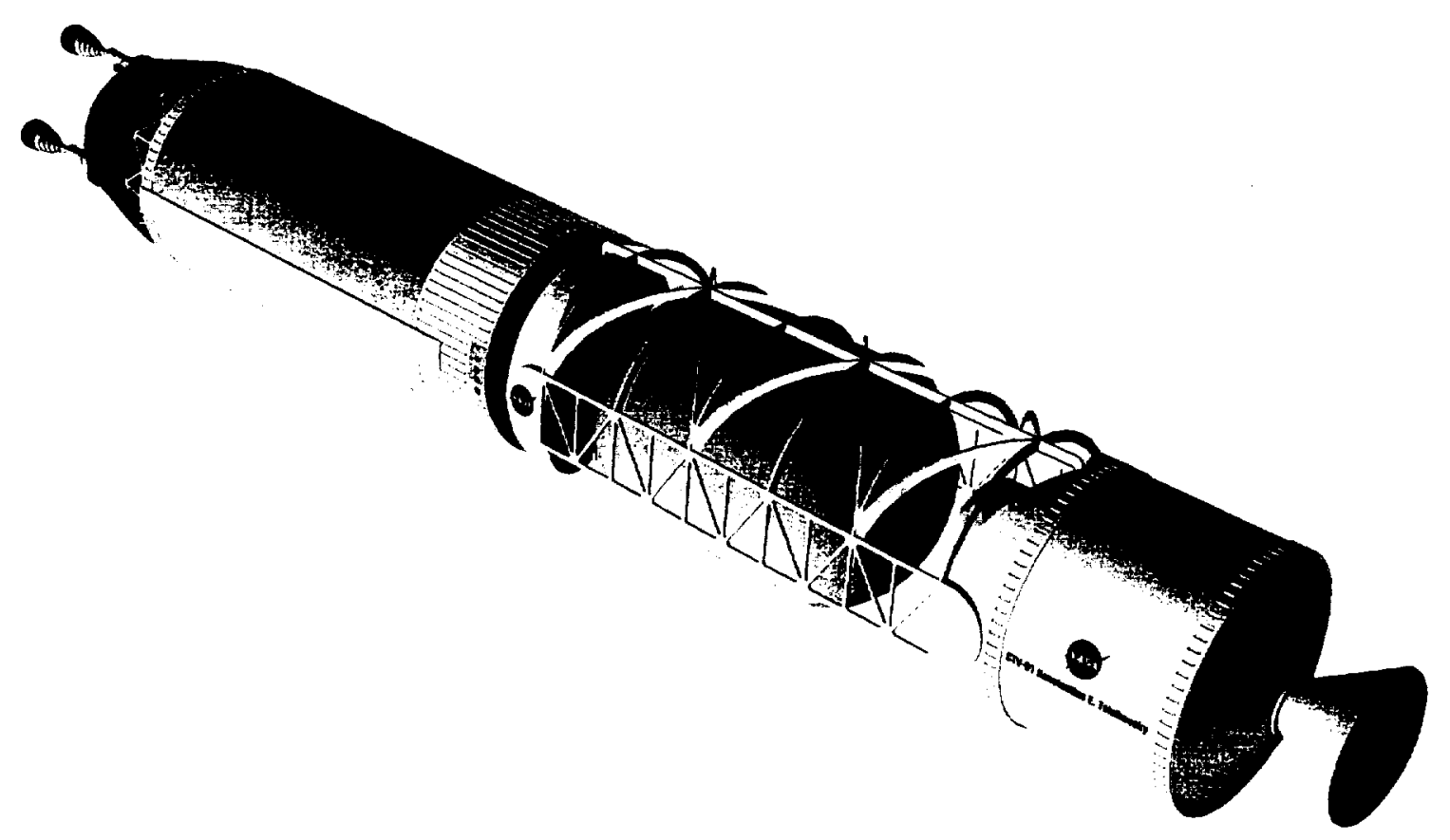

Fig. 17 3-D Image of BNTR / ERV with Spare ECRV 
-157.8 t) even using a "2 perigee burn" departure.

The bimodal core stage $\mathrm{LH}_{2}$ tank is $\sim 19 \mathrm{~m}$ long and has a maximum $\mathrm{LH}_{2}$ propellant capacity of $-51 \mathrm{t}$ using a $3 \%$ ullage factor. In addition to avionics, storable RCS and docking systems, a turboBrayton refrigeration system is also located in the stage forward cylindrical adaptor section to eliminate $\mathrm{LH}_{2}$ boiloff during the lengthy ( -4.2 year) ERV mission. To remove the -75 watts of heat penetrating the 2 inch MLI system in LEO (where the highest tank heat flux occurs), the Brayton refrigeration system requires up to $\sim 15 \mathrm{kWe}$. At the aft end of the bimodal core stage, a conical extension of the stage thrust structure provides support for a "common", one-sided, pumped-loop heat rejection radiator system. Enclosed within this $\sim 71 \mathrm{~m}^{2}$ conical radiator is a closed Brayton cycle (CBC) power conversion system employing three $25 \mathrm{kWe}$ Brayton rotating units (one for each bimodal reactor) which operate at $-2 / 3$ of rated capacity and provide an "engine out" capability. The turbine inlet temperature of the working gas is $-1300 \mathrm{~K}$ and the total system specific mass is estimated to be $\sim 30 \mathrm{~kg} / \mathrm{kWe}$. A mass breakdown of the common BNTR core stage used in the "modified" DRM and the "all BNTR" mission scenarios described below is found in Table 8 .
Table 8. Mass Breakdown for "Common" Bimodal NTR Core Stage

\begin{tabular}{|l|c|}
\hline \multicolumn{1}{|c|}{ "Bimodal" NTR Core Stage Elements } & Mass (t) \\
\hline Structure & 2.5 \\
Avionics and Power & 1.47 \\
Reaction Control System (RCS) & $0.45-0.48$ \\
Propellant Tank (7.4 m I.D. x 19.0 m Igth.) & 5.98 \\
Passive TPS (@2 "MLI)/Micrometeor Shield & 1.29 \\
LH2 Refrigeration System (@ -75 Wt) & 0.30 \\
Brayton Power System (@ 50 kWe) & 1.35 \\
NTR Assemblies & \\
-15 klbf CIS NTRs (3) & 6.67 \\
- External Radiation Shields (3) & $0-2.82$ \\
• Propellant Feed, etc. & 0.47 \\
Contingency (15\%) & $3.07-3.50$ \\
\hline "Dry" Bimodal Core Stage & $23.55-26.83$ \\
\hline LH2 Propellant (max. LH ${ }_{2}$ Capacity) & 51.0 \\
RCS Propellant & $1.62-2.19$ \\
\hline "Wet" Bimodal Core Stage & $76.2-80.0$ \\
\hline
\end{tabular}

The bimodal transfer vehicle used for the cargo lander requires a much smaller in-line propellant tank and saddle truss arrangement (shown in Figure 18) than that used by the "3-burn" ERV mission, while the piloted lander requires only the bimodal core stage (see Figure 19). Because of the modest power needs currently identified for the cargo lander, payload mass reductions

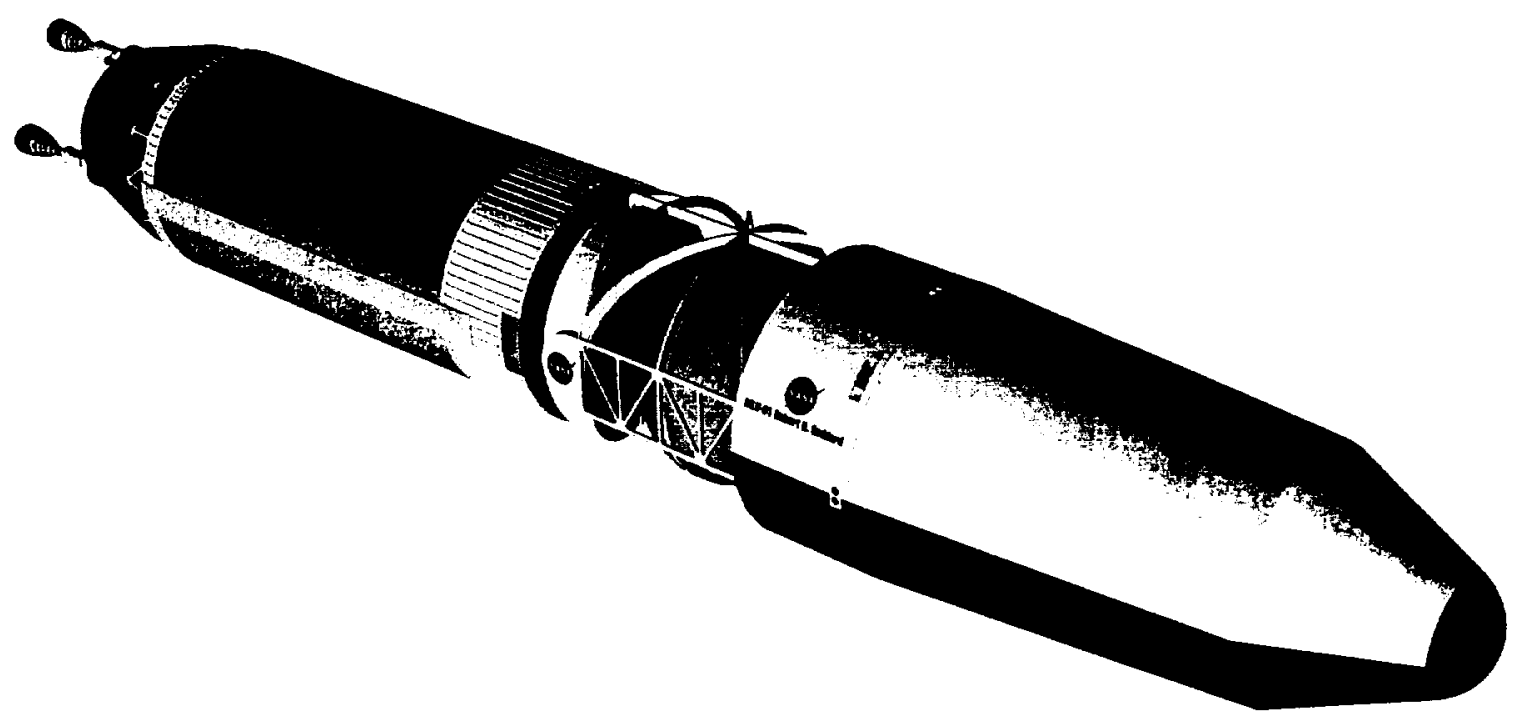

Fig. 18 3-D Image of BNTR Transfer Stage and Aerobraked Cargo Lander 


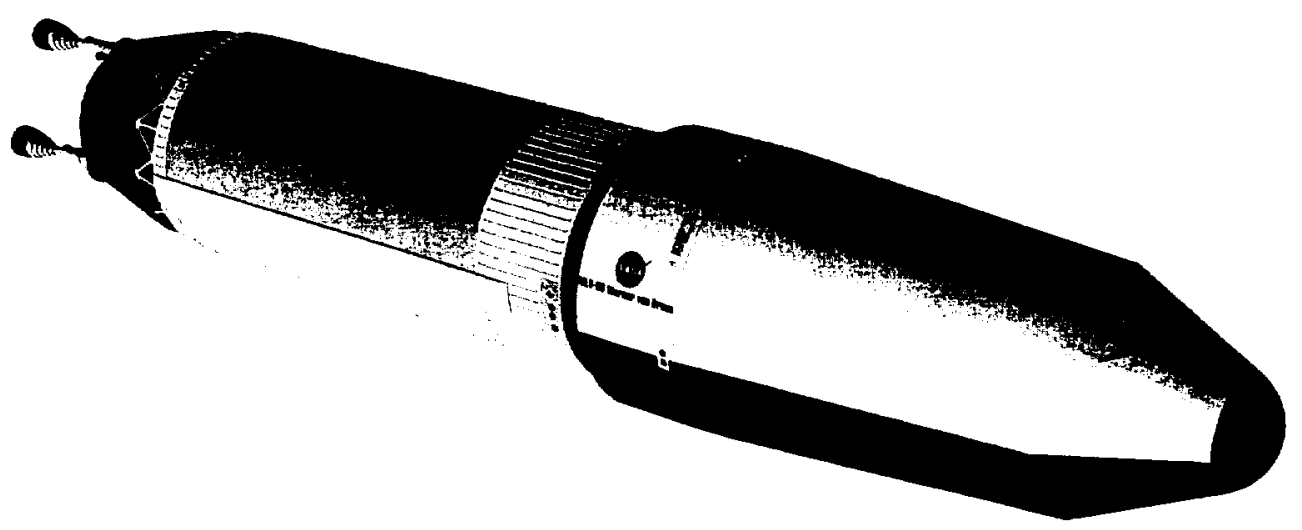

Fig. 19 3-D Image of BNTR Transfer Stage and Aerobraked Piloted Lander

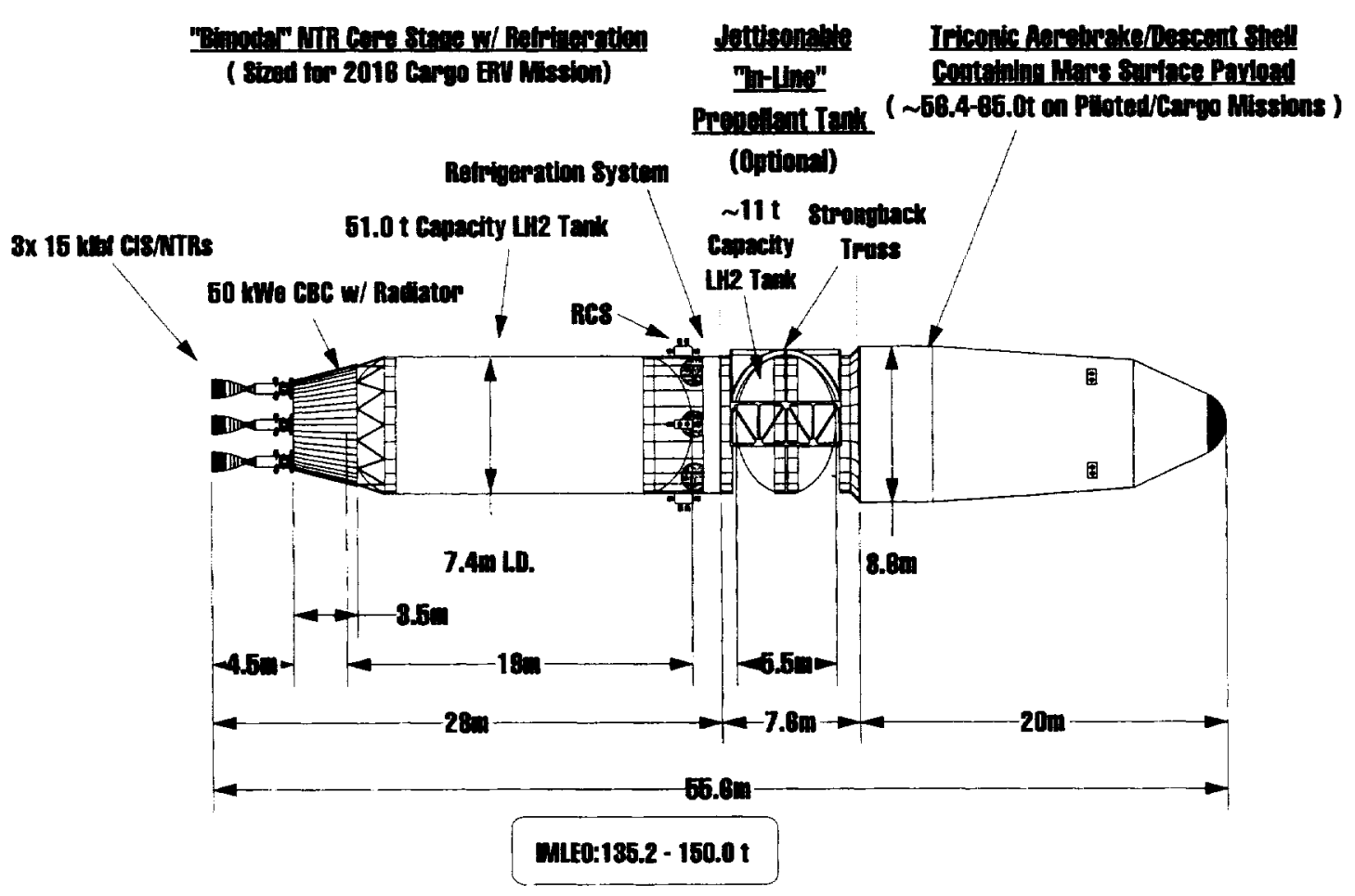

Fig. 20 Size, Mass and Key Features of BNTR Transfer Stage for Cargo and Piloted Lander Missions 
attributed to bimodal stage usage (see Figure 20) are small $(\sim 1 t)$ and associated with reduced propellant loading in the lander due to the absence of the MCC burn. However, the bimodal stage subsystems can support the cargo and piloted lander missions in a number of key ways not yet quantified. In addition to its $50 \mathrm{kWe}$ power capability, the bimodal stage's $\mathrm{LH}_{2}$ refrigeration system can be used to eliminate boiloff from the $\sim 4.5 \mathrm{t}$ of "seed" $\mathrm{LH}_{2}$ required for ascent propellant and water production, and its heat rejection system can help to dissipate "decay heat" from the -15 kWe dynamic isotope power system (DIPS) cart used to deploy the nuclear surface power system after landing. For the piloted lander mission, the elimination of the $30 \mathrm{kWe}$ PVA and MCC propellant helps to decrease descent stage propellant requirements and aerobrake TPS mass resulting in an $\sim 4.5 \mathrm{t}$ reduction in piloted lander mass. As with the cargo lander mission, the bimodal stage's $\mathrm{LH}_{2}$ refrigeration system could also be used to eliminate boiloff from the current $\mathrm{LOX} / \mathrm{CH}_{4}$ descent stage or a higher performance $\mathrm{LOX} / \mathrm{LH}_{2}$ stage.

Table 9 provides an IMLEO summary for the cargo lander, ERV and piloted lander missions using BNTR stages, and assuming a "single burn" Earth departure scenario. The ERV payload mass includes a spare ECRV and 554 days of contingency consumables (assuming $2.2 \mathrm{~kg} /$ day / person and a crew of six). Because of the ERV's lengthy mission duration and the need for multiple engine restarts to full power, the fuel temperature is held to $2900 \mathrm{~K}$ and the Isp to $940 \mathrm{~s}$ for conservatism. The $79 t$ core stage containing $\sim 50 t$ of $\mathrm{LH}_{2}$ is launched on the first Magnum booster. The second Magnum launch delivers the payload plus the $28.4 \mathrm{t}$ saddle truss and in-line tank containing $\sim 19.9 \mathrm{t}$ of $\mathrm{LH}_{2}$. The BNTR engines used on the cargo and piloted lander missions are operated at the higher performance levels ( $\sim 955 \mathrm{~s})$. Of the $\sim 55.2 \mathrm{t}$ of $\mathrm{LH}_{2}$ required for the cargo mission, a minimum of $\sim 4.2 \mathrm{t}$ would be located in the in-line tank. For the piloted lander mission, the entire propellant load $(-50.2 t)$ is contained within the core stage. The total IMLEO for this " 3 mission" bimodal scenario is $422.9 \mathrm{t}$.essentially identical to that of the DRM (Table 7) despite the more demanding requirements levied on the bimodal system.

A payload and stage mass comparison of the
DRM and "modified" DRM under similar operating conditions is shown in Table 10, and Figure 21 shows the relative size and mass of the bimodal NTR transfer vehicles used in the comparison. The IMLEO values assume a "2-perigee burn" Earth departure. Because the bimodal vehicles use "standardized" components, their reduced mass primarily reflects decreased propellant usage during the "2 burn" TMI maneuver. For the cargo lander mission, total propellant loading decreases from $-55.2 \mathrm{t}$ (for "single burn" departure and Isp 955 s) to $\sim 48.4 \mathrm{t}$ (for isp 940 s) eliminating the need for the small in-line tank (see Figure 21). In the case of the BNTR / ERV, the absence of the spare ECRV further decreases propellant loading to the point that the in-line tank is substantially offloaded--only $-42 \%$ of its maximum propellant capacity.

Because of its higher performance and abundant power, the BNTR / ERV mass in LEO is -26 tons lighter than the LOX / $\mathrm{CH}_{4}$ TEI stage which requires two large ( 8 meter $\times 45$ meter) PVAs to provide $\sim 30 \mathrm{kWe}$ in Mars orbit. Using the BNTR / ERV option also eliminates the development and recurring costs of the chemical TEl stage and its $30 \mathrm{kWe}$ PVA system, as well as the recurring cost of the aerobrake needed to place the heavy TEl stage into Mars orbit. On the cargo and piloted hab lander missions which utilize aerobraking, the common bimodal core stage provides both a $50 \mathrm{kWe}$ power source and the MCC propulsion which helps reduce the size and mass of these payload elements. Bimodal operation also simplifies mission operations by eliminating the need for multiple solar array deployment / retraction cycles and the complexities of array pointing and tracking of the Sun during transit and while in Earth and Mars orbit. Overall, the bimodal approach has a lower "3 mission" IMLEO ( $396 \mathrm{t}$ versus $422 \mathrm{t}$ for the DRM) while providing substantially more capability. It also provides one of the lowest cost and risk options for Mars exploration because it requires fewer major systems.

Lastly, the requirements on total engine bum time and fuel burnup are considered modest. For the most demanding BNTR / ERV mission (multiple burns and total mission duration $\sim 4.2$ years), the total engine burn time is $\sim 50.8$ minutes, assuming a "single burn" departure and a spare ECRV. The TMI burn is the longest at $\sim 36.9$ minutes, and includes the effect of a substantial gravity loss 
Table 9. Modified DRM "Three Mission" IMLEO Summary for Single Bum Earth Departure and Spare ECRV (IMLEO $\leq 160 \mathrm{t} / 2$ - $80 \mathrm{t}$ Magnum / Shuttle C HLLVs)

\begin{tabular}{|c|c|c|c|c|}
\hline $\begin{array}{l}\text { Payload/Nehicle } \\
\text { Propulsion/lsp }\end{array}$ & $\begin{array}{c}\text { Element } \\
\text { Masses (t) }\end{array}$ & $\begin{array}{c}2011 \\
\text { Cargo Lander } \\
\text { Mission }\end{array}$ & $\begin{array}{c}2011 \\
\text { ERV } \\
\text { Mission }\end{array}$ & $\begin{array}{c}2014 \\
\text { Piloted Lander } \\
\text { Mission }\end{array}$ \\
\hline \multirow{3}{*}{$\begin{array}{c}\text { Earth Retum } \\
\text { Vehicle } \\
\text { Payload }\end{array}$} & Crew Hab Module & & 18.15 & \\
\hline & Spare ECRV & & 4.83 & \\
\hline & Contingency Consumables & & 7.31 & \\
\hline \multirow{4}{*}{$\begin{array}{c}\text { Ascent Stage } \\
\text { LOX/CH } \\
\text { Isp }=379 \mathrm{~s} \\
(\mathrm{O} / \mathrm{F}=3.5: 1)\end{array}$} & Crew (6) \& Suits & & & 1.44 \\
\hline & MAV Crew Cab/ECRV & 4.83 & & \\
\hline & Ascent Stage & 4.06 & & \\
\hline & Propellant* & 38.40 & & \\
\hline \multirow{6}{*}{$\begin{array}{c}\text { Descent Stage } \\
\text { LOX } / \mathrm{CH}_{4} \\
\text { Isp }=379 \mathrm{~s} \\
(\mathrm{O} / \mathrm{F}=3.5: 1)\end{array}$} & Surface Payload & 31.34 & & 26.81 \\
\hline & Descent Stage & 4.20 & & 4.20 \\
\hline & Aerobrake/Descent Shell ${ }^{+}$ & 9.88 & & 13.24 \\
\hline & Parachutes & 0.70 & & 0.70 \\
\hline & Propellant** & 10.03 & & 9.99 \\
\hline & Total Payload Mass & 65.04 & 30.29 & 56.38 \\
\hline \multirow{6}{*}{$\begin{array}{l}\text { Common } \\
\text { NTR Vehicles } \\
\text { w/ Modular } \\
\text { Components }\end{array}$} & CIS Engines (\#) & $7.67(3)$ & $7.67(3)$ & $7.67(3)$ \\
\hline & $F(k \mid b f)$ per engine/lsp(s) & $14.76 / 955$ & $15 / 940$ & $14.76 / 955$ \\
\hline & Radiation Shields (\#) & & $3.24(3)$ & $3.24(3)$ \\
\hline & $\begin{array}{l}\text { "In-Line" TMI LH }{ }_{2} \\
\text { Tank \& Structure }\end{array}$ & 4.26 & 8.52 & \\
\hline & $\begin{array}{l}\text { TMI "Core" Stage } \\
\text { Tank \& Structure }\end{array}$ & 11.77 & & 11.77 \\
\hline & $\begin{array}{c}\text { TM!MOC/TEl "Core" Stage } \\
\text { Tank \& Structure }\end{array}$ & & 11.77 & \\
\hline \multirow{4}{*}{$I s p=940-955 \mathrm{~s}$} & $\begin{array}{c}\text { Brayton Power } \\
\text { System ( } 50 \mathrm{kWe})\end{array}$ & 1.55 & 1.55 & 1.55 \\
\hline & $\begin{array}{l}\text { LH2 Refrigeration } \\
\text { System ** }\end{array}$ & 0.34 & 0.34 & 0.34 \\
\hline & Avionics \& Aux. Power & 1.69 & 1.69 & 1.69 \\
\hline & Propellant*** & 55.24 & 69.84 & 50.19 \\
\hline \multirow{5}{*}{$\begin{array}{c}\text { RCS } \\
\text { NTO/MMH } \\
\text { Isp }=320 \mathrm{~s}\end{array}$} & Propuision \& Tankage & 0.54 & 0.56 & 0.54 \\
\hline & Propellant & 1.89 & 2.19 & 1.83 \\
\hline & & & & \\
\hline & Total NTR Vehicle Mass & 84.95 & 107.37 & 78.82 \\
\hline & Total IMLEO & 149.99 & 137.66 & 135.20 \\
\hline
\end{tabular}


Table 10. "Three Mission" IMLEO Comparison of DRM and "Modified" DRM Using BNTR

NTR/Aerobrake (DRM) and "Modified" DRM: 80 t Magnum

Mission Feature(s): Uses JSC "Supplied" payload masses adjusted for "bimodal" NTR operation fixed 4.2 $\mathrm{t}$ LOX/CH descent stage and $0.7 \mathrm{t}$ parachutes for descent

assist $\left(\Delta \mathrm{V}_{\omega \mathrm{ux}}=632 \mathrm{~m} / \mathrm{s}\right)$, and "2 Perigee Burm" Earth departure

\begin{tabular}{|c|c|c|c|c|c|c|c|c|c|}
\hline \multirow{2}{*}{$\begin{array}{l}\text { Magnum } \\
\text { Launch }\end{array}$} & \multirow{2}{*}{$\frac{\text { Flight Element }}{\text { Mission Type }}$} & \multicolumn{2}{|c|}{2011 Cargo Lander } & \multicolumn{2}{|c|}{2011 ERV * } & \multicolumn{2}{|c|}{2014 Piloted Lander } & \multicolumn{2}{|c|}{ Totals } \\
\hline & & DRM & $\begin{array}{l}\text { modified } \\
\text { DRM *** }\end{array}$ & DRM & $\begin{array}{l}\text { modified } \\
\text { DRM ** }\end{array}$ & DRM & $\begin{array}{l}\text { modified } \\
\text { DRM ** }\end{array}$ & DRM & $\begin{array}{l}\text { modified } \\
\text { DRM ** }\end{array}$ \\
\hline \multirow{3}{*}{ \#1 } & Payload & 66.0 & 65.0 & 74.1 & 25.5 & 60.8 & 56.4 & 200.9 & 146.9 \\
\hline & $\begin{array}{l}\text { - Surface/"In-Space" } \\
\text { - Transportation }\end{array}$ & $\begin{array}{l}-40.2 \\
-25.8\end{array}$ & $\begin{array}{l}-40.2 \\
-24.8\end{array}$ & $\begin{array}{l}-29.1 \\
-45.0\end{array}$ & -25.5 & $\begin{array}{l}-30.9 \\
-29.9\end{array}$ & $\begin{array}{r}-28.4 \\
-28.0\end{array}$ & $\begin{array}{l}-100.2 \\
-100.7\end{array}$ & $\begin{array}{l}-94.1 \\
-52.8\end{array}$ \\
\hline & $\begin{array}{l}\text { "In - Line" } \\
\text { Propellan/Tankage } \\
\left(\text { LH }_{2} \& / \text { or LOX) }\right.\end{array}$ & - & - & - & 20.8 & - & - & - & 20.8 \\
\hline \multirow[t]{3}{*}{$\# 2$} & $\begin{array}{l}\text { NTR TMI stage } \\
\text { ("Modified" DRM } \\
\text { uses "bimodal" NTRs) }\end{array}$ & 71.1 & 73.9 & 75.4 & 79.0 & 75.0 & 75.6 & 221.5 & 228.5 \\
\hline & Total & 137.1 & 138.9 & 149.5 & 125.3 & 135.8 & 132.0 & 422.4 & 396.2 \\
\hline & \# Magnurns & 2 & 2 & 2 & 2 & 2 & 2 & 6 & 6 \\
\hline
\end{tabular}

- 2011 ERV mission using "bimodal" NTRs for MOC and TEI is lighter than DRM by $-24 \mathrm{t}$ and eliminates DDT\&E and recurring costs for LOXCH, TEI stage, also recuring cost for $30 \mathrm{kWe}$ PVA and aerobrake.

* Common "Bimodal" NTR "core" stage provides $50 \mathrm{kWe}$ power capability to the ERV, Cargo and Piloted lander missions. Also supplies MCC burns for these missions. For cargo lander, the "Bimodal" stage refrigeration/heat rejection systems can be used to cryocool $4.5 \mathrm{t}$ of "seed" $\mathrm{LH}_{2}$ and dump "waste he at" from $15 \mathrm{kWe}$ DIPS power cart.

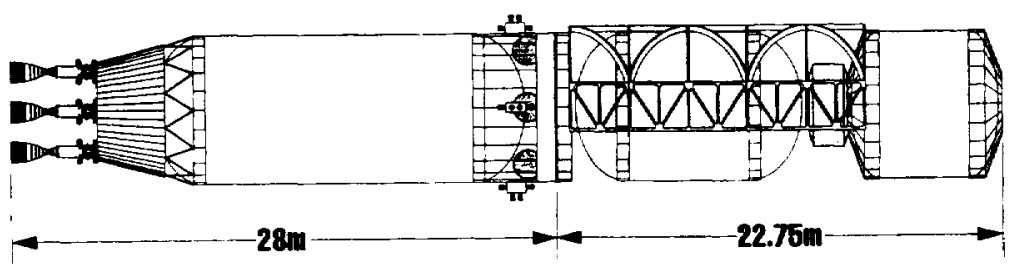

2011 B Burn" Bn

MLE0: $125.2 t$

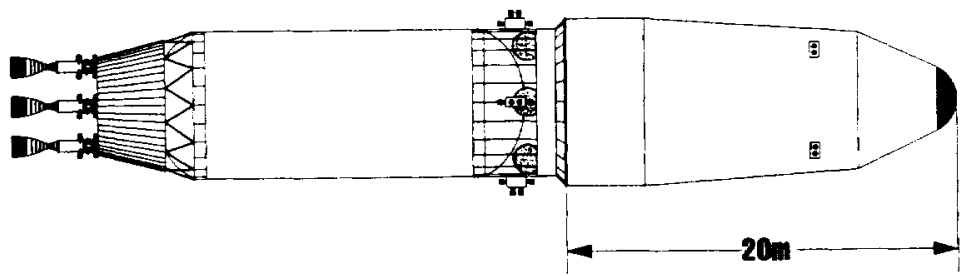

2011 Goys Ladar

CIER: 138.8

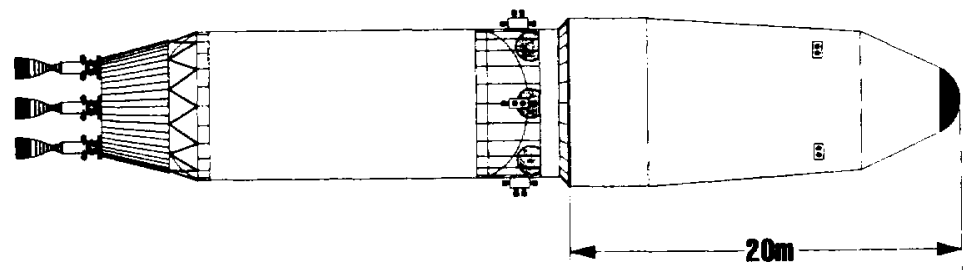

2014 pinted the lanter

MIE0: 182.0

Fig. 21 BNTR Transfer Vehicles Used in Comparison with the DRM 
(estimated at $-345 \mathrm{~m} / \mathrm{s}$ for $\mathrm{C} 3=8.97 \mathrm{~km}^{2} / \mathrm{s}^{2}$, Isp 940 s, and a vehicle thrust-to-weight ratio of 0.15). With regard to uranium-235 consumption, estimates indicate a fuel burnup of $-0.05 \%$ during the "propulsion mode" and $-0.73 \%$ during the "power mode" assuming a continuous $50 \mathrm{kWe}$ power output from the three bimodal engines over a 5 year period.

\section{IHE "ALL PROPULSIVE" BIMODAL NTR OPTION}

The next logical application of the BNTR stage beyond the modified DRM is propulsive capture of all payload elements into Mars orbit. This "all propulsive" NTR option makes the most efficient use of the bimodal engines which are now available to supply abundant power to spacecraft and payloads in Mars orbit for long periods. Even after payload separation and landing on the Mars surface, the core stages become valuable orbiting resources and can serve as high power communications relays and/or surface navigational aids. Propulsive capture into the reference " $250 \mathrm{~km}$ by 1 sol" ellpitical Mars parking orbit also makes it possible to design a standardized, reduced mass "aerodescent" shell for landing all payloads on the
Mars surface. From this reference parking orbit (similar to that used by the Viking lander missions in 1976), the payload entry velocity is $\sim 4.5 \mathrm{~km} / \mathrm{s}$ and the mass of the "triconic-shaped" aerodescent shell varies by only $\sim 0.53$ tover a payload mass range of 40 to $65 \mathrm{t}$ (see Table 2).

The size, mass and key vehicle features for the "all BNTR" Mars mission option is shown in Figure 22 and the associated cargo lander, ERV and piloted lander IMLEO values are summarized in Table 11. With propulsive capture, the total cargo lander mass decreases from $\sim 66 \mathrm{t}$ in the DRM to $\sim 62.3 t$, which is attributed to a lighter aerodescent shell $(-8.2 t)$ and a reduced descent stage propellant loading ( $-8.9 \mathrm{t}$ ). A detailed "3 mission" IMLEO summary for the "all BNTR" option is found in Appendix Table A-4. Despite this mass reduction, the substantial payload carried by the cargo lander increases the propellant requirements on the BNTR transfer vehicle to $\sim 68.3+$ with the core stage holding $51 \mathrm{t}$. The remaining $\sim 17.3 \mathrm{t}$ of $\mathrm{LH}_{2}$ is contained in the common $11.5 \mathrm{~m}$ in-line tank also used on the ERV and piloted lander missions. The total mass of the "in-line" tank, its propellant load and the cargo lander determine the maximum lift

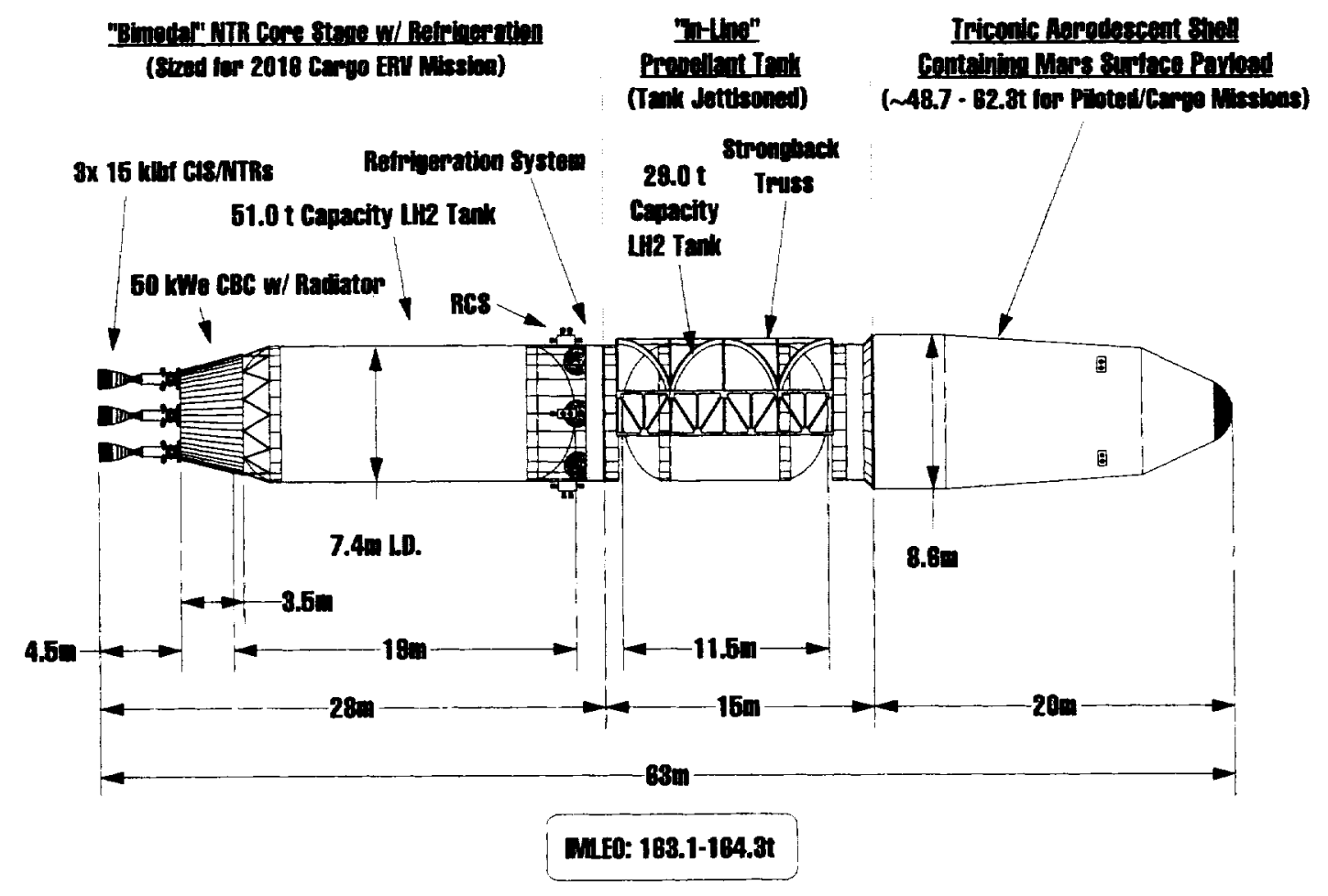

Fig. 22 Characteristics of "All BNTR" Transfer Vehicles for Piloted and Cargo Lander Missions 
Table 11. Payload / Stage Mass Manifest for "All BNTR" Option

\begin{tabular}{|c|c|c|c|c|c|}
\hline $\begin{array}{l}\text { Magnum } \\
\text { Launch }\end{array}$ & Flight Element & $\begin{array}{c}2011 \text { Cargo } \\
\text { Lander* }\end{array}$ & $\begin{array}{c}2011 \\
\text { ERV* }\end{array}$ & $\begin{array}{l}2014 \text { Piloted } \\
\text { Lander* }\end{array}$ & Totals \\
\hline \multirow{3}{*}{ \#1 } & Payload & 62.3 & 25.5 & 48.7 & 136.5 \\
\hline & $\begin{array}{l}\text { - Surface/"In-Space" } \\
\text { - Transportation }\end{array}$ & $\begin{array}{l}-40.2 \\
-22.1\end{array}$ & -25.5 & $\begin{array}{l}-28.0^{\circ} \\
-20.7\end{array}$ & $\begin{array}{l}-93.7 \\
-42.8\end{array}$ \\
\hline & $\begin{array}{l}\text { "In - Line" } \\
\text { Propellant/Tankage } \\
\left(\mathrm{LH}_{2} \& / \text { or LOX) }\right.\end{array}$ & 25.8 & 20.8 & 35.0 & 81.6 \\
\hline \multirow[t]{3}{*}{$\# 2$} & $\begin{array}{l}\text { "Bimodal" NTR } \\
\text { Core Stage }\end{array}$ & 76.2 & 79.0 & 79.4 & 234.6 \\
\hline & Total & 164.3 & 125.3 & 163.1 & 452.7 \\
\hline & \# Magnums & 2 & 2 & 2 & 6 \\
\hline
\end{tabular}

requirement for the Magnum booster which is $\sim 88 \mathrm{t}$ for this mission option. Because the maximum possible payload length for the Magnum booster is - $33 \mathrm{~m}$ (including the $28 \mathrm{~m}$ cylindrical section and payload shroud nose cone), a smaller in-line tank or shortened triconic aeroshell length (to $\sim 18 \mathrm{~m}$ ) is required to launch these components on a single 88 t Magnum.

The piloted lander mission employs a "220 day" outbound transit time $\left(\mathrm{C} 3=14.47 \mathrm{~km}^{2} / \mathrm{s}^{2}\right)$ to Mars to maintain $\mathrm{LH}_{2}$ propellant requirements within the maximum propellant capacity provided by the common vehicle design. A "2-perigee" burn Earth departure is also assumed for all three missions to reduce gravity losses. With propulsive capture, the total piloted lander mass is decreased by $\sim 20 \%$ (from $\sim 61 \mathrm{t}$ down to $\sim 49 \mathrm{t}$ ). The main reductions are in the aerodescent shell mass $(\sim 7.9 t$ versus $13.6 t$ for the DRM ) and the reduced descent stage propellant loading ( $7.9 \mathrm{t}$ compared to $11.4 \mathrm{t}$ in the DRM). The piloted mission has longest total engine burn time at $\sim 58$ minutes. This includes 45 minutes for the 2 perigee burns, $\sim 12$ minutes for MOC, and an -1 minute disposal burn to remove the bimodal core stage from Mars orbit after crew departure and send it into heliocentric space (see Table 5).

\section{"ALLBNTR" OPTION USING "TRANSHAB"}

The attractiveness of the "all propulsive" bimodal NTR option is further increased by the utilization of of the lightweight, inflatable "TransHab" module12. TransHab was designed to be launched in the Space Shuttle cargo bay fully outfitted. A central structural core $-3.4 \mathrm{~m}$ in diameter provides regenerative life support, thermal control, crew accommodations, avionics and communications, meteoroid and orbital debris protection, a storm shelter for crew radiation protection, and an airlock. Once on orbit, the outer shell surrounding the central core is inflated and corrugated flooring and partitions are deployed into place. Fully inflated, Transhab has an outer diameter of $-9.44 \mathrm{~m}$, a height of $\sim 9.65 \mathrm{~m}$, and provides $-500 \mathrm{~m}^{3}$ of habitable volume (see Figure 23).

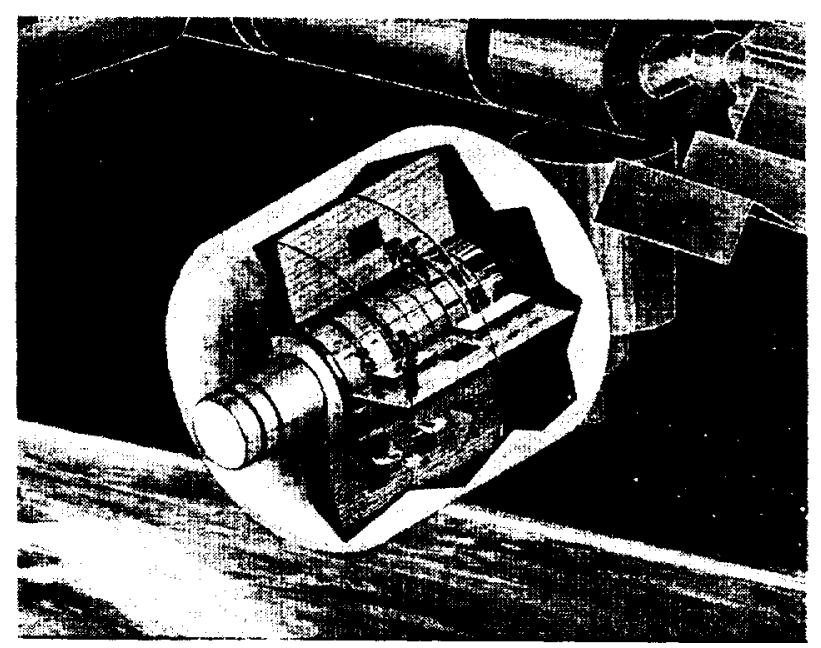

Fig. 23 Illustration Showing TransHab Module Attached to International Space Station 
In addition to volume augmentation, the substitution of TransHab for the heavier, hard-shell hab module used on the bimodal ERV in Figures 16 and 17 , provides an $-18 \%$ reduction in element mass and introduces the potential for propulsive recovery of the bimodal ERV in Earth orbit and its reuse on subsequent missions. The characteristics and 3-D image of the reusable bimodal ERV and TransHab crew module are shown in Figures 24 and 25, respectively. The reusable ERV departs

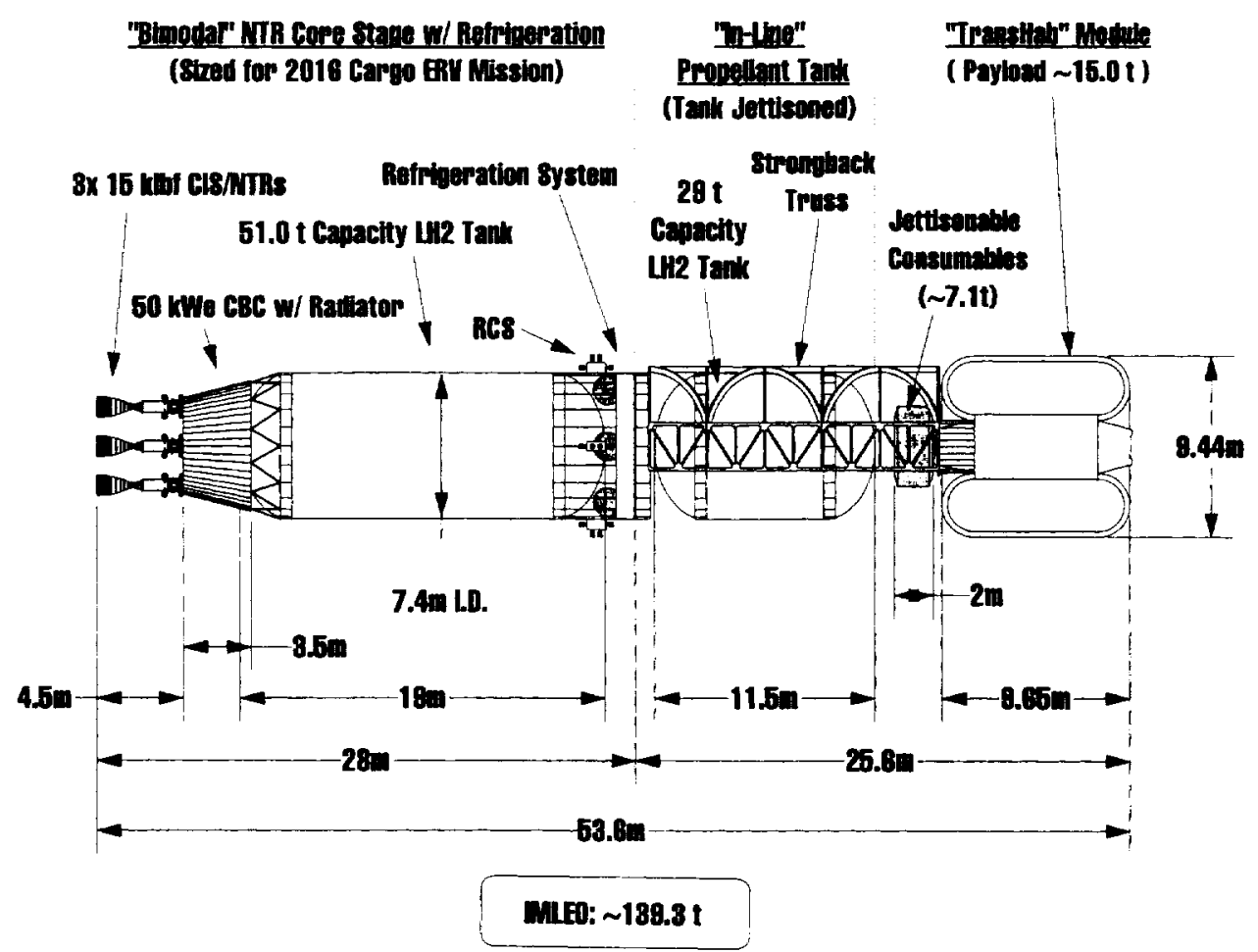

Fig. 24 Size, Mass and Key Features of Reusable Bimodal ERV Using TransHab

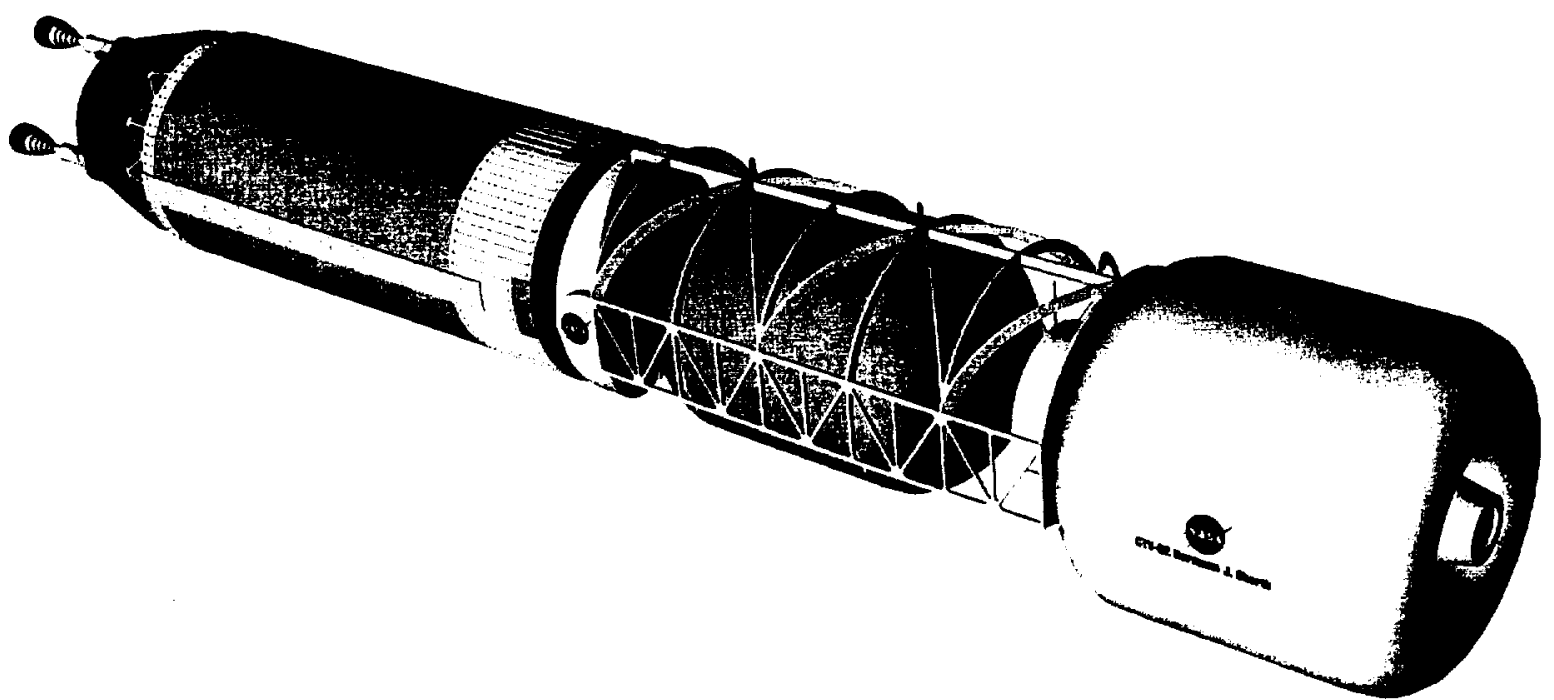

Fig. 25 3-D Image of Reusable Bimodal ERV with Inflatable TransHab Crew Module 
Mars on February 7, 2016 and returns to Earth 180 days later on August 5, 2016. The crew reenters directly using the ECRV, while the ERV propulsively captures into a $500 \mathrm{~km}$ by $\sim 71,136 \mathrm{~km}$ elliptical parking orbit with a period of -24 hours. Using a 2-perigee burn departure, the reusable ERV mission utilizes nearly the full propellant capacity of the bimodal core stage and its in-line tank. At a hydrogen exhaust temperature of $\sim 2900 \mathrm{~K}$ (Isp 940 s), the bimodal engines are estimated to have a "full power" operational lifetime of $\sim 4.5$ hours. With a total engine burn time of $\sim 58$ minutes for the four primary maneuvers, a multimission capability exists for the bimodal ERV. At Earth, a space-based upper stage could rendezvous with the ERV supplying it with a small in-line tank containing the propellant needed to return the ERV to LEO. Here, the core stage could be refueled, a new in-line propellant tank attached, and necessary consumable provided for the next mission. Reuse of the core stage, saddle truss and TransHab would reduce vehicle recurring costs but must be evaluated against the increased development and operational costs of the support infrastructure.
Although the diameter of the aerodescent shell does not allow the same degree of volume augmentation available on the ERV mission, the use of TransHab on the piloted lander reduces its mass and allows the inflatable surface hab module on the cargo lander to be offloaded to the piloted mission. This and a 210 day outbound transit time results in a total propellant requirement of $-79.2 \mathrm{t}$ with $28.2 \mathrm{t}$ located in the in-line tank. It is the combined "wet" in-line tank and piloted lander mass that sizes the Magnum lift capability at $\sim 85 \mathrm{t}$. By offloading the inflatable surface hab from the cargo lander, the propellant loading in the bimodal transfer vehicle is also reduced to $-65.5 \mathrm{t}$. The payload and stage mass manifest for the two cargo and piloted flights are summarized in Table 12. The IMLEO values for the two lander missions reflect a 2-perigee burn departure and engine operation at an Isp value of $955 \mathrm{~s}$.

\section{MARS/PHOBOS MISSION OPTION USING LANTB}

The benefits of a human expedition to Phobos have been discussed previously 2,25 and range

Table 12. Payload / Stage Mass Manifest for "All BNTR" Option Using TransHab

Mission Feature(s): "Bimodal" NTR Core Stage provides power, MCC and all primary propulsion. ERV propulsively returned to Earth orbit. JSC "TransHab" masses for

piloted lander and ERV. Fixed $4.2 \mathrm{t} \mathrm{LOX} / \mathrm{CH}_{4}$ descent stage and $0.7 \mathrm{t}$ parachutes

for descent assist $\left(\Delta V_{\text {decc }}=632 \mathrm{~m} / \mathrm{s}\right)$. Inflatable surface hab module $(-3.1 \mathrm{t})$ is "offloaded" from the cargo to the piloted lander mission.

\begin{tabular}{|c|c|c|c|c|c|}
\hline $\begin{array}{l}\text { Magnum } \\
\text { Launch }\end{array}$ & Flight Element & $\begin{array}{l}2011 \text { Cargo } \\
\text { Lander** }\end{array}$ & $\begin{array}{c}2011 \\
\text { ERV** }\end{array}$ & $\begin{array}{l}2014 \text { Piloted } \\
\text { Lander* }\end{array}$ & Totals \\
\hline \multirow{3}{*}{ \#1 } & Payload & 58.5 & 22.0 & 47.9 & 128.4 \\
\hline & $\begin{array}{l}\text { - Surface/"In-Space" } \\
\text { - Transporation }\end{array}$ & $\begin{array}{l}-37.1 \\
-21.4\end{array}$ & -22.0 & $\begin{array}{l}-27.3 \\
-20.6\end{array}$ & $\begin{array}{l}-86.4 \\
-42.0\end{array}$ \\
\hline & $\begin{array}{l}\text { "In - Line" } \\
\text { Propellant/Tankage } \\
\left(\mathbf{L H}_{\mathbf{2}} \text { \&/or LOX) }\right.\end{array}$ & 23.0 & 37.3 & 36.7 & 97.0 \\
\hline \multirow[t]{3}{*}{$\# 2$} & $\begin{array}{l}\text { "Bimodal" NTR } \\
\text { Core Stage }\end{array}$ & 76.1 & 80.0 & 79.3 & 235.4 \\
\hline & Total & 157.6 & 139.3 & 163.9 & 460.8 \\
\hline & \# Magnums & 2 & 2 & 2 & 6 \\
\hline
\end{tabular}

- Common "Bimodal" NTR "core" stage provides $50 \mathrm{kWe}$ power capability to the ERV, Cargo and Piloted lander missions. Also supplies MCC burns for these missions. For cargo lander, the "Bimodal" stage refrigeration/heat rejection systems can be used to cryocool $4.5 \mathrm{t}$ of "seed" $\mathrm{LH}_{2}$ and dump "waste heat" from $15 \mathrm{kWe}$ DIPS power power cart. 
from basic scientific knowledge to practical applications of the moon as an operating node and potential propellant depot for future human exploration and development activities on Mars. The Mariner 9 and Viking Orbiter missions in the 1970 s provided images and spectral data suggesting that both Phobos and Deimos were formed within the asteroid belt and later captured by Mars. Their low mean densities $\left(-2 \mathrm{~g} / \mathrm{cm}^{3}\right)$ and reflectivities 26 also suggest a chemical composition similar to carbonaceous chondrite meteorites, which contain substantial quantities of water and carbon-containing materials. Should this be true, Phobos could provide an abundant source of propellants for future reusable Mars transfer and landing vehicles. A Phobos mission would also provide expertise on operations both near and on a small, essentially gravity free planetary body of value to the exploration of other near Earth asteroids.

The introduction of LANTR and its integration into the bimodal stage opens the possibility for a "side trip" to Phobos within the current DRM. The reusable ERV mission just discussed showed the benefits of using TransHab. It also indicated, however, that the second Magnum booster was only utilizing $\sim 75 \%$ of its lift capability in launching TransHab, the in-line propellant tank and saddle truss (see Table 12). Stretching the in-line $\mathrm{LH}_{2}$ tank size and propellant capacity is also limited because of the volume constraints of the Magnum payload shroud. Using LANTR engines at modest $O / H$ mixture ratios increases bulk propellant density (by substituting high-density LOX for low-density $\mathrm{LH}_{2}$ ) and improves vehicle performance while staying within the available payload length limits. LANTR operation also helps to increase engine thrust, shorten burn times and extend engine life.

\section{Phobos Mission Description Using LANTR}

The Phobos mission scenario utilizes LANTR engines only for Earth departure. At an operating temperature of $2900 \mathrm{~K}$ and an $\mathrm{O} / \mathrm{H} \mathrm{MR}=0.0\left(\mathrm{LH}_{2}\right.$ only operation), the thrust from the LANTR engine is $15 \mathrm{klbf}$ (see Figure 8). At an O/H MR $=0.5$, the thrust per engine is increased by a factor of $\sim 1.33$ while the Isp decreases from $-940 \mathrm{~s}$ to $831 \mathrm{~s}$. During the $\sim 29$ minute long, 2-perigee burn TMI maneuver, the three LANTR engines produce a total thrust of $\sim 59.7 \mathrm{klbf}$ while using $\sim 39.5 \mathrm{t}$ of $\mathrm{LH}_{2}$ (including "cooldown" propellant) and $\sim 19.2 \mathrm{t}$ of
LOX. Following the TMI burn, the spent in-line $\mathrm{LH}_{2}$ tank and two spherical LOX tanks attached to it are jettisoned from the saddle truss to reduce vehicle weight. On all subsequent burns, the LANTR engines operate at MR $=0.0$ and lsp $=940 \mathrm{~s}$. The bimodal LANTR vehicle concept with TransHab crew module is illustrated in Figure 26 and its corresponding 3-D image is shown in both Figure 27 and on our cover page.

At Mars, the LANTR transfer vehicle propulsively captures into a $250 \mathrm{~km}$ by $33,793 \mathrm{~km}$ elliptical parking orbit where it remains during most of the crew surface stay. Approximately 32 days before TEI, the LANTR ERV jettisons its $\sim 6.3 \mathrm{t}$ of contingency consumables and then executes three propulsive maneuvers to rendezvous with Phobos. At apoapse, the LANTR engines burn to change plane to near equatorial. The required $\Delta V$ is $\sim 212 \mathrm{~m} / \mathrm{s}$ assuming an arrival declination of $\sim 27$ degrees. Next, the periapse is raised to Phobos altitude of $5981 \mathrm{~km}(\Delta \mathrm{V} \sim 228 \mathrm{~m} / \mathrm{s})$. A final circularization burn to lower apoapsis to $5981 \mathrm{~km}$ requires a $\Delta V$ of $\sim 664 \mathrm{~m} / \mathrm{s}$. Including an additional $-100 \mathrm{~m} / \mathrm{s}$ to rendezvous with Phobos, the total $\Delta V$ requirement is $\sim 1105 \mathrm{~m} / \mathrm{s}$.

Once in position, the crew lifts off from the Mars surface and rendezvous with the LANTR / ERV to begin a month long investigation of Phobos. Detailed spectroscopic analysis and other scientific measurements (including impact probes and deep penetrating radar imaging) would be carried out onboard the ERV to determine whether or not water is present. Prior to TEI, the ERV departs its near-equatorial orbit and returns to an inclined elliptical orbit matching the declination for the outgoing launch asymptote. The same $\sim 1105 \mathrm{~m} / \mathrm{s}$ is assumed for these return maneuvers. The total IMLEO for the LANTR / ERV mission to Phobos is $\sim 157.9 \mathrm{t}$ with each Magnum booster now delivering $\sim 79$ to LEO (see Table 13). The cargo lander mission is unchanged from Table 12 and the piloted lander mass decreases slightly due to the shortened surface stay time ( -475 days) and reduced crew consumables required for the Phobos mission.

By stretching the LANTR / ERV in-line $\mathrm{LH}_{2}$ tank size and capacity to $\sim 13.5 \mathrm{~m}$ and $35 \mathrm{t}$ to increase performance, a more robust Phobos exploration scenario is possible. Rather than relying on remote data acquisition alone, the "strecth" LANTR / ERV 


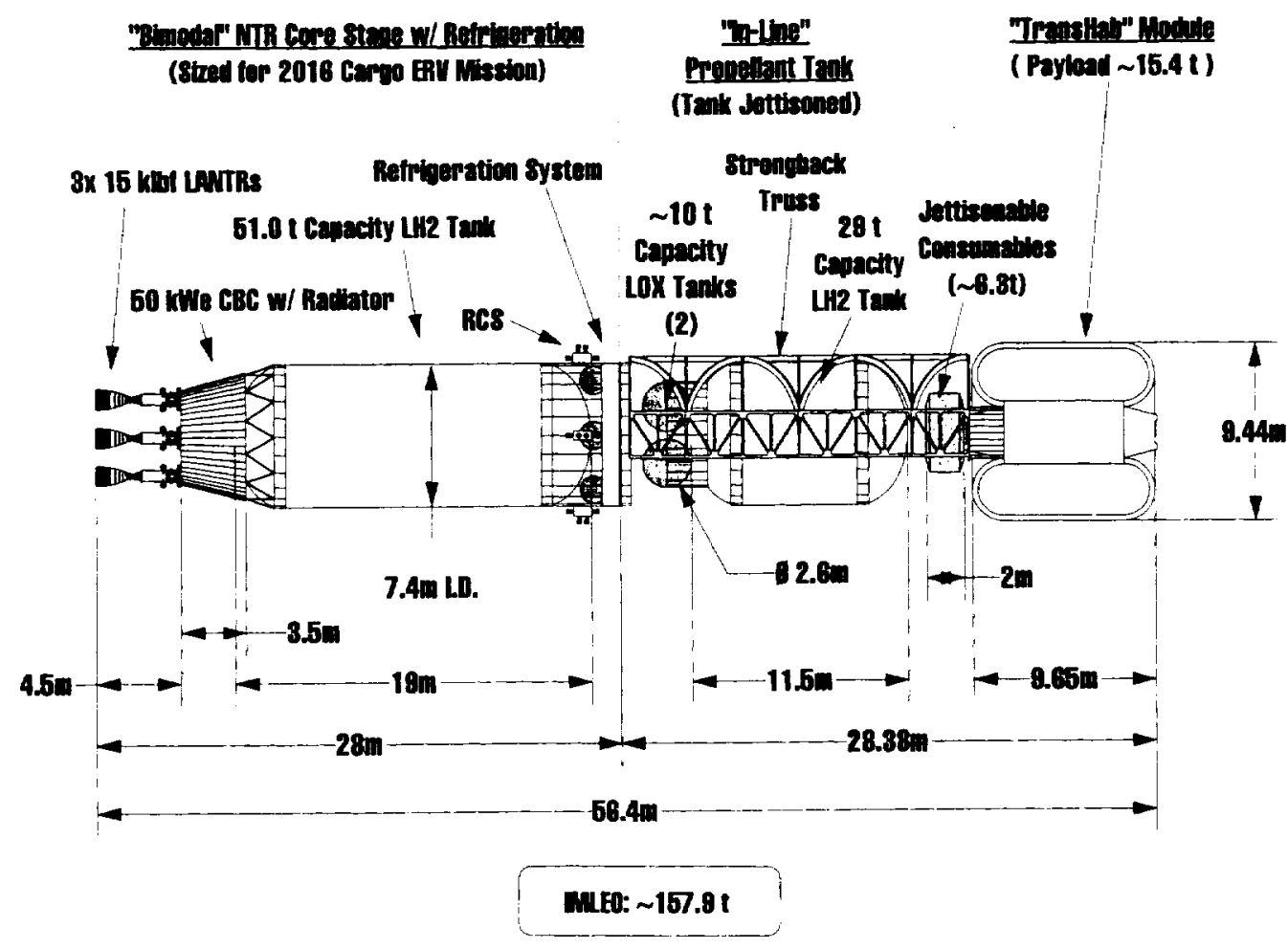

Fig. 26 Size, Mass and Key Features of Bimodal LANTR Transfer Vehicle for Mars / Phobos Mission Option

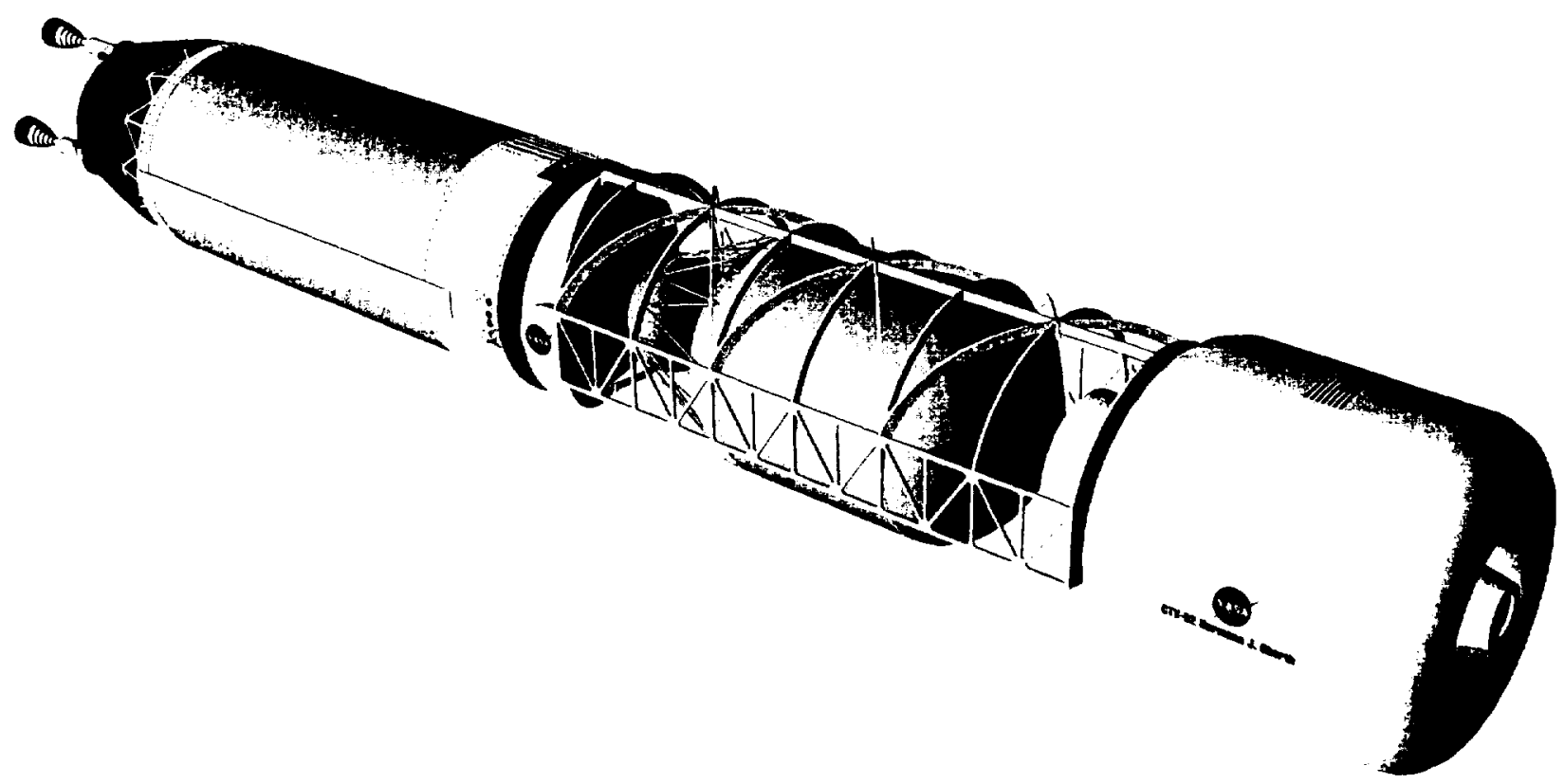

Fig. 27 3-D Image of Bimodal LANTR Transfer Vehicle for Mars / Phobos Mission Option 
Table 13. Payload / Stage Mass Manifest for "Bimodal LANTR" Mars /Phobos Option

Mission Feature(s): Bimodal "LANTR"-powered ERV visits Phobos before TEI. LANTR engines provide thrust augmentation (MR $=0.5$ ) for TMI with $M R=0$ for remaining primary propulsive maneuvers. "TransHab" masses used on ERV and piloted mission.

Fixed $4.2 \mathrm{t} \mathrm{LOX} / \mathrm{CH}_{4}$ descent stage and $0.7 \mathrm{t}$ parachutes for $\left(\Delta \mathrm{V}_{\mathrm{dex}}=632 \mathrm{~m} / \mathrm{s}\right)$.

\begin{tabular}{|c|c|c|c|c|c|}
\hline $\begin{array}{l}\text { Magnum } \\
\text { Launch }\end{array}$ & Flight Element & $\begin{array}{l}2011 \text { Cargo } \\
\text { Lander* }\end{array}$ & $\begin{array}{c}2011 \text { ERV* } \\
\text { (Visits Phobos) }\end{array}$ & $\begin{array}{l}2014 \text { Piloted } \\
\text { Lander* }\end{array}$ & Totals \\
\hline \multirow{3}{*}{$\# 1$} & Payload & 58.5 & 21.7 & 47.0 & 127.2 \\
\hline & $\begin{array}{l}\text { - Surface/"In-Space" } \\
\text { - Transportation }\end{array}$ & $\begin{array}{l}-37.1 \\
-21.4\end{array}$ & -21.7 & $\begin{array}{l}-26.6 \\
-20.4\end{array}$ & $\begin{array}{l}-85.4 \\
-41.8\end{array}$ \\
\hline & $\begin{array}{l}\text { "In - Line" } \\
\text { Propellant/Tankage } \\
\left(\mathbf{L H}_{2} \text { \& LOX) }\right.\end{array}$ & 23.0 & 57.0 & 35.8 & 115.8 \\
\hline \multirow[t]{3}{*}{$\# 2$} & $\begin{array}{l}\text { "Bimodal" NTR } \\
\text { Core Stage }\end{array}$ & 76.1 & 79.2 & 79.3 & 234.6 \\
\hline & Total : & 157.6 & 157.9 & 162.1 & 477.6 \\
\hline & \# Magnums & 2 & 2 & 2 & 6 \\
\hline
\end{tabular}

- Common "Bimodal" NTR "core" stage provides $50 \mathrm{kWe}$ power capability to the ERV, Cargo and Piloted lander missions. Also supplies MCC burns for these missions.

(shown in Figure 28) would carry a 2-person "multiple sortie" lander and $\sim 250 \mathrm{~kg}$ of scientific equipment to Phobos orbit. The $\sim 6.3 \mathrm{t}$ of contingency consumables are also transported to Phobos orbit to build up an easily accessible emergency food cache thereby allowing subsequent missions to transport an inflatable surface hab and other equipment needed to establish a permanent foothold on Phobos. The Phobos lander (shown to scale in Figure 28) is sized for ten round trip sorties to the surface of Phobos and back. On each mission, two astronauts deploy $-25 \mathrm{~kg}$ of scientific equipment and return to the ERV with $\sim 10 \mathrm{~kg}$ of samples. Because the escape velocity from Phobos is very low $(\sim 15 \mathrm{~m} / \mathrm{s})$, the total storable propellant requirements for the entire ten mission set is only $\sim 160 \mathrm{~kg}$. The $\sim 1.73 \mathrm{t}$ Phobos lander mass includes the "dry" lander (at $\sim 1.10 \mathrm{t}$ ) and its propellant load $(\sim 0.16 t)$, two EVA suits with life support $(\sim 0.22 t)$ and scientific equipment $(\sim 0.25 \mathrm{t})$. The payload / stage mass manifest for this robust Phobos option is provided in Table 14 and the associated " 3 mission" IMLEO summary in Table 15. To compensate for the increased propellant loadings in the in-line $\mathrm{LH}_{2}$ and $\mathrm{LOX}$ tank sets, the TransHab crew module and 32 days of extra consumables (totaling $\sim 15.4 t$ ) are delivered to the ERV using the Space Shuttle or "lower cost" RLV.
The remaining $\sim 155.6 \mathrm{t}$ are launched on two Magnums.

\section{AN "ALTERNATIVE MISSION PROFILE" USING BNTR AND TRANSHAB}

The BNTR transfer vehicle in combination with TransHab provides a high degree of mission versatility. In addition to providing a reuse capability for the ERV, a Phobos mission option is also possible through the addition of LOX "afterburner" nozzles and propellant feed system for LANTR operation. The BNTR and TransHab combination also allows one to consider an alternative mission profile in which the crew travels to and from Mars on the same bimodal transfer vehicle as depicted schematically in Figure 29. This approach cuts the duration of the ERV mission approximately in half-. from $\sim 4.7$ to 2.5 years--while the remaining two mission elements (the cargo and "unpiloted" crew lander) are left unattended by humans for no more than $\sim 2.8$ years.

The roundtrip piloted transfer vehicle departs Earth on January 21, $2014\left(\mathrm{C} 3=15.35 \mathrm{~km}^{2} / \mathrm{s}^{2}\right)$ and propulsively captures into Mars orbit 210 days later on August 19, 2014. The outbound transit time is extended by 30 days to maintain propellant requirements within the capacity of the bimodal 


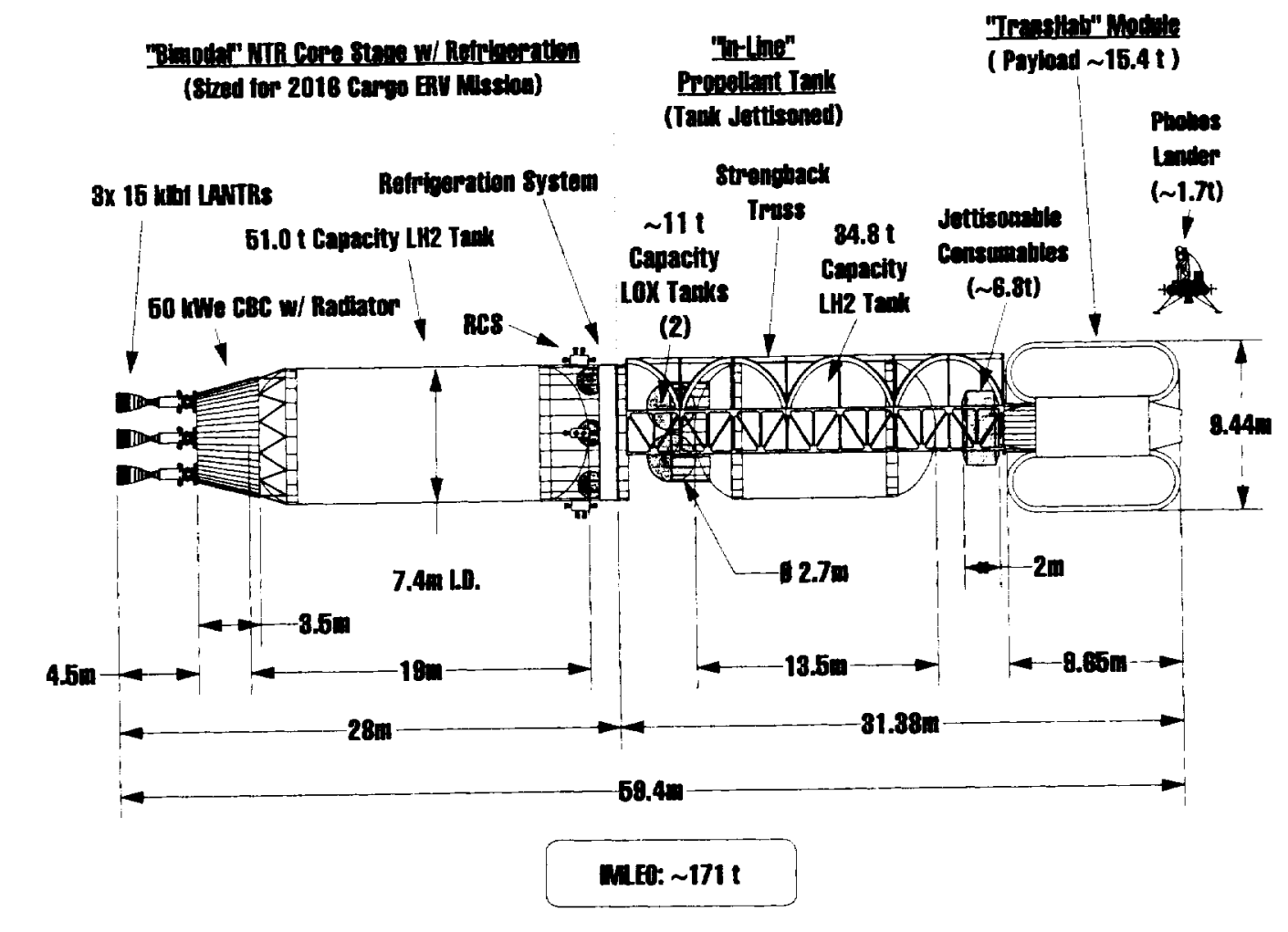

Fig. 28 Size, Mass and Key Features of "Stretch" LANTR / ERV for Phobos Lander Option

Table 14. Mass Manifest for "Stretch" LANTR / Phobos Lander Mission

Mission Feature(s): Bimodal "LANTR"-powered ERV visits Phobos before TEI. LANTR engines provide thrust augmentation (MR $=0.5$ ) for $T M I$ with $M R=0$ for remaining primary propulsive maneuvers. "TransHab" masses used on ERV and piloted mission.

Fixed $4.2 \mathrm{t}$ LOX/CH, descent stage and $0.7 \mathrm{t}$ parachutes for $\left(\Delta \mathrm{V}_{\mathrm{dex}}=632 \mathrm{~m} / \mathrm{s}\right)$.

ERV also carries " 2 person" multiple sortie Phobos lander and scientific equipment.

\begin{tabular}{|c|c|c|c|c|c|}
\hline $\begin{array}{l}\text { Magnum } \\
\text { Launch }\end{array}$ & Flight Element & $\begin{array}{l}2011 \text { Cargo } \\
\text { Lander* }\end{array}$ & $\begin{array}{c}2011 \text { ERV* } \\
\text { (Visits Phobos) } \\
\end{array}$ & $\begin{array}{c}2014 \text { Piloted } \\
\text { Lander* }\end{array}$ & Totals \\
\hline \multirow{3}{*}{ \#1 } & Payload & 58.5 & 23.4 & 47.0 & 128.9 \\
\hline & $\begin{array}{l}\text { - Surface/"ln-Space" } \\
\text { - Transportation }\end{array}$ & $\begin{array}{l}-37.1 \\
-21.4\end{array}$ & -23.4 & $\begin{array}{l}-26.6 \\
-20.4\end{array}$ & $\begin{array}{l}-87.1 \\
-41.8\end{array}$ \\
\hline & $\begin{array}{l}\text { "In - Line" } \\
\text { Propellant/Tankage } \\
\left(\mathbf{L H}_{\mathbf{2}} \text { \& LOX) }\right.\end{array}$ & 23.0 & 68.4 & 35.8 & 127.2 \\
\hline \multirow[t]{3}{*}{$\# 2$} & $\begin{array}{l}\text { "Bimodal" NTR } \\
\text { Core Stage }\end{array}$ & 76.1 & 79.2 & 79.3 & 234.6 \\
\hline & Total & 157.6 & $171.0^{+}$ & 162.1 & 490.7 \\
\hline & \# Magnums & 2 & $2^{+}$ & 2 & 6 \\
\hline
\end{tabular}

- Common "Bimodal" NTR "core" stage provides $50 \mathrm{kWe}$ power capability to the ERV, Cargo and Piloted lander missions. Also supplies MCC burns for these missions. For cargo lander, the "Bimodal" stage refrigeration/heat rejection systems can be used to cryocool $4.5 \mathrm{t}$ of "seed" $\mathrm{LH}_{1}$ and dump "waste heat" from $15 \mathrm{kWe}$ DIPS power power cart.

+ On 2011 ERV mission, "TransHab" module and extra consumables $(-15.4 t)$ would be launched on Shuttle or lower cost RLV with remaining mass $(-155.6 \mathrm{t})$ launched on two Magnums. 
Table 15. IMLEO Summary for Phobos Lander Option Using LANTR ("Single Bum" Earth Departure Scenario)

(IMLEO $\leq 166 \mathrm{t} / \mathrm{2}$ - $83 \mathrm{t}$ Magnum / Shuttle C HLLVs)

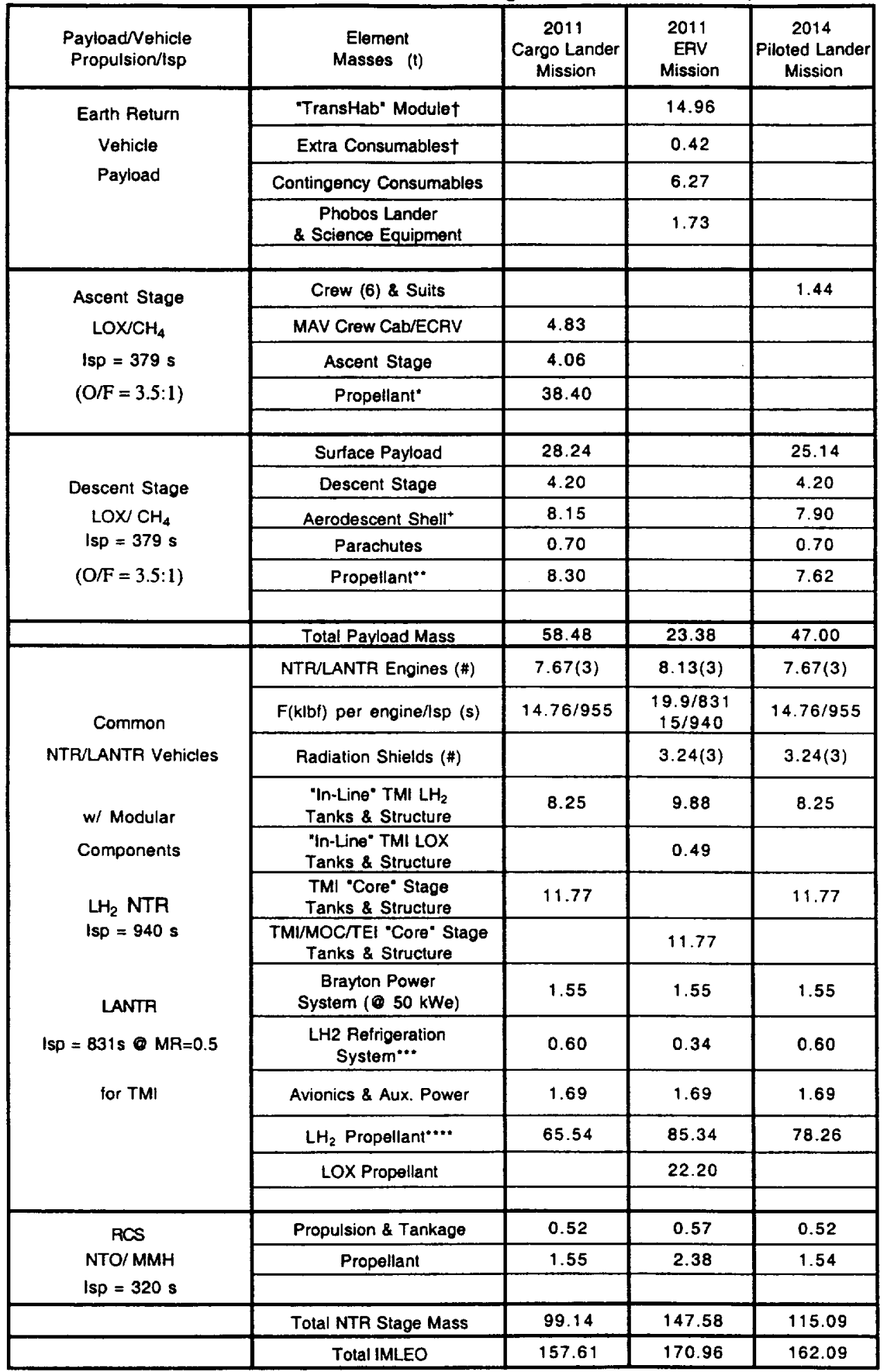

t Delivered on Shuttle or lower cost RLV

- Produced at Mars using "in-situ" resources

- Assumes parachutes and $632 \mathrm{~m} / \mathrm{s}$ descent $\Delta V$

* Cooling capacity of "core"/"in-line" tank -75/46 Wt, respectively

-.. Contains boiloff, cooldown, "tank trapped" residual and disposal LH2 also

+ Using ARC Triconic aerobrake mass estimation formula with $\mathrm{Ve}=4.5 \mathrm{~km} / \mathrm{s}$ 


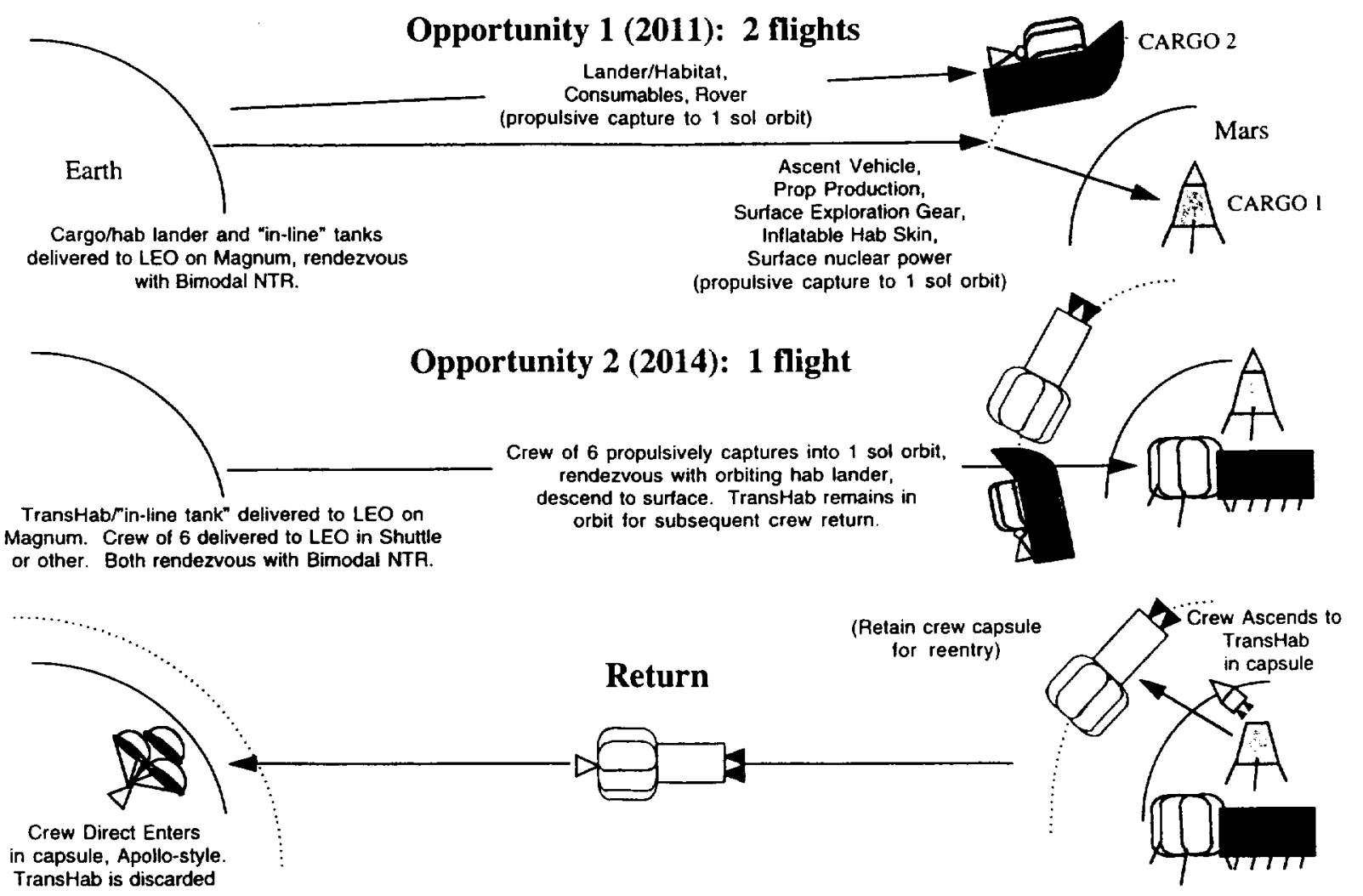

Fig. 29 "Alternative Mission Profile": Round Trip Piloted Transfer Vehicle Using BNTR and TransHab

core stage $(\sim 51 \mathrm{t})$ and its $11.5 \mathrm{~m}$ "in-line" tank $(\sim 29 \mathrm{t})$. Table 16 shows the outbound piloted transit times possible over a 15 year period using the common bimodal transfer vehicle. Return transit times are held constant at 180 days.

Once in Mars orbit, the crew transfer vehicle (CTV) rendezvouses with the "unpiloted" hab lander (which is now delivered on an earlier cargo mission) and then descends to the surface. The absence of crew on the hab lander mission eliminates the need for 210 days of outbound consumables $(-2.77 t)$ and the engine crew radiation shields $(\sim 3.24 t)$. This allows the hab lander to carry the inflatable surface module $(\sim 3.1 \mathrm{t})$ and science equipment $(\sim 4.4 \mathrm{t})$ previously carried on the crowded cargo lander. Size, mass and key features of the bimodal vehicles used on the piloted and cargo / hab lander missions are shown in Figures 30 and 31 , respectively.

The piloted transfer vehicle uses the same common core stage, in-line propellant tank and saddle truss utilized on the bimodal ERVs discussed previously. The TransHab payload mass $(\sim 16.8 t)$ includes the mass of the six crew and their suits, and 30 days of extra consumables to account for the longer outbound transit time. Contingency consumables $(\sim 6.7 t)$ consistent with a 507 day surface stay are also carried. The total propellant required for the mission is $\sim 79 \mathrm{t}$, and the total vehicle length and IMLEO are $\sim 54 \mathrm{~m}$ and $\sim 140 \mathrm{t}$, respectively. A smaller $(-6.5 \mathrm{~m})$, in-line propellant tank is used on the common bimodal transfer vehicles that deliver the $\sim 46 \mathrm{t}$ hab and $\sim 54 \mathrm{t}$ cargo landers into Mars orbit. The total propellant needs for these transfer vehicles are $-57.3 \mathrm{t}$ and $\sim 64.3 \mathrm{t}$, respectively. A 3-D image of the bimodal cargo transfer vehicle showing its relative size is shown in Figure 32, and Table 17 summarizes the payload/ stage mass manifest for the " 3 mission" set. A detailed IMLEO summary is found in Appendix Table A-5.

\section{SUMMARY COMMENTS AND DISCUSSION}

The bimodal NTR propulsion and power system provides an extremely versatile space transportation option to the planners and designers of future human exploration missions to Mars. 


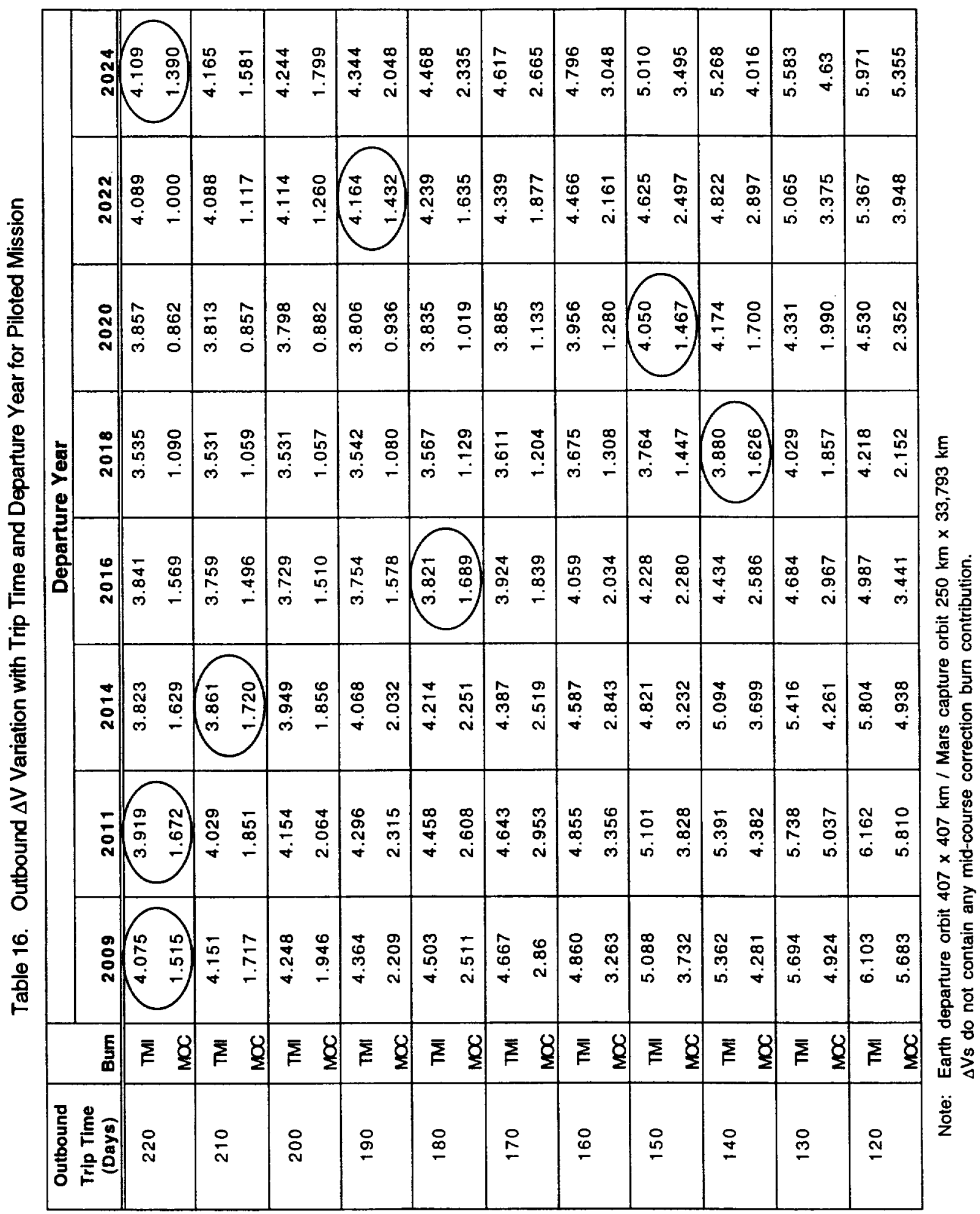




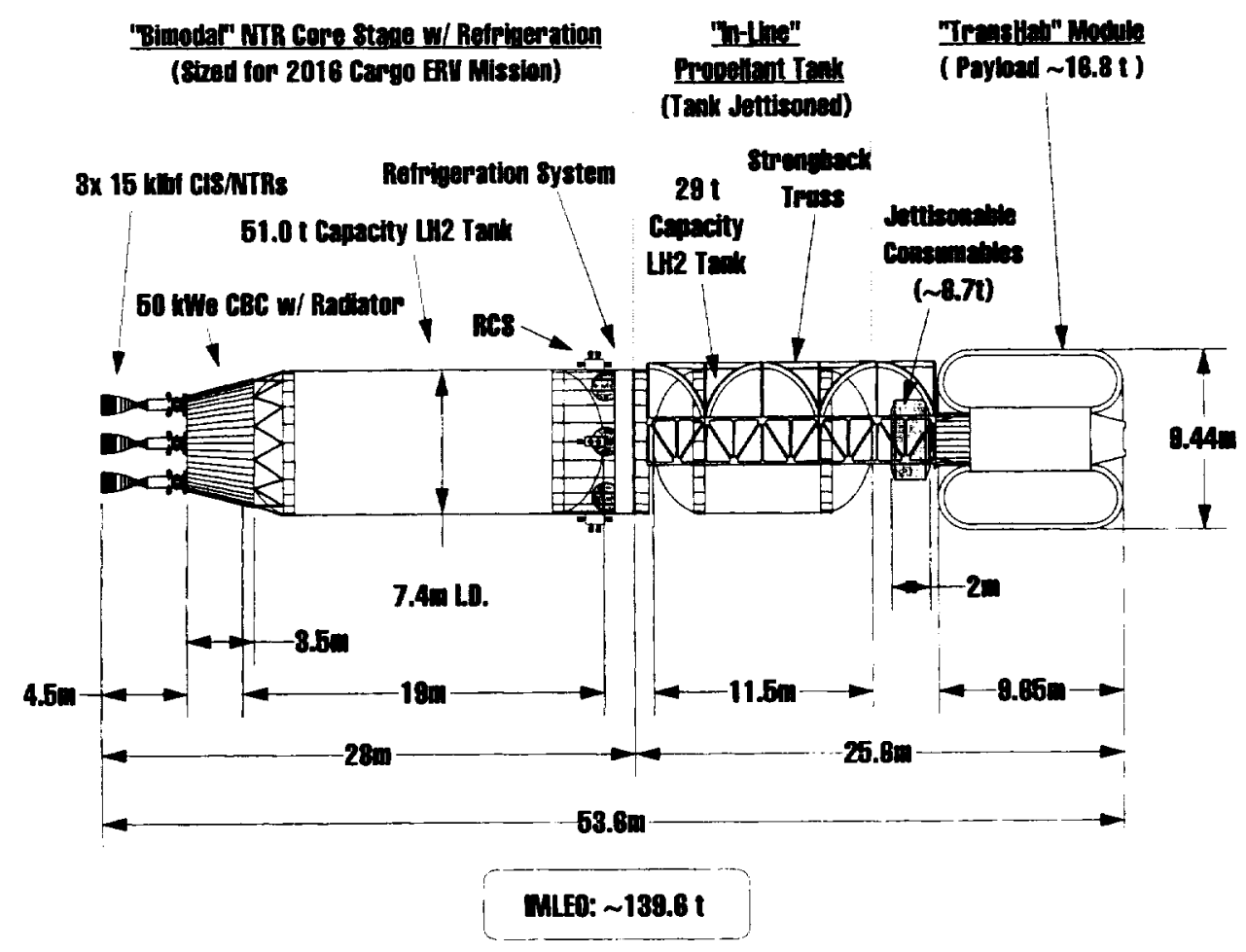

Fig. 30 Size, Mass and Key Features of Round Trip Piloted Transfer Vehicle

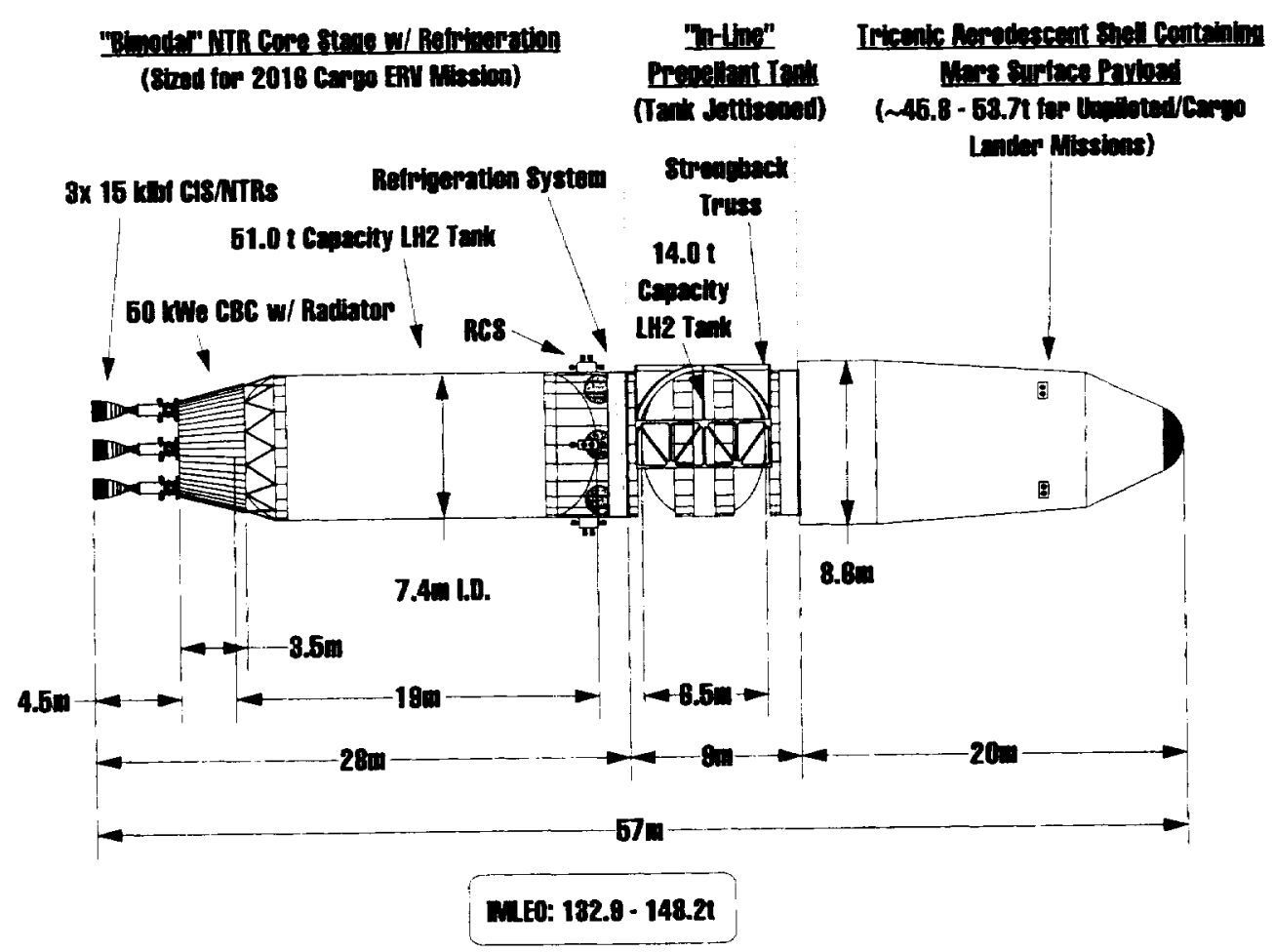

Fig. 31 Size, Mass and Key Features of BNTR Vehicles for Cargo and "Unpiloted" Hab Lander Missions 


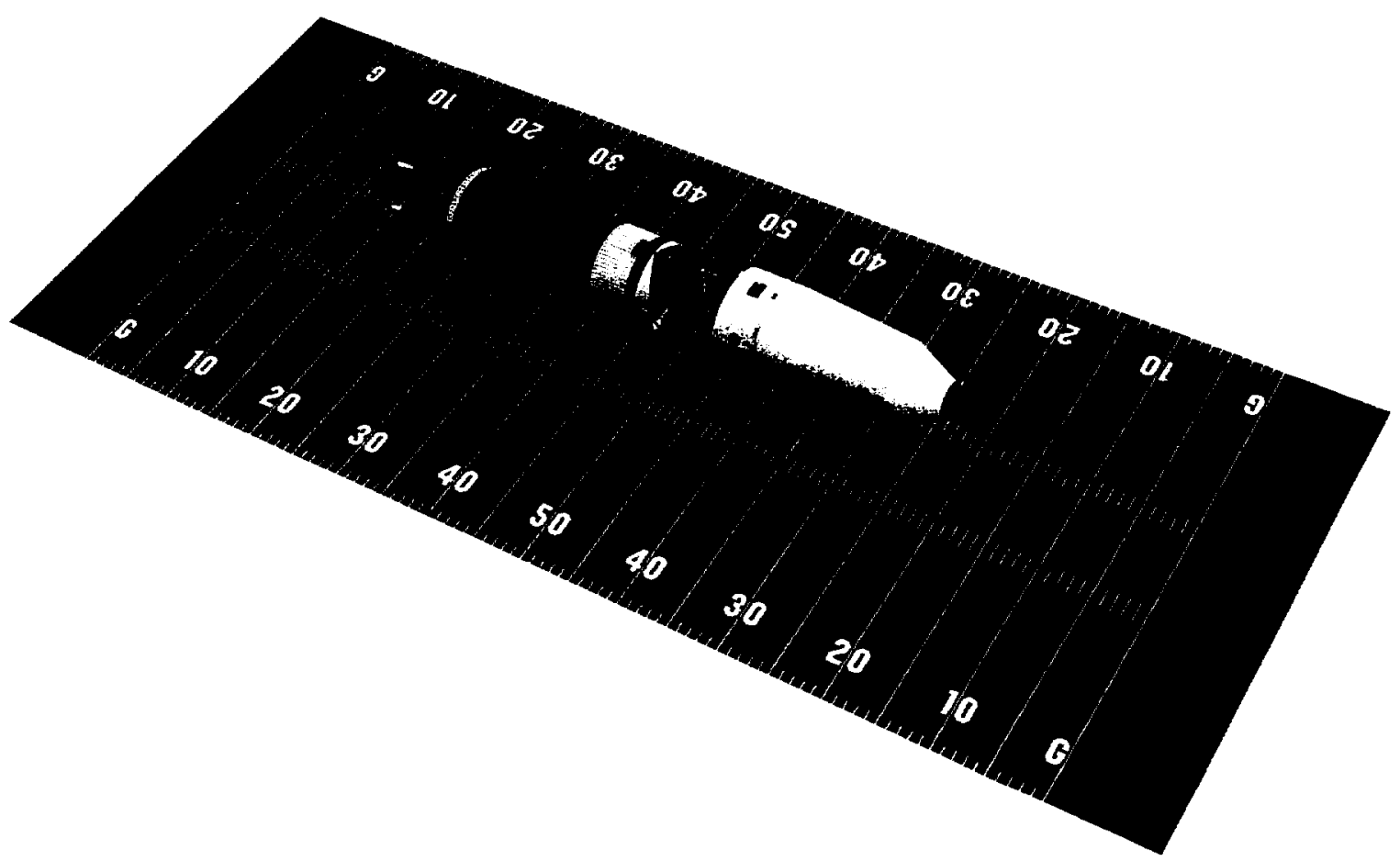

Fig. 32 3-D Image Showing Relative Size of Bimodal Cargo Transfer Vehicle

Table 17. Payload / Stage Mass Manifest for Alternative Mission Option

Mission Feanure(s): Crew travels to and from Mars using "bimodal" NTR transfer stage and "TransHab" module. Results based on JSC "supplied" payload masses adjusted for "bimodal" NTR operation, fixed $4.1 \mathrm{t} \mathrm{LOX} / \mathrm{CH}_{4}$ descent stage and $0.7 \mathrm{t}$ parachutes for descent assist $\left(\Delta \mathrm{V}_{\text {cece }}=632 \mathrm{~m} / \mathrm{s}\right)$. A "Single Burn" Earth departure is used along with outbound/inbound transit time of $210 / 180$ days, respectively.

\begin{tabular}{|c|c|c|c|c|c|}
\hline $\begin{array}{l}\text { Magnum } \\
\text { Launch }\end{array}$ & Flight Element & $\begin{array}{c}2011 \text { Cargo } \\
\text { Lander** }\end{array}$ & $\begin{array}{c}2011 \\
\text { "Unpiloted" Hab } \\
\text { Lander** }\end{array}$ & $\begin{array}{c}2014 \text { Piloted } \\
\text { Mission* }\end{array}$ & Totals \\
\hline \multirow{3}{*}{$\# 1$} & Payload & 53.7 & 45.8 & 23.5 & 123.0 \\
\hline & $\begin{array}{l}\text { - Surface/"In-Space" } \\
\text { - Transportation }\end{array}$ & $\begin{array}{l}-33.3 \\
-20.4\end{array}$ & $\begin{array}{l}-25.4 \\
-20.4\end{array}$ & -23.5 & $\begin{array}{l}-82.2 \\
-40.8\end{array}$ \\
\hline & $\begin{array}{l}\text { "In - Line" Propellant } \\
\text { Tankage/Structure } \\
\left(\mathbf{L H}_{2} \text { \&/or LOX) }\right. \\
\end{array}$ & 18.4 & 11.2 & 37.1 & 66.7 \\
\hline \multirow[t]{3}{*}{$\# 2$} & $\begin{array}{l}\text { "Bimodal" NTR } \\
\text { Core Stage }\end{array}$ & 76.0 & 75.8 & 79.0 & 230.8 \\
\hline & Total : & 148.1 & 132.8 & 139.6 & 420.5 \\
\hline & \# Magnums & 2 & 2 & 2 & 6 \\
\hline
\end{tabular}

- 2014 Piloted "round trip" transfer vehicle uses "bimodal" NTRs for MOC and TEI also, and eliminates the DDT\&E and recurring costs for the LOX/CH. TEI stage, as well as recurring cost for the $30 \mathrm{kWe}$ PVA and aerobrake.

* Common "bimodal" NTR transfer stage also provides $50 \mathrm{kWe}$ power capability to the cargo and "unpiloted" Hab lander missions. Also supplies MCC burns for these missions. 
Bimodal operation fully exploits the true performance potential of the NTR by tapping into the "rich source of energy" that exists within the engine's reactor core. Rather than throwing away a valuable transportation system asset after a single use, "better systems engineering" has led to the design of an integrated NTR "core" stage providing both propulsion and power generation. The core stage uses three small ( $\sim 15 \mathrm{klbf})$ bimodal NTR engines providing up to $50 \mathrm{kWe}$ of electrical power, a portion of which $(-15 \mathrm{kWe})$ is used to support an active refrigeration system for "zero boiloff," long term storage of $\mathrm{LH}_{2}$ propellant. The bimodal stage uses a Brayton power conversion system enclosed within the vehicle's conical thrust structure which also provides support for a common heat rejection radiator system. The incorporation of power generation and refrigeration systems results in a smaller, higher performance NTR stage with multiple burn, propulsive capture and reuse features. The use of multiple small engines also provides an "engine out" capability for the vehicle and should aid in the design of "contained" ground facilities for rigorous engine testing that are both cost-effective and meet current environmental regulations.

A simpler, lower cost transportation system requiring fewer major elements and providing greater mission capability are a few of the major benefits of the bimodal NTR option. Table 18 compares and summarizes the number of mission elements and the ETO requirements for the DRM, "modified" DRM and "all BNTR" options examined in this paper. The DRM uses NTR propulsion for TMI, a large 30 kWe PVA for in space power, a heavy, common aerobrake/descent shell for MOC and reentry, a "SP-100" type nuclear reactor for surface power, $\mathrm{LOX} / \mathrm{CH}_{4}$ engines for TEl and an ECRV for Earth return--a total of 6 mission elements. The introduction of the BNTR in the "modified" DRM cuts this number in half (lowering DDT\&E and recurring costs) while increasing the available power to payloads in transit and in Mars orbit to $50 \mathrm{kWe}$. The use of standardized modular components in the bimodal

Table 18. Comparison of DRM, "Modified" DRM and "All BNTR" Mars Mission Options

\begin{tabular}{|c|c|c|c|c|c|c|}
\hline $\begin{array}{l}\text { Mission Elements/ } \\
\text { and ETO Requirements }\end{array}$ & DRM & $\begin{array}{c}\text { "Modified" } \\
\text { DRM } \\
\text { (BNTR) }\end{array}$ & $\begin{array}{l}\text { "All NTR" } \\
\text { (BNTR) }\end{array}$ & $\begin{array}{l}\text { "All NTR" } \\
\text { (BNTR) with } \\
\text { "TransHab" }\end{array}$ & $\begin{array}{c}\text { "All NTR" } \\
\text { (BNTR) with } \\
\text { "TransHab" and } \\
\text { LANTR }\end{array}$ & $\begin{array}{c}\text { ALT. ARCH. } \\
\text { "All BNTR" } \\
\text { with } \\
\text { "TransHab" }\end{array}$ \\
\hline TMI & NTR & BNTR * & BNTR & BNTR & BLANTR ** & BNTR \\
\hline In-Space Power & $\begin{array}{c}\text { PVA } \\
(30 \mathrm{kWe})\end{array}$ & $\begin{array}{c}\text { BNTR } \\
(50 \mathrm{kWe})\end{array}$ & $\begin{array}{c}\text { BNTR } \\
(50 \mathrm{kWe})\end{array}$ & $\begin{array}{c}\text { BNTR } \\
(50 \mathrm{kWe})\end{array}$ & $\begin{array}{l}\text { BLANTR } \\
(50 \mathrm{kWe})\end{array}$ & $\begin{array}{c}\text { BNTR } \\
(50 \mathrm{kWe})\end{array}$ \\
\hline MOCS & $\mathbf{A B}^{*}$ & AB \& BNTR & BNTR & BNTR & BLANTR & BNTR \\
\hline Mars Orbit Power & $\begin{array}{c}\text { PVA } \\
(30 \mathrm{kWe})\end{array}$ & $\begin{array}{c}\text { BNTR } \\
(50 \mathrm{kWe})\end{array}$ & $\begin{array}{c}\text { BNTR } \\
(3 \times 50 \mathrm{kWe})\end{array}$ & $\begin{array}{c}\text { BNTR } \\
(3 \times 50 \mathrm{kWe})\end{array}$ & $\begin{array}{c}\text { BLANTR } \\
(3 \times 50 \mathrm{kWe})\end{array}$ & $\begin{array}{c}\text { BNTR } \\
(3 \times 50 \mathrm{kWe})\end{array}$ \\
\hline $\begin{array}{l}\text { Mars Reentry } \\
\text { System }\end{array}$ & $\begin{array}{l}\text { Common } \\
\mathrm{AB} / \mathrm{AS}\end{array}$ & $\begin{array}{l}\text { Common } \\
\text { AB/AS }\end{array}$ & AS & AS & AS & AS \\
\hline Surface Power & $\begin{array}{l}\text { Nuc. Rx. } \\
\text { (Brayton) }\end{array}$ & $\begin{array}{l}\text { Common Rx. } \\
\text { (Brayton) }\end{array}$ & $\begin{array}{l}\text { Common Rx. } \\
\text { (Brayton) }\end{array}$ & $\begin{array}{l}\text { Common Rx. } \\
\text { (Brayton) }\end{array}$ & $\begin{array}{l}\text { Common Rx. } \\
\text { (Brayton) }\end{array}$ & $\begin{array}{l}\text { Common Rx. } \\
\text { (Brayton) }\end{array}$ \\
\hline TEI & $\mathrm{LOX}_{\mathrm{CH}} \mathrm{CH}_{4}$ & BNTR & BNTR & BNTR & BLANTR & BNTR \\
\hline EOC & ECRV † & ECRV & ECRV & $\begin{array}{l}\text { ECRV \& } \\
\text { BNTR }\end{array}$ & ECRV & ECRV \\
\hline Total \# Major Systems & 6 & 3 & 3 & 3 & 4 & 3 \\
\hline $\begin{array}{l}\text { \# Magnum Launches } \\
\text { [Required lift (t)] }\end{array}$ & $\begin{array}{c}6 \\
{[80]}\end{array}$ & $\begin{array}{c}6 \\
{[80]}\end{array}$ & $\begin{array}{c}6 \\
{[88]}\end{array}$ & $\begin{array}{c}6 \\
{[85]}\end{array}$ & $\begin{array}{c}6 \\
{[83]}\end{array}$ & $\begin{array}{c}6 \\
{[80]}\end{array}$ \\
\hline IMLEO (t) & -422 & -396 & -453 & -461 & $-478 \cdot 491$ & $<421$ \\
\hline
\end{tabular}




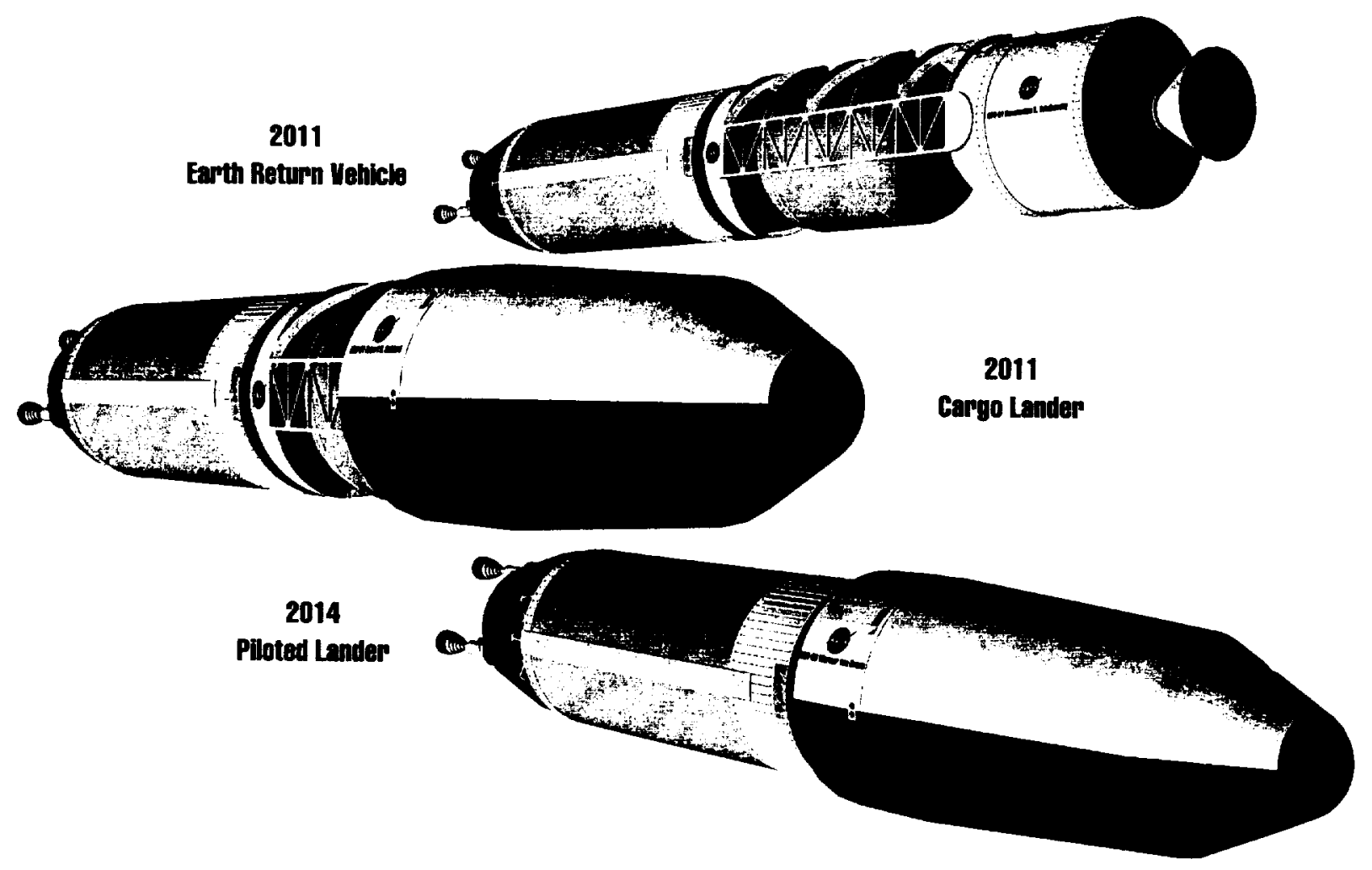

Fig. 33 Family of Bimodal NTR Transfer Vehicles Using "Modular" Components

transfer vehicles (shown in Figure 33) and "common" gas-cooled reactor technology for both the bimodal engines and surface power reactor system helps reduce costs further. With its integrated power system, the bimodal core stage also simplifies space operations and lowers mission risk by eliminating the operational complexities of multiple PVA "deployment / retraction" cycles (e.g., prior to and after TMI, aerobraking and TEI maneuvers).

With propulsive capture at Mars, the power available in Mars orbit grows to $150 \mathrm{kWe}$ per mission--five times that of the DRM. The more complex, higher risk aerobraking and capture maneuver is also replaced by a simpler atmospheric reentry using a "standardized", lower mass "aerodescent" shell. The introduction of TransHab and LANTR affords further mission flexibility and downstream growth capability. The BNTR / TransHab combination provides options for reusing the ERV and shortening its mission duration by halving the crew travel to and from Mars on the same bimodal transfer vehicle. The addition of LANTR engines enhances the performance of "volume- limited" vehicles by increasing their bulk propellant density. Using bimodal LANTR and TransHab, Phobos rendezvous and landing options can be added to the current DRM.

If water is discovered on Phobos and its extraction for return propellant proves feasible, then Phobos could become an important staging point for the future exploration and developemnt of Mars. A Phobos station and propellant depot would provide reusable LANTR-powered Mars transfer vehicles with their return propellant allowing them to shorten trip times or transport more high value cargo to Mars instead of bulk propellant. Reusable biconic-shaped LANTRpowered ascent / descent vehicles, operating from specially prepared sites on Mars, would ferry modular payload elements to and from the surface. Should Phobos be dry, they would also resupply orbiting transfer vehicles with propellants needed to reach refueling depots in the asteroid belt (see Figure 34). From there, the LANTR-powered transfer vehicles could continue on to the "water rich" moons of the Jovian system, providing a reliable foundation for the development and eventual human settlement of the Solar System. 


\section{How far can we go with LANTR propulsion?}

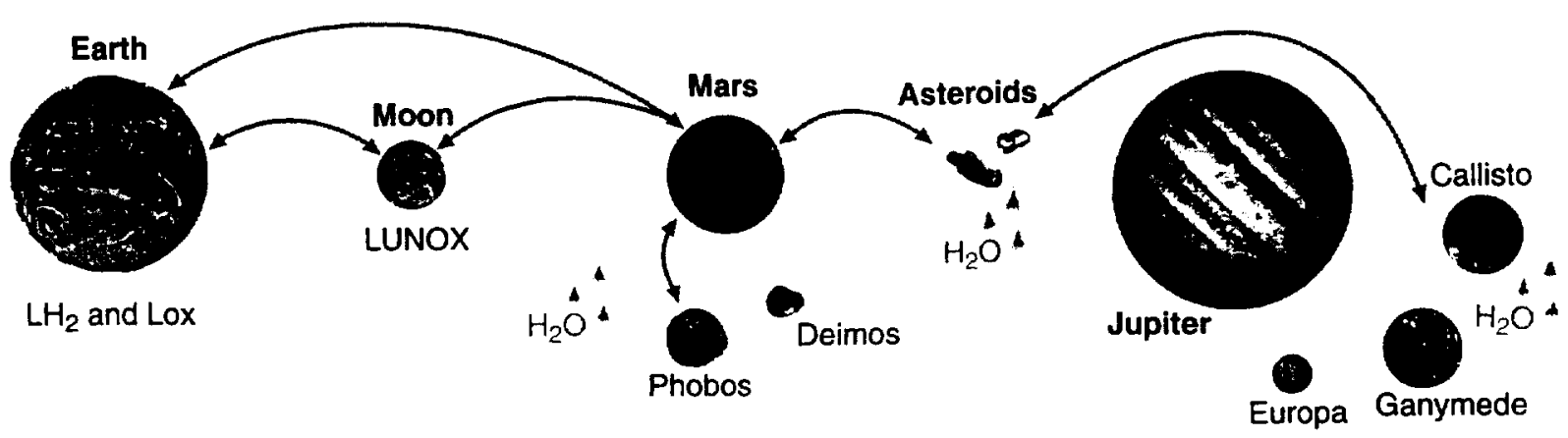

Fig. 34 Human Expansion Possibilities with LANTR Transfer Vehicles

\section{ACKNOWLEDGEMENTS}

The authors wish to express their thanks to LeRC management (Pat Symons, Harry Cikanek and Joe Nieberding) and NASA Headquarters (Lewis Peach) for support and encouragement during the course of this work, and to a number of individuals for key contributions to various topics addressed in this study. They include: Don Culver (Aerojet) on bimodal $\mathrm{CIS}$ engine design issues, Lee Mason (NASA Lewis) on Brayton cycle PCU analysis and system characterization, Dave Plachta (NASA Lewis) on $\mathrm{LH}_{2}$ thermal protection and active refrigeration systems, Mike Stancati (Science Applications International Corporation--SAIC) on disposal $\triangle V$ estimates and Pat Rawlings (SAIC) for artwork depicted in Figure 2.

\section{BEFERENCES}

1. The Space Science Enterprise Strategic Plan-Origin. Evolution and Destiny of the Cosmes and Life, National Aeronautics and Space Administration (November 1997).

2. Beyond Earth's Boundaries - Human Exploration of the Solar System in the 21st Century, Office of Exploration Annual Report to the Administrator, National Aeronautics and Space Administration (1988).

3. S. K. Borowski, "Impact of Solid Core Nuclear Thermal Rocket (SC/NTR) Propulsion on Human Expeditions to Phobos/Mars," in Exploration Studies Technical Report--FY 1988 Status, Office of Exploration, NASA Technical Memorandum 4075, (December 1988), pp. 5-11 to 5-17.

4. Beport of the 90-Day Study on Human Exploration of the Moon and Mars. National Aeronautics, National Aeronautics and Space Administration, (Nov. 1989).

5. S. K. Borowski, "An Evolutionary Lunar-toMars Space Transportation System Using Modular NTR / Stage Components," AlAA-91-3573. American Institute of Aeronautucs and Astronautics (Jan. 1991).

6. America at the Threshold - America's Space Expleration Initiative, Report of the Synthesis Group, Available from the Superintendent of Documents, U. S. Government Printing Office, Washington, DC 20402 (June 1991).

7. J. K. Soldner and B. K. Joosten, "Mars Trajectory Options for the Space Exploration Initiative," AAS-91-438, ASS/AIAA Astrodynamics Specialist Conference (Aug. 1991).

8. B. K. Joosten, B. G. Drake, D. B. Weaver and J. K. Soldner, "Mission Design Strategies for the Human Exploration of Mars," IAF-91-336, 42nd Congress of the International Astronautical Federation (Oct. 1991).

9. R. M. Zubrin, D Baker, and O. Gwynne, "Mars Direct: A Simple, Robust, and Cost-Effective Architecture for the Space Exploration Initiative," AlAA-91-0326, American Institute of Aeronautics and Astronautics (Jan. 1991). 
10. S. K. Borowski, et al., "Nuclear Thermal Rocket/Vehicle Design Options for Future NASA Missions to the Moon and Mars," AlAA-93-4170. American Institute of Aeronautics and Astronautics (Sept. 1993) and NASA Technical Memorandum 107071 (Sept.1995).

11. Human Exploration of Mars: The Reference Missien of the NASA Mars Exploration Study Team, S. J. Hoffman and D. I. Kaplan, eds., NASA Special Publication 6107 (July 1997).

12. Beference Mission Version 3.0 Addendum to the Human Exploration of Mars: The Reference Mission of the NASA Mars Exploration Study Team, B. G. Drake, ed., Exploration Office Document EX13-98-036 (June, 1998).

13. D. R. Koeing, "Experience Gained from the Space Nuclear Rocket Program (Rover)," LA10062-H, Los Alamos National Laboratory (May 1986).

14. J. S. Clark, S. K. Borowski, R. J. Sefcik and T. J. Miller, "A Comparison of Technology Development Costs and Schedule for Nuclear Thermal Rockets for Missions to Mars," AlAA-932263. American Institute of Aeronautics and Astronautics (June 1993).

15. J. S. Clark, M. C. Mcllwain, V. Smetanikov, E. K. D'Yakov, and V. A Pavshook, "US/CIS Eye Joint Nuclear Rocket Venture," Aerospace America, Vol. 31, (July 1993).

16. D. W. Culver, et al., "Development of Life Prediction Capabilities for Liquid Propellant Rocket Engines," Iask Ne. 8 (NTRE Extended Life Eeasibility Assessment), Aerojet Propulsion Division Final Reports under NASA Contract NAS3-25883 (Oct. 1992 and July 1993).

17. D. W. Culver, V. Kolganov, and R. Rochow, "Low Thrust, Deep Throttling, US / CIS Integrated NTRE," 11 th Symposium on Space Nuclear Power Systems, Albuquerque, New Mexico, (January 913, 1994).

18. S. K. Borowski, et al., "A Revolutionary Lunar Space Transportation System Architecture Using Extraterrestrial LOX-Augmented NTR Propulsion," AlAA-94-3343, American Institute of Aeronautics and Astronautics (June 1994) and NASA Technical Memorandum 106726 (August 1994).
19. S. K. Borowski, D. W. Culver and M. J. Bulman, "Human Exploration and Settlement of the Moon Using LUNOX-Augmented NTR Propulsion," 12th Symposium on Space Nuclear Power and Propulsion Systems, Albuquerque, New Mexico, (January 8-12, 1995) and NASA Technical Memorandum 107093 (October 1995).

20. D. W. Plachta, personal communications, NASA Lewis Research Center (1998).

21. R. H. Knoll, R. J. Stochl, and R. Sanabria, "A Review of Candidate Multilayer Insulation Systems for Potential Use on Wet-Launched $\mathrm{LH}_{2}$ Tankage for the Space Exploration Initiative Lunar Mission," AlAA-91-2176, American Institute of Aeronautics and Astronautics (June 1991).

22. R.M. Zubrin, "The Use of Low Power Dual Mode Nuclear Thermal Rocket Engines to Support Space Exploration Missions," AlAA-91. 3406. American Institute of Aeronautics and Astronautics, (Sept. 1991).

23. M. L. Stancati, personal communications, Science Applications International Corporation (1998).

24. M. L. Stancati and J. T. Collins, "Mission Design Considerations for Nuclear Risk Mitigation," Proc. Nuclear Propulsion Technical Interchange Meeting, R. R. Corban, ed., NASA Conference Publication 10116, October 20-23, 1992, Vol.1, pp. 358-365.

25. B. O'Leary, "Rationales for Early Human Missions to Phobos and Deimos," in Lunar Bases and Space Activities of the 21st Century, Lunar and Planetary Institute, Houston, 1985, pp. 801-808.

26. P. Moore, G. Hunt, I. Nicolson, and P. Cattermole, The Atlas of the Solar System, Crescent Books, New York, 1990, pp.240-241. 
Table A-1. Earth Return Vehicle Payload Mass (kg)

\begin{tabular}{|l|r|}
\hline Habitat Element & 26581 \\
Life Support System & 4661 \\
Crew Accom. + Consumables & 12058 \\
Health Care & 0 \\
EVA equipment & 243 \\
Comm/info Management & 320 \\
30 kW PVA power system & 3249 \\
Thermal Control system & 550 \\
Structure & 5500 \\
Science equipment & 600 \\
Spares $\quad 1924$ \\
\multicolumn{1}{|c|}{ Total Cargo Mass } & $\mathbf{2 9 1 0 5}$ \\
\hline TEI stage dry mass & 4806 \\
Propellant mass & 28866 \\
Earth return RCS propellant & 1115 \\
Aerobrake & 10180 \\
\multicolumn{1}{|c|}{ Total Payload Mass } & $\mathbf{7 4 0 7 2}$ \\
\hline
\end{tabular}

Table A-2. Cargo Lander Payload Mass (kg)

\begin{tabular}{|c|c|}
\hline \multirow[t]{2}{*}{$\overline{\text { Earth Entry/Mars Ascent Ca }}$} & 4829 \\
\hline & 4069 \\
\hline ISRU plant & 3941 \\
\hline Hydrogen feedstock & 5420 \\
\hline PVA keep-alive power system & 825 \\
\hline $160 \mathrm{~kW}$ nuclear power plant & 11425 \\
\hline $1.0 \mathrm{~km}$ power cables, $\mathrm{PMAD}$ & 837 \\
\hline Communication system & 320 \\
\hline Pressurized Rover & \\
\hline Inflatable Laboratory Module & 3100 \\
\hline $15 \mathrm{kWe}$ DIPS cart & 1500 \\
\hline Unpressurized Rover & 550 \\
\hline 3 teleoperable science rovers & 1500 \\
\hline Water storage tank & 150 \\
\hline Science equipment & 1770 \\
\hline Total Cargo Mass & 40236 \\
\hline $\begin{array}{l}\text { Vehicle structure } \\
\text { Terminal propulsion system }\end{array}$ & $\begin{array}{l}3186 \\
1018\end{array}$ \\
\hline $\begin{array}{r}\text { Total Landed Mass } \\
\end{array}$ & 44440 \\
\hline Propellant & 10985 \\
\hline Forward aeroshell & 9918 \\
\hline Parachutes and mec & 700 \\
\hline Total Pay & 66043 \\
\hline
\end{tabular}

Table A-3. Piloted Hab Lander Payload Mass (kg)

\begin{tabular}{|c|c|}
\hline Habitat element 2 & $\underline{28505}$ \\
\hline Life Support System & 4661 \\
\hline Health Care & 0 \\
\hline Crew Accomodations & 12058 \\
\hline EVA equipment & 243 \\
\hline Comm/info management & 320 \\
\hline Power & 3249 \\
\hline Thermal & 550 \\
\hline Structure & 5500 \\
\hline Science & 0 \\
\hline Spares & 1924 \\
\hline Crew & 500 \\
\hline $3 \mathrm{~kW}$ PVA keep-alive power & 0 \\
\hline Unpressurizes rover 3 & 550 \\
\hline EVA consumables & 446 \\
\hline EVA suits & 940 \\
\hline Total Cargo Mass & 30941 \\
\hline $\begin{array}{l}\text { Vehicle structure } \\
\text { Terminal propulsion system }\end{array}$ & $\begin{array}{l}3186 \\
1018\end{array}$ \\
\hline $\begin{array}{r}\text { Total Landed Mass } \\
\end{array}$ & 35145 \\
\hline Propellant & 11381 \\
\hline Forward aeroshell & 13580 \\
\hline Parachutes and mechanisms & 700 \\
\hline Total Payload Mass & 60806 \\
\hline
\end{tabular}


Table A-4. "Three Mission" IMLEO Summary for "All BNTR" Option

("2 - Perigee Burn" Earth Departure Scenario / Transit Times: 220 (OB) \& 180 (IB) Days) (IMLEO $\leq 178$ t / 2 - 88 t Magnum / Shuttle HLLVs)

\begin{tabular}{|c|c|c|c|c|}
\hline $\begin{array}{l}\text { Payload } / \text { Vehicle } \\
\text { Propulsion/lsp }\end{array}$ & $\begin{array}{c}\text { Element } \\
\text { Masses }(t)\end{array}$ & $\begin{array}{c}2011 \\
\text { Cargo Lander } \\
\text { Mission }\end{array}$ & $\begin{array}{c}2011 \\
\text { ERV } \\
\text { Mission }\end{array}$ & $\begin{array}{c}2014 \\
\text { Piloted Lander } \\
\text { Mission }\end{array}$ \\
\hline \multirow{3}{*}{$\begin{array}{c}\text { Earth Return } \\
\text { Vehicle } \\
\text { Payload }\end{array}$} & Crew Hab Module & & 18.15 & \\
\hline & Spare ECRV & & & \\
\hline & Contingency Consumables & & 7.31 & \\
\hline \multirow{4}{*}{$\begin{array}{c}\text { Ascent Stage } \\
\text { LOX/CH } \\
\text { Isp }=379 \mathrm{~s} \\
(\mathrm{O} / \mathrm{F}=3.5: 1)\end{array}$} & Crew (6) \& Suits & & & 1.44 \\
\hline & MAV Crew Cab/ECRV & 4.83 & & \\
\hline & Ascent Stage & 4.06 & & \\
\hline & Propellant* & 38.40 & & \\
\hline \multirow{6}{*}{$\begin{array}{c}\text { Descent Stage } \\
\text { LOX } \mathrm{CH}_{4} \\
\text { Isp }=379 \mathrm{~s} \\
(\mathrm{O} / \mathrm{F}=3.5: 1)\end{array}$} & Surface Payload & 31.34 & & 26.54 \\
\hline & Descent Stage & 4.20 & & 4.20 \\
\hline & Aerodescent Shell ${ }^{+}$ & 8.23 & & 7.94 \\
\hline & Parachutes & 0.70 & & 0.70 \\
\hline & Propellant** & 8.91 & & 7.92 \\
\hline & Total Payload Mass & 62.27 & 25.46 & 48.74 \\
\hline \multirow{6}{*}{$\begin{array}{l}\text { Common } \\
\text { NTR Vehicles } \\
\text { w/ Modular } \\
\text { Components }\end{array}$} & CIS Engines (\#) & $7.67(3)$ & $7.67(3)$ & $7.67(3)$ \\
\hline & $F(k l b f)$ per engine/lsp(s) & $14.76 / 955$ & $15 / 940$ & $14.76 / 955$ \\
\hline & Radiation Shields (\#) & & $3.24(3)$ & $3.24(3)$ \\
\hline & $\begin{array}{l}\text { "In-Line" TMI LH2 } \\
\text { Tank \& Structure }\end{array}$ & 8.25 & 8.52 & 8.25 \\
\hline & $\begin{array}{l}\text { TMI "Core" Stage } \\
\text { Tank \& Structure }\end{array}$ & 11.77 & & 11.77 \\
\hline & $\begin{array}{l}\text { TMI/MOC/TEl "Core" Stage } \\
\text { Tank \& Structure }\end{array}$ & & 11.77 & \\
\hline \multirow{4}{*}{ Isp $=940-955 \mathrm{~s}$} & $\begin{array}{c}\text { Brayton Power } \\
\text { System (@50 kWe) }\end{array}$ & 1.55 & 1.55 & 1.55 \\
\hline & $\begin{array}{c}\text { LH2 Refrigeration } \\
\text { System*** }\end{array}$ & 0.60 & 0.34 & 0.60 \\
\hline & Avionics \& Aux. Power & 1.69 & 1.69 & 1.69 \\
\hline & Propellant**** & 68.35 & 62.35 & 77.54 \\
\hline \multirow{5}{*}{$\begin{array}{c}\text { RCS } \\
\text { NTO/MMH } \\
\text { Isp }=320 \mathrm{~s}\end{array}$} & Propulsion \& Tankage & 0.52 & 0.55 & 0.52 \\
\hline & Propellant & 1.62 & 2.10 & 1.55 \\
\hline & & & & \\
\hline & Total NTA Vehicle Mass & 102.02 & 99.78 & 114.38 \\
\hline & Total IMLEO & 164.29 & 125.24 & 163.12 \\
\hline
\end{tabular}

* Produced at Mars using "in-situ" resources

* Assumes parachutes and $632 \mathrm{~m} / \mathrm{s}$ descent $\Delta \mathrm{V}$

** * Cooling capacity of "core" / "in-line" tanks $\sim 75 / 46 W_{1}$, respectively

* * * Contains boiloff, cooldown, "tank trapped" residual and disposal LH2 also

+ Using ARC Triconic aerobrake mass estimation formula with $\mathrm{Ve}=4.5 \mathrm{~km} / \mathrm{s}$ 
Table A-5. "Three Mission" IMLEO Summary for "Alternative Mission Profile" ("Single Burn" Earth Departure Scenario / Transit Times: 210 (OB) \& 180 (IB) Days) (IMLEO $\leq 160 \mathrm{t} / 2$ - 80 t Magnum / Shuttle C HLLVs)

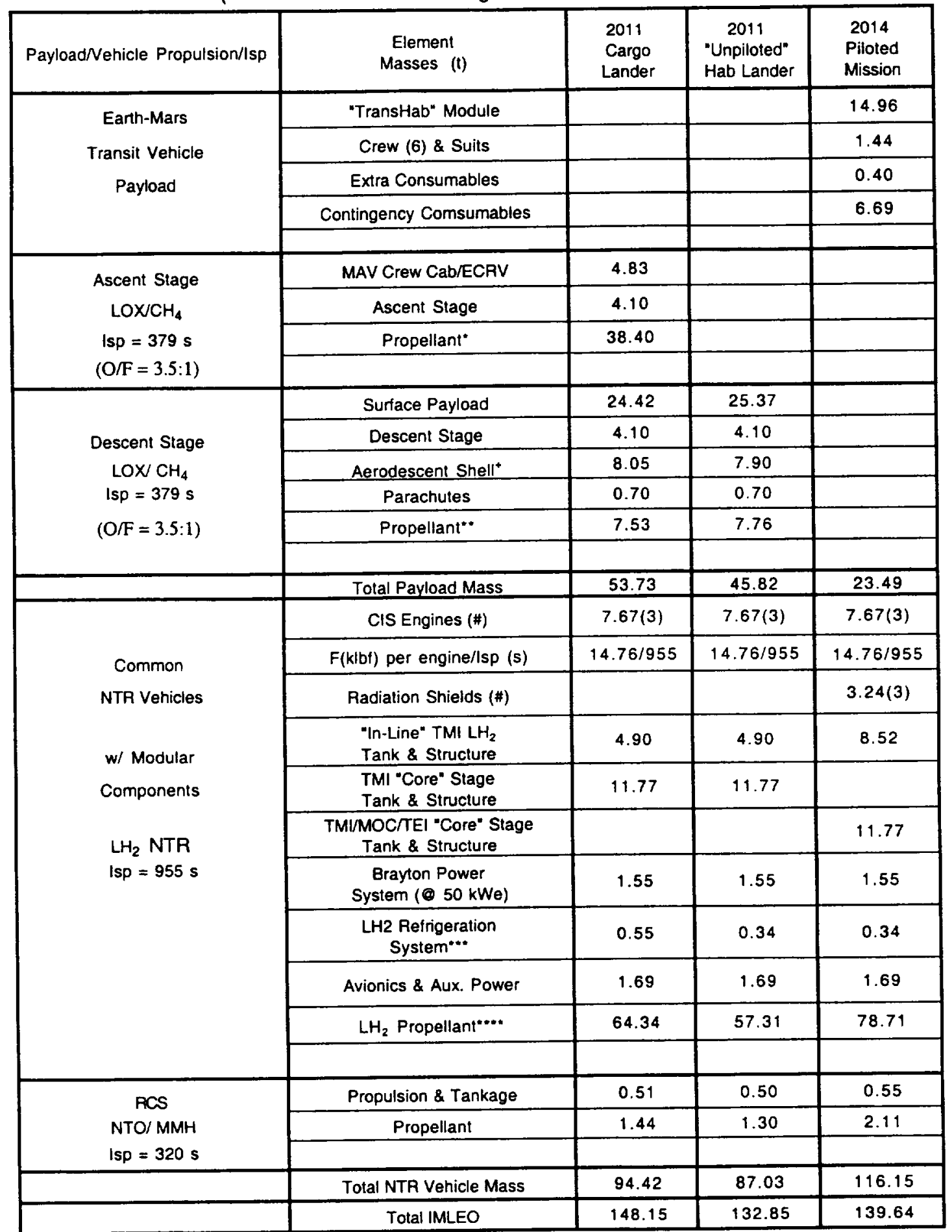

- Produced at Mars using "in-situ" resources

- Assumes parachutes and $632 \mathrm{~m} / \mathrm{s}$ descent $\Delta \mathrm{V}$

". Cooling capacity of "core"/"in-line" tank -75 and $27 \mathrm{Wt}$, respectively

-.. Contains boiloff, cooldown, "tank trapped" residual and disposal LH2 also

+ Using ARC Triconic aerobrake mass estimation formula with Ve $=4.5 \mathrm{~km} / \mathrm{s}$ 


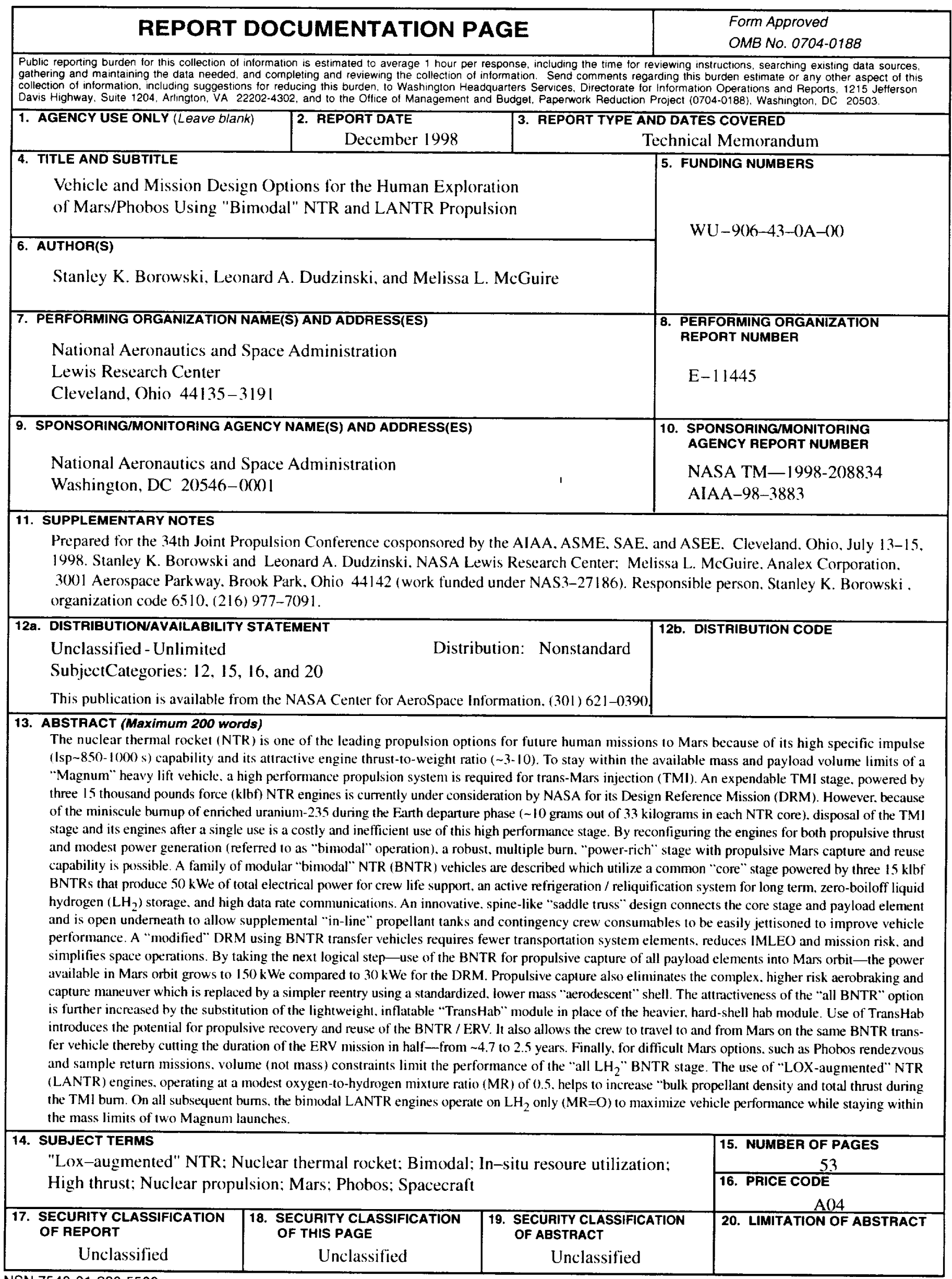

NSN 7540-01-280-5500

Standard Form 298 (Rev. 2-89)

Prescribed by ANSI Std. Z39-18 298-102 